\title{
An Evaluation of Gas Phase Enthalpies of Formation for Hydrogen-Oxygen $\left(\mathrm{H}_{x} \mathrm{O}_{y}\right)$ Species
}

\author{
Donald R. Burgess, Jr. \\ National Institute of Standards and Technology, \\ Gaithersburg, MD 20899 \\ donald.burgess@nist.gov
}

\begin{abstract}
We have compiled gas phase enthalpies of formation for nine hydrogen-oxygen species $\left(\mathrm{H}_{\mathrm{x}} \mathrm{O}_{\mathrm{y}}\right)$ and selected recommended values for $\mathrm{H}, \mathrm{O}, \mathrm{OH}, \mathrm{H}_{2} \mathrm{O}, \mathrm{HO}_{2}, \mathrm{H}_{2} \mathrm{O}_{2}, \mathrm{O}_{3}, \mathrm{HO}_{3}$, and $\mathrm{H}_{2} \mathrm{O}_{3}$. The compilation consists of values derived from experimental measurements, quantum chemical calculations, and prior evaluations. This work updates the recommended values in the NIST-JANAF (1985) and Gurvich et al. (1989) thermochemical tables for seven species. For two species, $\mathrm{HO}_{3}$ and $\mathrm{H}_{2} \mathrm{O}_{3}$ (important in atmospheric chemistry) and not found in prior thermochemical evaluations, we also provide supplementary data consisting of molecular geometries, vibrational frequencies, and torsional potentials which can be used to compute thermochemical functions. For all species, we also provide supplementary data consisting of zero point energies, vibrational frequencies, and ion reaction energetics.
\end{abstract}

Key words: ab initio thermochemistry; atomization energies; bond dissociation energies; enthalpy of formation; hydrogen-oxygen species; thermochemical network; thermodynamic properties.

Accepted: March 11, 2016

Published: March 30, 2016

http://dx.doi.org/10.6028/jres.121.005

\section{Introduction}

We have compiled gas phase enthalpies of formation for nine hydrogen-oxygen species $\left(\mathrm{H}_{\mathrm{x}} \mathrm{O}_{\mathrm{y}}\right)$ and selected recommended values for $\mathrm{H}, \mathrm{O}, \mathrm{OH}, \mathrm{H}_{2} \mathrm{O}, \mathrm{HO}_{2}, \mathrm{H}_{2} \mathrm{O}_{2}, \mathrm{O}_{3}, \mathrm{HO}_{3}$, and $\mathrm{H}_{2} \mathrm{O}_{3}$. Compared to uncertainties for the recommended values in the NIST-JANAF tables (1998) [1] and the thermochemical tables of Gurvich et al. (1989) [2] , the updated values are (50 to 100) times more precise for $\mathrm{H}$ atom, O atom, and $\mathrm{O}_{3}$, (5 to 10) times more precise for $\mathrm{OH}$ and $\mathrm{HO}_{2}$, and (25 to 35)\% more precise for $\mathrm{H}_{2} \mathrm{O}$ and $\mathrm{H}_{2} \mathrm{O}_{2}$. Enthalpies of formation for the species $\mathrm{HO}_{3}$ and $\mathrm{H}_{2} \mathrm{O}_{3}$, which are important in atmospheric chemistry, are not found in prior thermochemical evaluations. For these species, we also provide molecular geometries, vibrational frequencies, and torsional potentials which can be used to compute thermochemical functions $\left(C_{\mathrm{p}}, S^{\circ}, H^{\circ}\right.$, and $\left.\Delta_{\mathrm{f}} H^{\circ}\right)$.

This compilation of gas phase enthalpies of formation consists of values derived from experimental measurements, quantum chemical calculations, and prior evaluations. We list not only recent, more precise values, but older values for archival purposes. Uncertainties (where available) are given along with the enthalpies of formation. The uncertainties listed are in general $2 \sigma$ (a coverage factor of 2 having a level of confidence of approximately $95 \%$ ) [3]. Many workers did not explicitly state whether the uncertainties are $1 \sigma$ (standard uncertainty) or $2 \sigma-$ in these cases, we provide the uncertainties as reported.

In the tables of enthalpies of formation for each species, we also provide a column identifying the (experimental or computational) method used to derive the enthalpies of formation. A glossary for the notations used in the methods column is provided in Sec. 4. We also provide the reported values for dissociation energies, heats of reaction, appearance energies, or other quantities used to derive the enthalpy 
of formation. We provide these values in the original reported units. We utilized the following conversion factors: $1 \mathrm{~kJ} \mathrm{~mol}^{-1} \equiv 83.593472(4) \mathrm{cm}^{-1}, 1 \mathrm{eV} \equiv 96.4853365(21) \mathrm{kJ} \mathrm{mol}^{-1}, 1 \mathrm{eV} \equiv 8065.544005(50) \mathrm{cm}^{-1}$, 1 hartree $\equiv 2625.49962(13) \mathrm{kJ} \mathrm{mol}^{-1}$, and Rydberg Constant $\left(\mathrm{R}_{\infty}\right) \equiv 109737.31568539(55) \mathrm{cm}^{-1}$ taken from the CODATA values for the fundamental constants by Mohr et al. [4] and $1 \mathrm{kcal} \mathrm{mol}^{-1}=4.184 \mathrm{~kJ} \mathrm{~mol}^{-1}$ from the NIST-JANAF tables [1].

For each of the species, we provide a table of gas phase enthalpies of formation along with a short discussion in Sec. 2.1 to Sec. 2.9. This is followed by a summary table of the selected values of the enthalpies of formation in Sec. 2.10.

Many of the values selected for the $\mathrm{H}_{\mathrm{x}} \mathrm{O}_{\mathrm{y}}$ species are based on the ATcT (Active Thermochemical Tables) thermochemical network approach of Ruscic and coworkers [5-10]. We only include those ATcT values from published work and not those available only online (which have neither documentation nor references) [11, 12].

In addition to the compilation of gas phase enthalpies of formation for these hydrogen-oxygen species, in Sec. 3, we provide supplementary data consisting of zero point energies, vibrational frequencies, and ion reaction energetics. Zero point energies (ZPEs) are necessary when deriving ground state total atomization energies $\left(\Sigma \mathrm{D}_{0}\right)$ used to compute enthalpies of formation $\Delta_{\mathrm{f}} H^{\circ}(0 \mathrm{~K})$ from electronic total atomization energies $\left(\Sigma D_{\mathrm{e}}\right)$ obtained from quantum chemical calculations. In Sec. 3.1, we provide a table with vibrational frequencies, both experimental fundamental frequencies and calculated (or derived) harmonic frequencies. In Sec. 3.2, molecular geometries, vibrational frequencies, and torsional potentials for two species, $\mathrm{HO}_{3}$ and $\mathrm{H}_{2} \mathrm{O}_{3}$, are given, along with discussion of their use in computing thermochemical functions. In Sec. 3.3, ion reaction energetics, such as ionization energies, electron affinities, and appearance energies, are provided. These quantities are utilized to compute enthalpies of formation using thermochemical cycles involving ions.

\section{Hydrogen-Oxygen Species}

\subsection{H Atom}

Literature values for the gas phase enthalpy of formation of $\mathrm{H}$ atom are given in Table 1 . The majority of the measurements are based on the dissociation energy of $\mathrm{H}_{2}$. The selected enthalpy of formation $\Delta_{\mathrm{f}} H^{\mathrm{O}}(298.15 \mathrm{~K})$ for $\mathrm{H}$ atom is based on the $\mathrm{H}_{2}$ photoionization measurements of Liu et al. (2009) [20] and Zhang et al. (2004) [22] who determined the dissociation energy to $0.0004 \mathrm{~cm}^{-1}$ and $0.01 \mathrm{~cm}^{-1}$, respectively. These values translate to an uncertainty of on the order of less than $0.0001 \mathrm{~kJ} \mathrm{~mol}^{-1}$ in the enthalpy of formation of $\mathrm{H}$ atom (such a small uncertainty is not important from any practical chemical perspective). Earlier, Eyler, and Melikechi (1993) [24] measured substantially the same dissociation energy, but with a higher uncertainty of $0.04 \mathrm{~cm}^{-1}$. We select the experimentally-derived value from Zhang et al. (2004), because the higher precision value from Liu et al. (2009) is partially dependent upon quantum calculations for $\mathrm{D}_{0}\left(\mathrm{H}_{2}{ }^{+}\right)$in an ion thermochemical cycle (although the uncertainty in the theoretical component for $\mathrm{D}_{0}\left(\mathrm{H}_{2}{ }^{+}\right)$is negligible). In addition, the difference between two values is less than $0.0001 \mathrm{~kJ} \mathrm{~mol}^{-1}-\mathrm{a}$ chemically-negligible amount. The measured value of the dissociation energy is essentially identical to that from the relativistic-corrected Born-Oppenheimer energy quantum calculations of Piszczatowski et al. (2009) [36]. Ruscic et al. (2013, 2004) [6, 9] have evaluated the enthalpy of formation for $\mathrm{H}$ atoms using a thermochemical network approach and recommend the same value within the uncertainty limits.

\subsection{O Atom}

Literature values for the gas phase enthalpy of formation of $\mathrm{O}$ atom are given in Table 2 . The selected enthalpy of formation for $\mathrm{O}$ atom is largely derived from the photodissociation measurements of $\mathrm{O}_{2} \rightarrow$ $\mathrm{O}\left({ }^{3} \mathrm{P}\right)+\mathrm{O}\left({ }^{1} \mathrm{D}\right)$ by Gibson et al. (1991) [54] and Lewis et al. (1985) [55]. The singlet excited $\mathrm{O}\left({ }^{1} \mathrm{D}_{2}\right)$ state produced in the reaction is $15867.862 \mathrm{~cm}^{-1}\left(189.82178 \mathrm{~kJ} \mathrm{~mol}^{-1}\right)$ above the ground state $\mathrm{O}\left({ }^{3} \mathrm{P}_{2}\right)$ oxygen atom [51]. A weighted average of the results from the photodissociation measurements shown in the table 
Table 1. Gas phase enthalpies of formation $\Delta_{\mathrm{f}} H^{\mathrm{o}}(298.15 \mathrm{~K})$ for $\mathrm{H}$ atom

\begin{tabular}{|c|c|c|c|c|}
\hline $\begin{array}{c}\Delta_{\mathrm{f}} \mathrm{H}^{\mathbf{0}} \\
\left(\mathrm{kj} \mathrm{mol}^{-1}\right)\end{array}$ & $\begin{array}{l}\text { Uncert } \\
\left(\mathbf{k j ~ m o l}^{-1}\right)\end{array}$ & Reference & Method & Notes \\
\hline \multicolumn{5}{|c|}{ Evaluation } \\
\hline 217.9979 & 0.0001 & This work & Selected & 2004ZHA/CHE [22] \\
\hline 217.9979 & $<0.0001$ & 2014RUS/FEL [9] & Thermo network & $\Delta_{\mathrm{f}} H^{\circ}(0 \mathrm{~K})=216.0340 \mathrm{~kJ} / \mathrm{mol}$ \\
\hline 217.9979 & $<0.0001$ & 2011SPR/JUN [13] & Review & $\mathrm{D}_{0}=36118.06962(37) \mathrm{cm}^{-1}$ \\
\hline 217.998 & 0.001 & 2011SAN/ABB [14] & Review & \\
\hline 217.9978 & $<0.0001$ & 2004RUS/PIN [6] & Thermo network & \\
\hline 217.9978 & 0.0002 & 2001STO [15] & Review & $\mathrm{D}_{0}=36118.06(4) \mathrm{cm}^{-1}$ \\
\hline 217.999 & 0.006 & 1998CHA [1] & Review & $\begin{array}{l}\Delta_{\mathrm{f}} H^{\circ}(0 \mathrm{~K})=216.035 \mathrm{~kJ} / \mathrm{mol} \\
\text { Data last reviewed } 1982\end{array}$ \\
\hline 217.998 & 0.012 & 1989COX/WAG [16] & Review & \\
\hline 217.998 & 0.006 & 1989GUR/VEY [2] & Review & $\Delta_{\mathrm{f}} H^{\mathrm{o}}(0 \mathrm{~K})=216.035 \mathrm{~kJ} / \mathrm{mol}$ \\
\hline 218.001 & 0.003 & 1970STW [17] & Review & $\mathrm{D}_{0}=36118.6(5) \mathrm{cm}^{-1}$ \\
\hline 217.96 & 0.02 & 1970DAR [18] & Review & $\mathrm{D}_{0}=432.00(0.04) \mathrm{kJ} / \mathrm{mol}$ \\
\hline 217.995 & 0.012 & 1969JEZ/KOT [19] & Review & $\mathrm{D}_{0}=36117.5(2.0) \mathrm{cm}^{-1}$ \\
\hline \multicolumn{5}{|c|}{ Experimental } \\
\hline 217.9979 & $<0.0001$ & $\begin{array}{l}\text { 2009LIU/SAL [20] } \\
\text { 2012LIU/SPR [21] }\end{array}$ & Ioniz/Quantum & $\mathrm{D}_{0}=36118.06962(37) \mathrm{cm}^{-1}$ \\
\hline 217.9979 & 0.0001 & 2004ZHA/CHE [22] & Photodissoc & $\mathrm{D}_{0}=36118.062(10) \mathrm{cm}^{-1}$ \\
\hline 217.9979 & 0.0001 & 2004ZHA/CHE [22] & Photodissoc & $\begin{array}{l}\mathrm{D}_{0}=36118.073(4) \mathrm{cm}^{-1} \\
\text { (alternate threshold) }\end{array}$ \\
\hline 217.9982 & 0.0005 & 1994BAL/SMI [23] & Photodissoc & $\begin{array}{l}\mathrm{D}_{0}(1 \mathrm{~S}+2 \mathrm{~S})=118377.06(4) \mathrm{cm}^{-1} \\
\mathrm{D}_{0}=36118.11(8) \mathrm{cm}^{-1}\end{array}$ \\
\hline 217.9979 & 0.0002 & 1993EYL/MAL [24] & Photodissoc & $\begin{array}{l}\mathrm{D}_{0}(1 \mathrm{~S}+2 \mathrm{~S})=118377.00(7) \mathrm{cm}^{-1} \\
\mathrm{D}_{0}=36118.06(4) \mathrm{cm}^{-1} \\
\text { (double resonance) }\end{array}$ \\
\hline 217.9982 & 0.0005 & 1992BAL/SMI [25] & Photodissoc & $\begin{array}{l}\mathrm{D}_{0}(1 \mathrm{~S}+2 \mathrm{~S})=118377.06(4) \mathrm{cm}^{-1} \\
\mathrm{D}_{0}=36118.11(8) \mathrm{cm}^{-1} \\
\text { (fluorescence excitation) }\end{array}$ \\
\hline 217.9991 & 0.0012 & 1991MCC/EYL [26] & Photodissoc & $\begin{array}{l}\mathrm{D}_{0}(1 \mathrm{~S}+2 \mathrm{~S})=118377.23(20) \mathrm{cm}^{-1} \\
\mathrm{D}_{0}=36118.26(20) \mathrm{cm}^{-1}\end{array}$ \\
\hline 217.999 & 0.008 & 1970HER [27] & Absorp limit & $\mathrm{D}_{0}=36118.3(14) \mathrm{cm}^{-1}$ \\
\hline 217.968 & 0.002 & 1960HER/MON [28] & Absorp limit & $\mathrm{D}_{0}=36113.0(3) \mathrm{cm}^{-1}$ \\
\hline 217.99 & 0.04 & 1936BEU/JUN [29] & Absorp limit & $\mathrm{D}_{0}=36116(6) \mathrm{cm}^{-1}$ \\
\hline 217.4 & 3.9 & 1929RIC/DAV [30] & Absorp limit & $\mathrm{D}_{0}=4.465(40) \mathrm{eV}$ \\
\hline 213 & 10 & 1927DIE/HOP [31] & Absorp limit & $\mathrm{D}_{0}=4.38 \mathrm{eV}$ \\
\hline 210 & 12 & 1915ISA [32] & Absorp limit & $\begin{array}{l}\mathrm{D}_{0}=416 \mathrm{~kJ} / \mathrm{mol} \\
\text { See also } 1924 \mathrm{WOL}[33]\end{array}$ \\
\hline 205 & & $\begin{array}{l}\text { 1915LAN [34] } \\
\text { 1926LAN [35] }\end{array}$ & Flame & $\mathrm{D}_{0}=406 \mathrm{~kJ} / \mathrm{mol}$ \\
\hline \multicolumn{5}{|l|}{ Calculation } \\
\hline 217.9979 & $<0.0001$ & 2009PIS/LAC [36] & Quantum & $\mathrm{D}_{0}=36118.0695(10) \mathrm{cm}^{-1}$ \\
\hline 217.9979 & $<0.0001$ & 1995WOL [37] & Quantum & $\mathrm{D}_{0}=36118.069(1) \mathrm{cm}^{-1}$ \\
\hline 217.9978 & & 1993KOL/RYC [38] & Quantum & $\mathrm{D}_{0}=36118.049 \mathrm{~cm}^{-1}$ \\
\hline 217.9979 & 0.0001 & 1993WOL [39] & Quantum & $\mathrm{D}_{0}=36118.06(1) \mathrm{cm}^{-1}$ \\
\hline 217.9979 & & 1987SCH/LER [40] & Quantum & $\mathrm{D}_{0}=36118.074 \mathrm{~cm}^{-1}$ \\
\hline 217.9980 & & 1986KOL/SZA [41] & Quantum & $\mathrm{D}_{0}=36118.088 \mathrm{~cm}^{-1}$ \\
\hline 217.9976 & & 1983WOL [42] & Quantum & $\mathrm{D}_{0}=36118.01 \mathrm{~cm}^{-1}$ \\
\hline 217.9970 & & 1978BIS/CHE [43] & Quantum & $\mathrm{D}_{0}=36117.92 \mathrm{~cm}^{-1}$ \\
\hline 217.998 & & 1975KOL/WOL [44] & Quantum & $\mathrm{D}_{0}=36118 \mathrm{~cm}^{-1}$ \\
\hline 217.996 & & 1972BUN [45] & Quantum & $\mathrm{D}_{0}=36117.8 \mathrm{~cm}^{-1}$ \\
\hline 217.994 & & 1968KOL/WOL [46] & Quantum & $\mathrm{D}_{0}=36117.4 \mathrm{~cm}^{-1}$ \\
\hline 217.995 & 0.004 & 1966HUN [47] & Quantum & $\mathrm{D}_{0}=36117.59 \mathrm{~cm}^{-1}$ \\
\hline 217.973 & & 1964KOL/WOL [48] & Quantum & $\mathrm{D}_{0}=36113.9 \mathrm{~cm}^{-1}$ \\
\hline 217.975 & & 1960KOL/ROO [49] & Quantum & $\mathrm{D}_{0}=36114.2 \mathrm{~cm}^{-1}$ \\
\hline 217.9 & 1.0 & 1933JAM/COO [50] & Quantum & $\mathrm{D}_{\mathrm{e}}=4.73(2) \mathrm{eV}$ \\
\hline
\end{tabular}


Table 2. Gas phase enthalpies of formation $\Delta_{\mathrm{f}} H^{\mathrm{o}}(298.15 \mathrm{~K})$ for $\mathrm{O}$ atom

\begin{tabular}{|c|c|c|c|c|}
\hline $\begin{array}{c}\Delta_{\mathrm{f}} \mathrm{H}^{\mathbf{0}} \\
\left(\mathrm{kj} \mathrm{mol}^{-1}\right)\end{array}$ & $\begin{array}{l}\begin{array}{l}\text { Uncert } \\
\left(\mathbf{k j ~ m o l}^{-1}\right)\end{array} \\
\end{array}$ & Reference & Method & Notes \\
\hline \multicolumn{5}{|c|}{ Evaluation } \\
\hline 249.229 & 0.002 & This work & Selected & 2014RUS/FEL [9] \\
\hline 249.229 & 0.002 & 2014RUS/FEL [9] & Thermo network & $\Delta_{\mathrm{f}} H^{\mathrm{o}}(0 \mathrm{~K})=246.844 \mathrm{~kJ} / \mathrm{mol}$ \\
\hline 249.229 & 0.002 & 2011SAN/ABB [14] & Review & \\
\hline 249.229 & 0.002 & 2004RUS/PIN [6] & Thermo network & \\
\hline 249.17 & 0.10 & 1998CHA [1] & Review & Data last reviewed 1982 \\
\hline 249.160 & 0.007 & 1992COS/HUE [52] & Review & $\begin{array}{l}\mathrm{D}_{0}(\mathrm{~B})=57125.4(1.1) \mathrm{cm}^{-1} \\
\left.\mathrm{O}_{2}\left(\mathrm{~B}^{3} \Sigma_{\mathrm{u}}^{-}\right) \rightarrow \mathrm{O}\left({ }^{1} \mathrm{D}_{2}\right)+\mathrm{O}^{3} \mathrm{P}_{2}\right)\end{array}$ \\
\hline 249.180 & 0.10 & 1989GUR/VEY [2] & Review & $\Delta_{\mathrm{f}} H^{\circ}(0 \mathrm{~K})=246.795 \mathrm{~kJ} / \mathrm{mol}$ \\
\hline 249.18 & 0.1 & 1989COX/WAG [16] & Review & \\
\hline 249.18 & 0.2 & 1970DAR [18] & Review & $\mathrm{D}_{0}=493.59(0.4) \mathrm{kJ} / \mathrm{mol}$ \\
\hline \multicolumn{5}{|c|}{ Experimental } \\
\hline 249.215 & 0.004 & 1997MAR/HEP [53] & Ion pair dissoc & $\begin{array}{l}\mathrm{IPF}\left(\mathrm{O}^{+}, \mathrm{O}^{-} / \mathrm{O}_{2}\right)=139319.1(0.7) \mathrm{cm}^{-1} \\
\mathrm{D}_{0}=41266.7(0.7) \mathrm{cm}^{-1}\end{array}$ \\
\hline 249.226 & 0.005 & 1991GIB/LEW [54] & Photodissoc & $\mathrm{D}_{0}(\mathrm{~B})=57136.4(0.9) \mathrm{cm}^{-1}$ \\
\hline 249.223 & 0.003 & 1985LEW/BER [55] & Absorp limit & $\mathrm{D}_{0}(\mathrm{~B})=57136.0(0.5) \mathrm{cm}^{-1}$ \\
\hline 249.22 & 0.018 & 1985LEW/BER [55] & Reevaluation & $\begin{array}{l}\text { Reevaluated 1954BRI/HER [61] } \\
D_{0}(\mathrm{~B})=57135(3) \mathrm{cm}^{-1}\end{array}$ \\
\hline 249.2 & & 1981BLY/POW [56] & Ion cycle & $\begin{array}{l}\mathrm{AE}\left(\mathrm{O}^{+} / \mathrm{O}_{2}^{+}\right)=18.734 \mathrm{eV} \\
\mathrm{D}_{0}=41263 \mathrm{~cm}^{-1}\end{array}$ \\
\hline 249.19 & 0.02 & 1979PER/DUR [57] & Photofrag spec & $\mathrm{D}_{0}=41256.6(3.8) \mathrm{cm}^{-1}$ \\
\hline 249.22 & 0.06 & 1978ALB/MOS [58] & Photofrag spec & $\mathrm{D}_{0}=41262(10) \mathrm{cm}^{-1}$ \\
\hline 249.16 & 0.06 & 1975DEH/CHU [59] & Ion pair dissoc & $\begin{array}{l}\mathrm{IPF}\left(\mathrm{O}^{+}, \mathrm{O}^{-} / \mathrm{O}_{2}\right)=139316.6(9.7) \mathrm{cm}^{-1} \\
\mathrm{D}_{0}=41257.7 \mathrm{~cm}^{-1}\end{array}$ \\
\hline 249.17 & & 1972DAN/ELA [60] & Absorp limit & $\mathrm{D}_{0}(\mathrm{~B})=57128 \mathrm{~cm}^{-1}$ \\
\hline 249.17 & 0.03 & 1954BRI/HER [61] & Absorp limit & $\mathrm{D}_{0}(\mathrm{~B})=57128(5) \mathrm{cm}^{-1}$ \\
\hline \multicolumn{5}{|c|}{ Calculation } \\
\hline 249.07 & 0.29 & 2014FEL/PET [62] & $\mathrm{CC} / \mathrm{cbs}$ & $\begin{array}{l}\mathrm{D}_{\mathrm{e}}=502.79(0.50) \mathrm{kJ} / \mathrm{mol} \\
\text { this work using expt ZPE }\end{array}$ \\
\hline 249.52 & & 2014LIU/SHI [63] & $\mathrm{MRCI} / \mathrm{cbs}$ & $\begin{array}{l}\mathrm{D}_{\mathrm{e}}=5.2203 \mathrm{eV} \\
\text { this work using expt ZPE }\end{array}$ \\
\hline 249.07 & & 2010BYT/MAT [64] & $\mathrm{FCI} / \mathrm{cbs}$ & $\begin{array}{l}\mathrm{D}_{\mathrm{e}}=42030.1 \mathrm{~cm}^{-1} \\
\text { this work using expt ZPE }\end{array}$ \\
\hline 248.5 & & 2007VAR [65] & MRCI/cbs & $\mathrm{D}_{\mathrm{e}}=191.08 \mathrm{mHartree}$ \\
\hline 248.7 & & 2005BYA/RUE [66] & FCI(CEEIS)/cbs & $\mathrm{D}_{\mathrm{e}}=191.2$ mHartree \\
\hline 247.7 & & 1997PET/WIL [67] & $\mathrm{CC} / \mathrm{cbs}$ & $\mathrm{D}_{\mathrm{e}}=499.99 \mathrm{~kJ} / \mathrm{mol}$ \\
\hline 247.7 & & 1997PET/WIL [67] & MRCI/cbs & $\mathrm{D}_{\mathrm{e}}=499.99 \mathrm{~kJ} / \mathrm{mol}$ \\
\hline 243.8 & & 1996CSA/ALL [68] & CC/pVQZ & $\mathrm{D}_{\mathrm{e}}=492.2 \mathrm{~kJ} / \mathrm{mol}$ \\
\hline 239.6 & & 1991COL/HAS [69] & CC/6-311G & $\mathrm{D}_{\mathrm{e}}=5.15 \mathrm{eV}$ \\
\hline 217.2 & & 1977GUB [70] & CISD/DZ & $\mathrm{D}_{\mathrm{e}}=4.99 \mathrm{eV}$ \\
\hline
\end{tabular}

yields a value $\Delta_{\mathrm{f}} \mathrm{H}^{\mathrm{O}}(298.15 \mathrm{~K})=249.225 \pm 0.005 \mathrm{~kJ} \mathrm{~mol}^{-1}$, while the thermochemical network evaluation of Ruscic et al. (2013) [9] provides a value of $249.229 \pm 0.002 \mathrm{~kJ} \mathrm{~mol}^{-1}$ with a slightly lower uncertainty. Ruscic et al. corrected the bond dissociation energies reported by others to the lowest rovibrational level of $\mathrm{O}_{2}$, and we select the recommended (and corrected) value from Ruscic et al.

Values from the quantum chemical calculations of Feller et al. (2014) [62] and Bytautas et al. (2010) [64] are in excellent agreement with the experimental enthalpy of formation of $\mathrm{O}$ atom (within about $0.2 \mathrm{~kJ} \mathrm{~mol}^{-1}$ ). Please note that in order to derive the enthalpy of formation from the calculated dissociation energies of $D_{e}=42030.1 \mathrm{~cm}^{-1}$ from both Feller et al. and Bytautas et al., we used the experimentallyderived ZPE of $787.4 \mathrm{~cm}^{-1}$ (see Sec. 3.1) rather than the computed anharmonic ZPEs that were used in those studies.

\section{$2.3 \mathrm{OH}$ (hydroxyl radical)}

The selected value of the gas phase enthalpy of formation of $\mathrm{OH}$ is derived from the experimental work of Boyarkin et al. (2013) [76] and Maksyutenko et al. (2006) [77] who both directly measured the 
dissociation energy of water by determining the onset of the dissociative continuum $\mathrm{D}_{0}(\mathrm{HO}-\mathrm{H})=$ 41145.9(0.1) $\mathrm{cm}^{-1}$. Ruscic et al. (2014) [9] have evaluated the enthalpy of formation for $\mathrm{OH}$ using a thermochemical network approach using these two measurements and other input data and recommend a value that is within the uncertainties of the direct experimental determinations.

The selected value is in excellent agreement with the high level quantum calculations of Boyarkin et al. (2013) [76] (within $8 \mathrm{~cm}^{-1}$ or $0.1 \mathrm{~kJ} \mathrm{~mol}^{-1}$ - the estimated uncertainty in the calculations). The range of other quantum calculations given in Table 3 are almost as good, providing values within about $0.3 \mathrm{~kJ} \mathrm{~mol}^{-1}$ of the selected value.

Table 3. Gas phase enthalpies of formation $\Delta_{\mathrm{f}} H^{\mathrm{o}}(298.15 \mathrm{~K})$ for $\mathrm{OH}$

\begin{tabular}{|c|c|c|c|c|}
\hline $\begin{array}{c}\Delta_{\mathrm{f}} \mathrm{H}^{\mathbf{0}} \\
\left(\mathrm{kj} \mathrm{mol}^{-1}\right) \\
\end{array}$ & $\begin{array}{c}\text { Uncert } \\
\left(\mathbf{k j ~ m o l}^{-1}\right)\end{array}$ & Reference & Method & Notes \\
\hline \multicolumn{5}{|c|}{ Evaluation } \\
\hline 37.51 & 0.03 & This work & Selected & 2013BOY/KOS [76] \\
\hline 37.50 & 0.03 & 2015GAN/CSO [71] & Thermo network & $\Delta_{\mathrm{f}} H_{0}(0 \mathrm{~K})=37.25 \mathrm{~kJ} / \mathrm{mol}$ \\
\hline 37.492 & 0.026 & 2014RUS/FEL [9] & Thermo network & $\Delta_{\mathrm{f}} H_{0}(0 \mathrm{~K})=37.253 \mathrm{~kJ} / \mathrm{mol}$ \\
\hline 37.36 & 0.13 & 2011SAN/ABB [14] & Review & $\Delta_{\mathrm{f}} H_{0}(0 \mathrm{~K})=37.11 \mathrm{~kJ} / \mathrm{mol}$ \\
\hline 37.50 & 0.03 & 2010RUS [72] & Thermo network & $\Delta_{\mathrm{f}} H_{0}(0 \mathrm{~K})=37.26 \mathrm{~kJ} / \mathrm{mol}$ \\
\hline 37.36 & 0.13 & 2006RUS/PIN [73] & Thermo network & $\Delta_{\mathrm{f}} H_{0}(0 \mathrm{~K})=37.11 \mathrm{~kJ} / \mathrm{mol}$ \\
\hline 37.3 & 0.3 & 2005RUS/BOG [8] & Review & $\Delta_{\mathrm{f}} H_{0}(0 \mathrm{~K})=37.25 \mathrm{~kJ} / \mathrm{mol}$ \\
\hline 37.3 & 0.3 & 2002RUS/WAG [74] & Thermo network & $\Delta_{\mathrm{f}} H_{0}(0 \mathrm{~K})=37.0 \mathrm{~kJ} / \mathrm{mol}$ \\
\hline 37.4 & 0.1 & 2001JOE [75] & Thermo network & $\mathrm{D}_{0}(\mathrm{OH})=35584(10) \mathrm{cm}^{-1}$ \\
\hline 38.987 & 1.2 & 1998СНА [1] & Review & $\begin{array}{l}\Delta_{\mathrm{f}} H_{0}(0 \mathrm{~K})=38.390 \mathrm{~kJ} / \mathrm{mol} \\
\text { Data last reviewed } 1977\end{array}$ \\
\hline 39.349 & 0.21 & 1989GUR/VEY [2] & Review & $\Delta_{\mathrm{f}} H_{0}(0 \mathrm{~K})=39.110 \mathrm{~kJ} / \mathrm{mol}$ \\
\hline \multicolumn{5}{|c|}{ Experimental } \\
\hline 37.51 & 0.03 & 2013BOY/KOS [76] & Dissoc continuum & $\mathrm{D}_{0}\left(\mathrm{H}_{2} \mathrm{O}\right)=41145.92(0.12) \mathrm{cm}^{-1}$ \\
\hline 37.51 & 0.03 & 2006MAK/RIZ [77] & Dissoc continuum & $\mathrm{D}_{0}\left(\mathrm{H}_{2} \mathrm{O}\right)=41145.94(0.15) \mathrm{cm}^{-1}$ \\
\hline 37.3 & 0.3 & 2002RUS/WAG [74] & Ion cycle & Various $\mathrm{AP}\left(\mathrm{OH}+/ \mathrm{H}_{2} \mathrm{O}\right)$ \\
\hline 37.3 & 0.7 & 2002HER/HAN [78] & Kinetics/equil & $\mathrm{H}_{2} / \mathrm{O}_{2}$ shock tube modeling \\
\hline 37.20 & 0.38 & 2001RUS/FEL [79] & Ion cycle & $\mathrm{AP}\left(\mathrm{OH}+/ \mathrm{H}_{2} \mathrm{O}\right)=18.115(0.004) \mathrm{eV}$ \\
\hline 37.58 & 0.07 & 2000HAR/HWA [80] & Photodissoc & $\mathrm{D}_{0}\left(\mathrm{H}_{2} \mathrm{O}\right)=41151(5) \mathrm{cm}^{-1}$ \\
\hline 37.2 & 0.5 & 1992WIE/TON [81] & Ion cycle & $\begin{array}{l}\mathrm{IP}(\mathrm{OH})=104989(2) \mathrm{cm}^{-1} \\
\text { see 2002RUS/WAG [74] }\end{array}$ \\
\hline 37.2 & 0.8 & 1976MCC [82] & Ion cycle & $\mathrm{AP}\left(\mathrm{OH}+/ \mathrm{H}_{2} \mathrm{O}\right)=18.115(0.008) \mathrm{eV}$ \\
\hline$<39.4$ & 0.2 & 1969CAR/DAL [83] & Spec dissoc limit & $\mathrm{D}_{0}(\mathrm{OH})<35420(15) \mathrm{cm}^{-1}$ \\
\hline 39.1 & 1.2 & 1956BAR [84] & Spec dissoc limit & $\mathrm{D}_{0}(\mathrm{OH})=35450(100) \mathrm{cm}^{-1}$ \\
\hline 39.9 & 2.7 & 1944DWY/OLD [85] & Equilibrium & $\begin{array}{l}4 \mathrm{OH} \rightarrow 2 \mathrm{H}_{2} \mathrm{O}+\mathrm{O}_{2} \\
\Delta_{\mathrm{r}} H(0 \mathrm{~K})=641.8(10.9) \mathrm{kJ} / \mathrm{mol}\end{array}$ \\
\hline 33.2 & 3.9 & 1934RIE/SEN [86] & Equilibrium & $\begin{array}{l}\mathrm{H}_{2} \mathrm{O} \rightarrow \mathrm{H}+\mathrm{OH} \\
\Delta_{\mathrm{r}} H(298 \mathrm{~K})=493.0(3.9) \mathrm{kJ} / \mathrm{mol}\end{array}$ \\
\hline \multicolumn{5}{|c|}{ Calculation } \\
\hline 37.5 & 0.1 & 2013BOY/KOS [76] & $\mathrm{CC} / \mathrm{cbs}$ & $\mathrm{D}_{0}\left(\mathrm{H}_{2} \mathrm{O}\right)=41145(8) \mathrm{cm}^{-1}$ \\
\hline 37.2 & 0.2 & 2010CSA/FUR [87] & NEAT & \\
\hline 37.1 & & 2010CSA/MAT [88] & MRCI/pV6Z & $\mathrm{D}_{0}\left(\mathrm{H}_{2} \mathrm{O}\right)=41109 \mathrm{~cm}^{-1}$ \\
\hline 37.7 & 0.4 & 2009GRA/DIX [89] & $\mathrm{CC} / \mathrm{cbs}$ & \\
\hline 37.1 & & 2009GRE/BOY [90] & $\mathrm{MRCI} / \mathrm{pCV} 6 \mathrm{Z}$ & $\mathrm{D}_{0}\left(\mathrm{H}_{2} \mathrm{O}\right)=41108 \mathrm{~cm}^{1}$ \\
\hline 37.2 & & 2008HAR/VAZ [91] & HEAT & $\mathrm{D}_{0}\left(\mathrm{H}_{2} \mathrm{O}\right)=41116 \mathrm{~cm}^{-1}$ \\
\hline 37.7 & 0.4 & 2008FEL/PET [92] & $\mathrm{CC} / \mathrm{cbs}$ & \\
\hline 37.4 & & 2005MA/BIA [93] & MRCI/cbs & $\mathrm{D}_{0}(\mathrm{OH})=35569 \mathrm{~cm}^{-1}$ \\
\hline 37.9 & & 2002PEE/MAR [94] & $\mathrm{CC} / \mathrm{cbs}$ & $\mathrm{D}_{0}\left(\mathrm{H}_{2} \mathrm{O}\right)=492.6 \mathrm{~kJ} / \mathrm{mol}$ \\
\hline 37.3 & 0.8 & 2002RUS/WAG [74] & $\mathrm{CC} / \mathrm{cbs}$ & $\mathrm{D}_{0}(\mathrm{OH})=35591(42) \mathrm{cm}^{-1}$ \\
\hline 34.0 & & 2002JAN/ROS [95] & G3MP2B3 & \\
\hline 37.4 & 0.7 & 2001RUS/FEL [79] & CC/cbs & $\mathrm{D}_{0}\left(\mathrm{H}_{2} \mathrm{O}\right)=41135(55) \mathrm{cm}^{-1}$ \\
\hline 37.4 & & 2001MAR [96] & $\mathrm{CC} / \mathrm{cbs}$ & $\mathrm{D}_{0}(\mathrm{OH})=4.4124 \mathrm{eV}$ \\
\hline 36.8 & & 2001PAR/MAR [145] & W2 & \\
\hline 37.7 & & 1998CUR/RAG1 [97] & CBS-Q & \\
\hline 35.1 & & 1998CUR/RAG2 [98] & G3 & \\
\hline 36.8 & & 1998MCK/WRI [99] & G2MP2 & $\mathrm{D}_{0}(\mathrm{O}-\mathrm{H})=426.3 \mathrm{~kJ} / \mathrm{mol}$ \\
\hline
\end{tabular}




\section{$2.4 \mathrm{H}_{2} \mathrm{O}$ (water)}

The gas phase enthalpy of formation of $\mathrm{H}_{2} \mathrm{O}$ (water) is largely based on the combustion measurements of liquid water by Rossini (1939) [102-104] decades ago. The gas phase enthalpy of formation was computed using the heat of vaporization for water (see Rossini). Ruscic and coworkers $[6,9,100]$ included $\mathrm{H}_{2} \mathrm{O}$ in thermochemical network evaluations (ATcT) - and the most recent ATcT value differs by only about $0.04 \mathrm{~kJ} \mathrm{~mol}^{-1}$ from the original value of Rossini (on the order of the uncertainty in the measurement). We select the slightly more precise recommended value from the thermochemical network approach of Ruscic et al. The high level quantum chemical calculations of Feller et al. [92] are in excellent agreement with the experimentally-derived value (within about $0.04 \mathrm{~kJ} \mathrm{~mol}^{-1}$ ). All available literature values for the gas phase enthalpy of formation of $\mathrm{H}_{2} \mathrm{O}$ are given in Table 4.

Table 4. Gas phase enthalpies of formation $\Delta_{\mathrm{f}} H^{\mathrm{o}}(298.15 \mathrm{~K})$ for $\mathrm{H}_{2} \mathrm{O}$

\begin{tabular}{|c|c|c|c|c|}
\hline $\begin{array}{c}\Delta_{\mathrm{f}} \mathrm{H}^{\mathbf{0}} \\
\left(\mathrm{kj} \mathrm{mol}^{-1}\right)\end{array}$ & $\begin{array}{l}\text { Uncert } \\
\left(\mathbf{k j ~ m o l}^{-1}\right)\end{array}$ & Reference & Method & Notes \\
\hline \multicolumn{5}{|c|}{ Evaluation } \\
\hline-241.831 & 0.026 & This work & Selected & 2013RUS [100] \\
\hline-241.831 & 0.026 & 2013RUS [100] & Thermo network & $\Delta_{\mathrm{f}} H_{0}(0 \mathrm{~K})=-238.928 \mathrm{~kJ} / \mathrm{mol}$ \\
\hline-241.826 & 0.040 & 2011SAN/ABB [14] & Review & $\Delta_{\mathrm{f}} H_{0}(0 \mathrm{~K})=-238.923 \mathrm{~kJ} / \mathrm{mol}$ \\
\hline-241.818 & 0.033 & 2004RUS/PIN [6] & Thermo network & $\Delta_{\mathrm{f}} H_{0}(0 \mathrm{~K})=-238.916 \mathrm{~kJ} / \mathrm{mol}$ \\
\hline-241.826 & 0.042 & 1998CHA [1] & Review & $\begin{array}{l}\Delta_{\mathrm{f}} H_{0}(0 \mathrm{~K})=-238.921 \mathrm{~kJ} / \mathrm{mol} \\
\text { Data last reviewed } 1979\end{array}$ \\
\hline-241.826 & 0.040 & 1989COX/WAG [16] & Review & \\
\hline-241.826 & 0.040 & 1989GUR/VEY [2] & Review & $\Delta_{\mathrm{f}} H_{0}(0 \mathrm{~K})=-238.923 \mathrm{~kJ} / \mathrm{mol}$ \\
\hline \multicolumn{5}{|c|}{ Experimental } \\
\hline-241.833 & 0.12 & 1968KIN/ARM [101] & Heat combustion & $\Delta_{\mathrm{f}} H_{0}(\mathrm{l})=-285.84(0.12) \mathrm{kJ} / \mathrm{mol}$ \\
\hline-241.788 & 0.040 & 1939ROS [102-104] & Heat combustion & $\begin{array}{l}\Delta_{\mathrm{f}} H_{0}(\mathrm{l})=-285.795(0.040) \mathrm{kJ} / \mathrm{mol} \\
\Delta_{\mathrm{v}} H=44.007(0.013) \mathrm{kJ} / \mathrm{mol}\end{array}$ \\
\hline \multicolumn{5}{|c|}{ Calculation } \\
\hline-241.79 & 0.38 & 2014FEL/PET [62] & $\mathrm{CC} / \mathrm{cbs}$ & $\Delta_{\mathrm{f}} H_{0}(0 \mathrm{~K})=-238.86 \mathrm{~kJ} / \mathrm{mol}$ \\
\hline-240.7 & 1.6 & 2014ALM [105] & FCI(SCI)/cbs & \\
\hline-241.1 & 0.2 & 2010CSA/FUR [87] & NEAT & \\
\hline-241.8 & 0.4 & 2009FEL/PET [106] & $\mathrm{CC} / \mathrm{cbs}$ & \\
\hline-241.8 & 0.8 & 2009GRA/DIX [89] & $\mathrm{CC} / \mathrm{cbs}$ & \\
\hline-241.8 & 0.8 & 2008FEL/PET [92] & $\mathrm{CC} / \mathrm{cbs}$ & \\
\hline-241.9 & 1.1 & 2006BYT/RUE [107] & FCI(CEEIS)/cbs & \\
\hline-242.7 & & 2001PAR/MAR [145] & W2 & \\
\hline-243.9 & & 2001PAR/MAR [145] & W1 & \\
\hline-242.3 & & 1998CUR/RAG1 [97] & CBS-Q & \\
\hline-240.6 & & 1998CUR/RAG2 [98] & G3 & \\
\hline-241.9 & 5.3 & 1997HEL/KLO [108] & CC-R12/cbs & \\
\hline
\end{tabular}

\section{$2.5 \mathrm{HO}_{2}$ (hydroperoxyl radical)}

We have selected the gas phase enthalpy of formation for $\mathrm{HO}_{2}$ from the Active Thermochemical Tables (ATcT) work of Ruscic et al. (2006) [73], but with a slightly higher uncertainty. Our rationale for assigning a higher uncertainty is as follows. The neutral and ion reaction energetics available to derive the enthalpy of formation for HO2 as compiled in Table 5 all have uncertainties of about (1.5 to 2.5) $\mathrm{kJ} \mathrm{mol}^{-1}$ (much higher than the $0.25 \mathrm{~kJ} \mathrm{~mol}^{-1}$ assigned by Ruscic et al.), while the quantum chemical calculations have (reported) uncertainties of about (0.3 to 0.8$) \mathrm{kJ} \mathrm{mol}^{-1}$. Thus, the ATcT value and its uncertainty are strongly influenced by theoretical values. Additionally, the enthalpies of formation from quantum calculations are dependent upon computed ZPEs (zero point energies) and there is about a $16 \mathrm{~cm}^{-1}\left(0.2 \mathrm{~kJ} \mathrm{~mol}^{-1}\right)$ uncertainty in computing anharmonic ZPEs (see Sec. 3). Although enthalpies of formation from the quantum calculations are much more precise than those derived from experimental measurements, we suggest a higher uncertainty $\left(0.35 \mathrm{~kJ} \mathrm{~mol}^{-1}\right)$ than assigned by Ruscic et al. considering the factors above. We do not recommend use of the value from the thermochemical network approach of Ganyecz et al. (2015), because of the limited data used in their thermochemical network and their value is substantially inconsistent with most experimentally-derived and calculated values. 
Table 5. Gas phase enthalpies of formation $\Delta_{\mathrm{f}} \mathrm{H}^{\mathrm{o}}(298.15 \mathrm{~K})$ for $\mathrm{HO}_{2}$

\begin{tabular}{|c|c|c|c|c|}
\hline $\begin{array}{c}\Delta_{\mathrm{f}} \mathrm{H}^{\mathbf{0}} \\
\left(\mathrm{kj} \mathrm{mol}^{-1}\right) \\
\end{array}$ & $\begin{array}{c}\text { Uncert } \\
\left(\mathbf{k j ~ m o l}^{-1}\right)\end{array}$ & Reference & Method & Notes \\
\hline \multicolumn{5}{|c|}{ Evaluation } \\
\hline 12.30 & 0.35 & This work & Selected & 2006RUS/PIN [73] \\
\hline 11.92 & 0.22 & 2015GAN/CSO [71] & Thermo network & $\Delta_{\mathrm{f}} H^{\circ}(0 \mathrm{~K})=14.85 \mathrm{~kJ} / \mathrm{mol}$ \\
\hline 12.30 & 0.25 & 2011SAN/ABB [14] & Review & $\Delta_{\mathrm{f}} H^{\circ}(0 \mathrm{~K})=15.22 \mathrm{~kJ} / \mathrm{mol}$ \\
\hline 12.27 & 0.16 & 2010RUS [72] & Thermo network & \\
\hline 12.30 & 0.25 & 2006RUS/PIN [73] & Thermo network & $\Delta_{\mathrm{f}} H^{\circ}(0 \mathrm{~K})=15.21 \mathrm{~kJ} / \mathrm{mol}$ \\
\hline 2.09 & 8.4 & 1998CHA [1] & Review & $\begin{array}{l}\Delta_{\mathrm{f}} H^{\circ}(0 \mathrm{~K})=5.01 \mathrm{~kJ} / \mathrm{mol} \\
\text { Data last reviewed } 1978\end{array}$ \\
\hline 9.689 & 3.0 & 1989GUR/VEY [2] & Review & $\Delta_{\mathrm{f}} H^{\circ}(0 \mathrm{~K})=12.600 \mathrm{~kJ} / \mathrm{mol}$ \\
\hline 14.6 & 4.2 & 1983SHU/BEN1 [109] & Review & \\
\hline 19.7 & 4.0 & 1970DAR [18] & Review & \\
\hline \multicolumn{5}{|c|}{ Experimental } \\
\hline 13.4 & 2.1 & 2002RAM/BLA [110] & Ion cycle & $\mathrm{EA}\left(\mathrm{HO}_{2}\right)=1.078(0.006) \mathrm{eV}$ \\
\hline 14.5 & 2.1 & 1998CLI/WEN [111] & Ion cycle & $\mathrm{EA}\left(\mathrm{HO}_{2}\right)=1.089(0.006) \mathrm{eV}$ \\
\hline 13.8 & 3.3 & 1998LIT/RUS [112] & Ion cycle & $\begin{array}{l}\mathrm{AE}\left(\mathrm{HO}_{2}{ }^{+} / \mathrm{H}_{2} \mathrm{O}_{2}\right)=15.112(0.035) \mathrm{eV} \\
\mathrm{IE}\left(\mathrm{HO}_{2}\right)=11.352(0.007) \mathrm{eV}\end{array}$ \\
\hline 12.1 & 2.5 & 1998LIT/RUS [112] & Ion cycle & Revised by 2006RUS/PIN [73] \\
\hline 13.4 & 5.0 & 1990FIS/ARM [113] & Ioniz threshold & Revised by 2006RUS/PIN [73] \\
\hline 15.9 & 5.0 & 1990FIS/ARM [113] & Ioniz threshold & $\begin{array}{l}\mathrm{CH}_{4}+\mathrm{O}_{2}^{+} \rightarrow \mathrm{CH}_{3}^{+}+\mathrm{HO}_{2} \\
\mathrm{E}_{\mathrm{T}}=0.20(0.05) \mathrm{eV}\end{array}$ \\
\hline 13.4 & 2.6 & 1985OAK/HAR [114] & Ion cycle & $\mathrm{EA}\left(\mathrm{HO}_{2}\right)=1.078(0.017)$ \\
\hline 12.6 & 1.7 & 1984HIL/HOW [115] & Kinetics & $\begin{array}{l}\mathrm{OH}+\mathrm{ClO} \rightarrow \mathrm{HO}_{2}+\mathrm{Cl} \\
\Delta_{\mathrm{r}} H=-6.3 \mathrm{~kJ} / \mathrm{mol}\end{array}$ \\
\hline 12.1 & 1.7 & 1984HIL/HOW [115] & Kinetics & Revised by 2006RUS/PIN [73] \\
\hline$>12.6$ & & 1983SHU/BEN2 [116] & Kinetics & $\mathrm{HI}+\mathrm{O}_{2} \rightarrow \mathrm{HO}_{2}+\mathrm{I}$ \\
\hline 13.8 & 2.5 & 1982LEE/HOW [117] & Kinetics & $\begin{array}{l}\mathrm{C} 1+\mathrm{HO}_{2} \rightarrow \mathrm{OH}+\mathrm{ClO} \\
\Delta_{\mathrm{r}} H=5.0 \mathrm{~kJ} / \mathrm{mol}\end{array}$ \\
\hline 6.7 & 10.5 & 1982KHA/NIA [118] & Equilibrium & $\begin{array}{l}\text { Estimated from } \\
\mathrm{CH}_{3}+\mathrm{O}_{2} \rightarrow \mathrm{CH}_{3} \mathrm{O}_{2}\end{array}$ \\
\hline 10.5 & 2.5 & 1980HOW [119] & Equilibrium & $\begin{array}{l}\mathrm{HO}_{2}+\mathrm{NO}=\mathrm{OH}+\mathrm{NO}_{2} \\
\Delta_{\mathrm{r}} H=-28.7 \mathrm{~kJ} / \mathrm{mol}\end{array}$ \\
\hline 15.5 & & 1980HOW [119] & Equilibrium & $\begin{array}{l}\mathrm{HO}_{2}+\mathrm{NO} \rightarrow \mathrm{OH}+\mathrm{NO}_{2} \\
\text { Analyzed by } 1975 \mathrm{GLA} / \mathrm{TRO}[120]\end{array}$ \\
\hline 3.8 & & 1974KOC/MO [121] & Kinetics & $\mathrm{HX}+\mathrm{O}_{2} \rightarrow \mathrm{HO}_{2}+\mathrm{X}(\mathrm{Cl}, \mathrm{Br}, \mathrm{I})$ \\
\hline 20.9 & 8.4 & 1962FON/HUD [122] & Ion cycle & $\begin{array}{l}\mathrm{AP}\left(\mathrm{HO}_{2}+/ \mathrm{H}_{2} \mathrm{O}_{2}\right)=15.36(0.05) \mathrm{eV} \\
\mathrm{IP}(\mathrm{HO})=11.53(0.02) \mathrm{eV}\end{array}$ \\
\hline$<10.5$ & 6.3 & 1959ROS/WIS [123] & Kinetics & $\begin{array}{l}\mathrm{HBr}+\mathrm{O}_{2} \rightarrow \mathrm{HO}_{2}+\mathrm{Br} \\
\mathrm{E}_{\mathrm{a}}=159.0 \mathrm{~kJ} / \mathrm{mol}\end{array}$ \\
\hline 21.3 & 8.4 & 1955FON/HUD [124] & Ion cycle & $\begin{array}{l}\mathrm{AP}\left(\mathrm{HO}_{2}+/ \mathrm{H}_{2} \mathrm{O}_{2}\right)=15.41(0.1) \mathrm{eV} \\
\mathrm{IP}\left(\mathrm{HO}_{2}\right)=11.53(0.1) \mathrm{eV}\end{array}$ \\
\hline \multicolumn{5}{|c|}{ Calculation } \\
\hline 11.88 & 0.33 & 2015GAN/CSO [71] & CC/cbs & \\
\hline 12.5 & & 2014SPR/IRI [125] & CC-F12 & \\
\hline 12.18 & 0.32 & 2010CSA/FUR [87] & NEAT & \\
\hline 12.38 & 0.59 & 2009KAR/PAR [126] & W4 & \\
\hline 12.44 & 0.82 & 2008FEL/PET [92] & CC/cbs & \\
\hline 12.10 & 0.74 & 2006BOM/VAZ [127] & HEAT & \\
\hline 12.38 & 0.42 & 2004FLO/SZA [128] & CC/cbs & \\
\hline 12.24 & 0.70 & 2004TAJ/SZA [129] & HEAT & \\
\hline 15.2 & & 2002DIX/FEL [130] & CC/cbs & \\
\hline 13.4 & & 2002JAN/ROS [95] & G3MP2B3 & \\
\hline 12.1 & 3.0 & 2001BLA/RAM [115] & CBS-Q/APNO & \\
\hline 11.7 & 0.8 & 1999KAR/OSH [131] & QCI/6-311G & \\
\hline 15.8 & & 1998MCK/WRI [99] & G2MP2 & $\mathrm{D}_{0}(\mathrm{HOO}-\mathrm{H})=364.3 \mathrm{~kJ} / \mathrm{mol}$ \\
\hline 9.3 & & 1998MCK/WRI [99] & G2MP2 & $\mathrm{D}_{0}(\mathrm{HO}-\mathrm{O})=270.9 \mathrm{~kJ} / \mathrm{mol}$ \\
\hline 11.9 & & 1996JUN/SEI [132] & CBS-Q/APNO & \\
\hline 11.7 & 2.1 & 1993BAU/PAR [133] & CC/cbs & \\
\hline
\end{tabular}




\section{6 $\mathrm{H}_{2} \mathrm{O}_{2}$ (hydrogen peroxide)}

As shown in Table 6, there are only two relatively direct measurements leading to a value for the gas phase enthalpy of formation of $\mathrm{H}_{2} \mathrm{O}_{2}$ - the calorimetry measurement of Giguere (1955) [140] and the $\mathrm{D}_{0}(\mathrm{O}-\mathrm{O})$ dissociation energy of Luo et al. (1992) [138]. We have selected the inherently more precise spectroscopic value from Luo et al., but assigned a higher uncertainty of $0.16 \mathrm{~kJ} \mathrm{~mol}^{-1}$ in consideration of the (0.33 $\left.\mathrm{kJ} \mathrm{mol}^{-1}\right)$ range of recommended values by Ganyecz et al. (2015) [71], Ruscic (2013) [134], Ruscic (2010) [72], and Ruscic et al. (2006) [73]. In the ATcT evaluations by Ruscic and coworkers, there are no details given on either the reactions used to compute the enthalpy of formation of $\mathrm{H}_{2} \mathrm{O}_{2}$ or why the two ATcT values differ outside their uncertainties.

The enthalpies of formation derived from quantum chemical calculations are within about $1.0 \mathrm{~kJ} \mathrm{~mol}^{-1}$ of the selected value. These values depend upon the zero point energy (ZPE) of the molecule and different anharmonic corrections were computed. In Sec. 3.1 "Zero Point Energies and Vibrational Frequencies," we show that the computed anharmonic ZPEs have an apparent uncertainty of about $0.4 \mathrm{~kJ} \mathrm{~mol}^{-1}$ and this may contribute to part of the difference between the computed and experimentally-derived values.

Table 6. Gas phase enthalpies of formation $\Delta_{\mathrm{f}} \mathrm{H}^{\mathrm{0}}(298.15 \mathrm{~K})$ for $\mathrm{H}_{2} \mathrm{O}_{2}$

\begin{tabular}{|c|c|c|c|c|}
\hline $\begin{array}{c}\Delta_{\mathrm{f}} \mathrm{H}^{\mathbf{0}} \\
\left(\mathrm{kj} \mathrm{mol}^{-1}\right)\end{array}$ & $\begin{array}{c}\begin{array}{l}\text { Uncert } \\
\left(\mathbf{k j ~ m o l}^{-1}\right)\end{array} \\
\end{array}$ & Reference & Method & Notes \\
\hline \multicolumn{5}{|c|}{ Evaluation } \\
\hline-135.51 & 0.16 & This work & Selected & 1992LUO/FLE [138] \\
\hline-135.51 & 0.06 & 2015GAN/CSO [71] & Thermo network & $\Delta_{\mathrm{f}} \mathrm{H}^{\circ}(0 \mathrm{~K})=-129.481 \mathrm{~kJ} / \mathrm{mol}$ \\
\hline-135.442 & 0.064 & 2013RUS2 [134] & Thermo network & \\
\hline-135.9 & 0.2 & 2011SAN/ABB [14] & Review & $\Delta_{\mathrm{f}} \mathrm{H}^{\circ}(0 \mathrm{~K})=-129.9 \mathrm{~kJ} / \mathrm{mol}$ \\
\hline-135.44 & 0.07 & 2010RUS [72] & Thermo network & \\
\hline-135.77 & 0.17 & 2006RUS/PIN [73] & Thermo network & $\Delta_{\mathrm{f}} H^{\circ}(0 \mathrm{~K})=-129.75 \mathrm{~kJ} / \mathrm{mol}$ \\
\hline-135.9 & 0.2 & 2003DOR/IOR [135] & Review & \\
\hline-136.106 & 8.4 & 1998CHA [1] & Review & $\begin{array}{l}\Delta_{\mathrm{f}} H^{\circ}(0 \mathrm{~K})=-129.808 \mathrm{~kJ} / \mathrm{mol} \\
\text { Data last reviewed } 1960\end{array}$ \\
\hline-135.880 & 0.22 & 1989GUR/VEY [2] & Review & $\Delta_{\mathrm{f}} H^{\circ}(0 \mathrm{~K})=-129.890 \mathrm{~kJ} / \mathrm{mol}$ \\
\hline-138.8 & 2.1 & 1970DAR [18] & Review & $\mathrm{D}_{0}(\mathrm{O}-\mathrm{O})=207.1(2.1) \mathrm{kJ} / \mathrm{mol}$ \\
\hline-136.1 & & 1955GIG/LIU [136] & Review & \\
\hline-140.6 & & 1936BIC/ROS [137] & Review & \\
\hline \multicolumn{5}{|c|}{ Experimental } \\
\hline-136.7 & 0.4 & 1998LIT/RUS [112] & Ion cycle & $\begin{array}{l}\mathrm{AE}\left(\mathrm{OH}+/ \mathrm{H}_{2} \mathrm{O}_{2}\right)=1464.1(0.4) \mathrm{kJ} / \mathrm{mol} \\
\mathrm{IE}(\mathrm{OH})=1255.95(0.04) \mathrm{kJ} / \mathrm{mol}\end{array}$ \\
\hline-135.51 & 0.05 & 1992LUO/FLE [138] & Dissoc continuum & $\mathrm{D}_{0}(\mathrm{O}-\mathrm{O})=17051.8(3.4) \mathrm{cm}^{-1}$ \\
\hline-132 & 12 & 1958FOR [139] & Kinetics & $\begin{array}{l}\mathrm{H}_{2} \mathrm{O}_{2} \rightarrow \mathrm{OH}+\mathrm{OH} \\
\Delta_{\mathrm{r}} H^{\circ}=201.3(12.1)\end{array}$ \\
\hline-135.9 & 0.2 & 1955GIG/MOR [140] & Calorim decomp & $\begin{array}{l}\Delta_{\mathrm{f}} H(\mathrm{l})=-187.78(0.08) \mathrm{kJ} / \mathrm{mol} \\
\Delta_{\mathrm{v}} H=51.92(0.15) \mathrm{kJ} / \mathrm{mol} \\
\text { 1920MAA/HAT }[141]\end{array}$ \\
\hline-135.8 & 0.2 & 1929MAT/MAA [142] & Calorim decomp & $\begin{array}{l}\Delta_{\mathrm{f}} H(\mathrm{l})=-187.72(0.08) \mathrm{kJ} / \mathrm{mol} \\
\Delta_{\mathrm{v}} H=51.92(0.15) \mathrm{kJ} / \mathrm{mol}\end{array}$ \\
\hline \multicolumn{5}{|c|}{ Calculation } \\
\hline-136.2 & & 2014SPR/IRI [125] & CC-F12 & \\
\hline-135.0 & 0.6 & 2009KAR/PAR [126] & W4 & \\
\hline-135.1 & 0.6 & 2009DEN/ORN [143] & CC/cbs & $\Delta_{\mathrm{f}} H^{\circ}(0 \mathrm{~K})=-129.00 \mathrm{~kJ} / \mathrm{mol}$ \\
\hline-124.2 & & 2009SEL/GEO [144] & CASPT2/pVTZ & $\mathrm{D}_{\mathrm{e}}(\mathrm{O}-\mathrm{O})=214.2 \mathrm{~kJ} / \mathrm{mol}$ \\
\hline-133.9 & 1.3 & 2009GRA/DIX [89] & CC/cbs & \\
\hline-133.9 & 1.3 & 2008FEL/PET [92] & CC/cbs & \\
\hline-136.4 & & 2001PAR/MAR [145] & W1 & \\
\hline-134.3 & & 2001PAR/MAR [145] & W2 & \\
\hline-132.6 & 2.9 & 2001BLA/RAM [146] & CBS-APNO & \\
\hline-130.6 & & 1999KUH/RIZ [147] & MRSDCI/pVTZ & $\mathrm{D}_{\mathrm{e}}(\mathrm{O}-\mathrm{O})=18439 \mathrm{~cm}^{-1}$ \\
\hline-136.8 & & 1998CUR/RAG1 [97] & CBS-Q & \\
\hline-131.0 & & 1998CUR/RAG2 [98] & G3 & \\
\hline-141.1 & & 1998MCK/WRI [99] & G2MP2 & $\mathrm{D}_{0}(\mathrm{O}-\mathrm{O})=208.8 \mathrm{~kJ} / \mathrm{mol}$ \\
\hline
\end{tabular}




\section{$2.7 \mathrm{O}_{3}$ (ozone)}

The selected gas phase enthalpy of formation for $\mathrm{O}_{3}$ (ozone) is taken from Ruscic et al. (2004) [6] which is largely based on the photofragment excitation measurements of Masumi and coworkers (1997, 1999) $[149,150]$. The other experimental determinations shown in Table 7 are in good agreement with this value within their stated uncertainties. Ruscic et al., in a thermochemical network evaluation, corrected the bond dissociation energies of Masumi and coworkers to the lowest rotational $\left(\mathrm{J}=0\right.$ ) level for the $\mathrm{O}_{2}$ products - changing the computed enthalpy of formation by about $0.15 \mathrm{~kJ} \mathrm{~mol}^{-1}$. The quantum chemical calculations of Dixon and coworkers $(2008,2009)[89,92]$ are within about $0.1 \pm 1.6 \mathrm{~kJ} \mathrm{~mol}^{-1}$ of the recommended value - excellent, and likely fortuitous, agreement given the unpaired electrons in ozone (multiconfigurational character causes problems for single reference methods).

Table 7. Gas phase enthalpies of formation $\Delta_{\mathrm{f}} H^{\circ}(298.15 \mathrm{~K})$ for $\mathrm{O}_{3}$

\begin{tabular}{|c|c|c|c|c|}
\hline $\begin{array}{c}\Delta_{\mathrm{f}} \mathrm{H}^{0} \\
\left(\mathrm{kj} \mathrm{mol}^{-1}\right)\end{array}$ & $\begin{array}{l}\text { Uncert } \\
\left(\mathrm{kj} \mathrm{mol}^{-1}\right)\end{array}$ & Reference & Method & Notes \\
\hline \multicolumn{5}{|l|}{ Evaluation } \\
\hline 141.73 & 0.04 & This work & Selected & 2004RUS/PIN [6] \\
\hline 141.75 & 0.04 & 2011RUS [148] & Thermo network & \\
\hline 141.732 & 0.039 & 2011SAN/ABB [14] & Review & $\Delta_{\mathrm{f}} H^{\circ}(0 \mathrm{~K})=144.386 \mathrm{~kJ} / \mathrm{mol}$ \\
\hline 141.732 & 0.039 & 2004RUS/PIN [6] & Thermo network & $\Delta_{\mathrm{f}} H^{\circ}(0 \mathrm{~K})=144.386 \mathrm{~kJ} / \mathrm{mol}$ \\
\hline 142.674 & 1.7 & 1998CHA [1] & Review & $\begin{array}{l}\Delta_{\mathrm{f}} H^{\circ}(0 \mathrm{~K})=145.348 \mathrm{~kJ} / \mathrm{mol} \\
\text { Data last reviewed } 1961\end{array}$ \\
\hline 141.800 & 2.0 & 1989GUR/VEY [2] & Review & $\Delta_{\mathrm{f}} H^{\circ}(0 \mathrm{~K})=144.454 \mathrm{~kJ} / \mathrm{mol}$ \\
\hline \multicolumn{5}{|c|}{ Experimental } \\
\hline 141.67 & 0.17 & 1999TAN/TAK [149] & Photofragment & $\begin{array}{l}\mathrm{O}_{3} \rightarrow \mathrm{O}\left({ }^{1} \mathrm{D}\right)+\mathrm{O}_{2}\left(\mathrm{a}^{1} \Delta_{\mathrm{g}}\right) \\
\mathrm{D}_{0}=386.59(0.04) \mathrm{kJ} / \mathrm{mol}\end{array}$ \\
\hline 142.61 & 0.35 & 1997TAK/KIS [150] & Photofragment & $\begin{array}{l}\mathrm{O}_{3} \rightarrow \mathrm{O}\left({ }^{3} \mathrm{P}_{2}\right)+\mathrm{O}_{2}\left(\mathrm{X}^{3} \Delta_{\mathrm{g}}^{-}\right) \\
\mathrm{D}_{0}=101.53(0.25) \mathrm{kJ} / \mathrm{mol}\end{array}$ \\
\hline 141.00 & 0.84 & 1965CLY/MCK [151] & Kinetics/Equil & $\begin{array}{l}\mathrm{O}_{2}+\mathrm{O} \rightarrow \mathrm{O}_{3} \\
\Delta_{\mathrm{r}} H=-101.25 \mathrm{~kJ} / \mathrm{mol}\end{array}$ \\
\hline 141.8 & 1.3 & 1932GUN/WAS [152] & Equilibrium & $\mathrm{O}_{3} \rightarrow 3 / 2 \mathrm{O}_{2}$ \\
\hline 144.3 & 4.2 & 1910KAI/JAH [153] & Heat Reaction & $\mathrm{O}_{3} \rightarrow 3 / 2 \mathrm{O}_{2}$ \\
\hline \multicolumn{5}{|c|}{ Calculation } \\
\hline 144.2 & & 2010HOL/SZA [154] & MR-CISD & $\mathrm{D}_{\mathrm{e}}=1.117 \mathrm{eV}$ \\
\hline 141.8 & 1.7 & 2009GRA/DIX [89] & $\mathrm{CC} / \mathrm{cbs}$ & \\
\hline 141.8 & 1.7 & 2008FEL/PET [92] & CC/cbs & \\
\hline 143.8 & 2.4 & 2003FLE/GRE [155] & $\mathrm{MRCI}+\mathrm{Q} / \mathrm{cbs}$ & $\mathrm{D}_{\mathrm{e}}=1.121 \mathrm{eV}$ \\
\hline 140.6 & & 1998CUR/RAG1 [97] & CBS-Q & \\
\hline 146.0 & & 1998CUR/RAG2 [98] & G3 & \\
\hline
\end{tabular}

\section{$2.8 \mathrm{HO}_{3}$ (hydrotrioxyl radical)}

$\mathrm{HO}_{3}$ has been termed an "elusive" radical $[160,164,167,169]$ with regard to detection, molecular structure, vibrational frequencies, and enthalpy of formation - from both experimental and theoretical points of view. The first measurement of its gas phase enthalpy of formation was derived indirectly from correlations in electron transfer efficiencies of the positive ion $\mathrm{HO}_{3}{ }^{+}$with the ionization energies of a series of neutral electron donors by Speranza (1996) [165]. This value had a very high uncertainty (about $20 \mathrm{~kJ} \mathrm{~mol}^{-1}$ ). Subsequent high level quantum chemical calculations, however, put the enthalpy of formation on the order of (20 to 40) kJ mol ${ }^{-1}$ higher - and the quantum calculations showed a wide spread (see Table 8). Thus, the experimental value from Speranza was much lower (about $25 \mathrm{~kJ} \mathrm{~mol}^{-1}$ ) than the currently accepted value and the theoretical values were much higher (about (10 to 15) $\mathrm{kJ} \mathrm{mol}^{-1}$ ) than the currently accepted value.

More recently, Lester and coworkers [161-164] measured the vibrational predissociation of $\mathrm{HO}_{3}$ putting an upper limit on its bond dissociation energy $\mathrm{D}_{0}(\mathrm{HO}-\mathrm{OO})$ moving the estimate for the enthalpy of formation upward by about (10 to 15) $\mathrm{kJ} \mathrm{mol}^{-1}$. In 2010, Le Picard et al. [160], using a spectroscopic kinetic/equilibrium measurement at low temperatures ( $87 \mathrm{~K}$ to $100 \mathrm{~K}$ ), determined the bond dissociation energy $\left(D_{0}\right)$ relatively precisely (reportedly within about $0.5 \mathrm{~kJ} \mathrm{~mol}^{-1}$ ) and thus, pinned down the enthalpy 
Table 8. Gas phase enthalpies of formation $\Delta_{\mathrm{f}} \mathrm{H}^{\mathrm{0}}(298.15 \mathrm{~K})$ for $\mathrm{HO}_{3}$

\begin{tabular}{|c|c|c|c|c|}
\hline 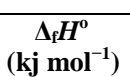 & $\begin{array}{l}\text { Uncert } \\
\left(\text { kj mol}^{-1}\right)\end{array}$ & Reference & Method & Notes \\
\hline \multicolumn{5}{|c|}{ Evaluation } \\
\hline 22.0 & 0.6 & This work & Selected & 2011BEA/LES [158] \\
\hline 27.8 & 0.7 & 2013RUS2 [134] & Thermo network & $\Delta_{\mathrm{f}} H^{\circ}(0 \mathrm{~K})=32.7 \mathrm{~kJ} / \mathrm{mol}$ \\
\hline 18.1 & 6.2 & 2011SAN/ABB [14] & Review & $\Delta_{\mathrm{f}} H^{\circ}(0 \mathrm{~K})=21.8 \mathrm{~kJ} / \mathrm{mol}$ \\
\hline 19.3 & 0.5 & 2010SMI/LEP [157] & Review & \\
\hline \multicolumn{5}{|c|}{ Experimental } \\
\hline 22.0 & 0.5 & 2011BEA/LES [158 & Reevaluation & $\begin{array}{l}\mathrm{D}_{0}=1004(24) \mathrm{cm}^{-1} \\
\Delta_{\mathrm{f}} H^{\circ}(0 \mathrm{~K})=25.26 \mathrm{~kJ} / \mathrm{mol} \\
\text { Reevaluated 2010LEP } / \text { TIZ [160] } \\
\text { using accurate torsion potential } \\
\left(\Delta \Delta_{\mathrm{f}} H^{\circ}(298 \mathrm{~K})=-3.3 \mathrm{~kJ} / \mathrm{mol}\right)[159]\end{array}$ \\
\hline 19.3 & 0.5 & 2010LEP/TIZ [160] & Kinetics/Equil & $\begin{array}{l}\mathrm{D}_{0}=12.3(0.3) \mathrm{kJ} / \mathrm{mol} ; 1030(30) \mathrm{cm}^{-1} \\
\Delta_{\mathrm{f}} H^{\circ}(0 \mathrm{~K})=24.9 \mathrm{~kJ} / \mathrm{mol} \\
\left(\Delta \Delta_{\mathrm{f}} H^{\circ}(298 \mathrm{~K}) \equiv-5.6 \mathrm{~kJ} / \mathrm{mol}\right)\end{array}$ \\
\hline$>10.4$ & & 2009MUR/DER [161] & Vib predissoc & $\mathrm{D}_{0}<1860 \mathrm{~cm}^{-1} ;<22.3 \mathrm{~kJ} / \mathrm{mol}$ \\
\hline$>10.5$ & & 2008DER/SEC [162] & Vib predissoc & $\mathrm{D}_{0}<1856 \mathrm{~cm}^{-1} ;<22.2 \mathrm{~kJ} / \mathrm{mol}$ \\
\hline$>7.1$ & & 2007MUR/DER [163] & Vib predissoc & $\begin{array}{l}\mathrm{D}_{0}<2140 \mathrm{~cm}^{-1} ;<25.6 \mathrm{~kJ} / \mathrm{mol} \\
\Delta_{\mathrm{f}} H^{\circ}(298 \mathrm{~K})=7.1 \mathrm{~kJ} / \mathrm{mol} \\
\left(\Delta \Delta_{\mathrm{f}} H^{\circ}(298 \mathrm{~K}) \equiv-4.5 \mathrm{~kJ} / \mathrm{mol}\right)\end{array}$ \\
\hline$>6.3$ & & 2007DER/MUR [164] & Vib predissoc & $\mathrm{D}_{0}<2208 \mathrm{~cm}^{-1} ;<26.4 \mathrm{~kJ} / \mathrm{mol}$ \\
\hline-4.2 & 21 & 1996SPE [165] & Ion cycle & $\mathrm{IE}=1059(17) \mathrm{kJ} / \mathrm{mol}$ \\
\hline \multicolumn{5}{|c|}{ Calculation } \\
\hline 29.5 & & 2014SPR/IRI [125] & CC-F12 & $\begin{array}{l}\Sigma \mathrm{D}_{\mathrm{o}}=923.3 \mathrm{~kJ} / \mathrm{mol} \\
\Delta \Delta_{\mathrm{f}} H^{\circ}(0 \mathrm{~K})=33.33 \mathrm{~kJ} / \mathrm{mol}\end{array}$ \\
\hline 28.9 & 8 & 2014BUR [166] & G3B3 & \\
\hline 21.1 & & 2013ZHO/HU [167] & $\mathrm{MRCI}+\mathrm{Q} / \mathrm{AV} 5 \mathrm{Z}$ & $\begin{array}{l}\mathrm{D}_{\mathrm{e}}=21.9 \mathrm{~kJ} / \mathrm{mol} \\
\mathrm{D}_{0}=10.5 \mathrm{~kJ} / \mathrm{mol}\end{array}$ \\
\hline 20.4 & 0.4 & 2012VAR [168] & $\mathrm{MRCI}+\mathrm{Q} / \mathrm{cbs}$ & $\begin{array}{l}\mathrm{D}_{\mathrm{e}}=19.7 \mathrm{~kJ} / \mathrm{mol} \\
\mathrm{D}_{0}=11.3 \mathrm{~kJ} / \mathrm{mol}\end{array}$ \\
\hline 21.6 & 0.4 & 2011VAR [169] & $\mathrm{MRCI}+\mathrm{Q} / \mathrm{cbs}$ & $\begin{array}{l}\mathrm{D}_{\mathrm{e}}=19.8 \mathrm{~kJ} / \mathrm{mol} \\
\mathrm{D}_{0}=10.0 \mathrm{~kJ} / \mathrm{mol}\end{array}$ \\
\hline 19.0 & & 2010ANG/OLI [170] & CASPT2 & $\begin{array}{l}\mathrm{D}_{\mathrm{e}}=24.3 \mathrm{~kJ} / \mathrm{mol} \\
\mathrm{D}_{0}=12.6 \mathrm{~kJ} / \mathrm{mol}\end{array}$ \\
\hline 21.3 & & 2009VAR/HAR [171] & CC/cbs & $\mathrm{D}_{0}=10.3 \mathrm{~kJ} / \mathrm{mol}$ \\
\hline 17.6 & 4.2 & 2009GRA/DIX [89] & CC/cbs & $\Delta_{\mathrm{f}} H^{\circ}(0 \mathrm{~K})=21.3 \mathrm{~kJ} / \mathrm{mol}$ \\
\hline 23.0 & 4.2 & 2009DEN/ORN [143] & $\mathrm{CC} / \mathrm{cbs}$ iso & $\Delta \Delta_{\mathrm{f}} H^{\circ}(298 \mathrm{~K})=-4.4 \mathrm{~kJ} / \mathrm{mol}$ \\
\hline 5.8 & & 2008BRA/YU [172] & DFT(HCTH) & $\mathrm{D}_{0}=2153 \mathrm{~cm}^{-1}$ \\
\hline 11.6 & & 2008SEM/KHU [173] & DFT(PBE0) & $\mathrm{D}_{0}=20 \mathrm{~kJ} / \mathrm{mol}$ \\
\hline 31.5 & & 2008DEN/ORN [174] & $\mathrm{CC} / \mathrm{cbs}$ & \\
\hline 23.0 & & 2007MAN/ANG [175] & CASPT2 & $\mathrm{D}_{0}=8.6 \mathrm{~kJ} / \mathrm{mol}$ \\
\hline 32.9 & & 2006JAN/FAB [176] & W1U & \\
\hline 15.3 & & 2005SUM/SUM [177] & MRCI & $\mathrm{D}_{0}=16.3 \mathrm{~kJ} / \mathrm{mol}$ \\
\hline 21.2 & & $2005 \mathrm{FAB} / \mathrm{KAL}$ [178] & $\mathrm{MR}-\mathrm{ACPF} / \mathrm{cbs}$ & $\Delta_{\mathrm{f}} H^{\circ}(0 \mathrm{~K})=26.1 \mathrm{~kJ} / \mathrm{mol}$ \\
\hline 32.9 & & 2005FAB/KAL [178] & $\mathrm{CC} / \mathrm{cbs}$ & \\
\hline 28.5 & & 2003DEN/KIE $[179,180]$ & CBS-APNO & \\
\hline 33.5 & & 2003DEN/KIE $[179,180]$ & CBS-QB3 & \\
\hline 35.6 & & 2003DEN/KIE $[179,180]$ & G3 & \\
\hline 36.8 & & 2003DEN/KIE $[179,180]$ & $\mathrm{CC} / \mathrm{cbs}$ & \\
\hline 24.9 & & 2002XU/GOD [181] & B3LYP/cc-pVTZ & \\
\hline 19.3 & & 2000SET/SAT [182] & CASSCF/MRMP2 & $\mathrm{D}_{0}=12.3 \mathrm{~kJ} / \mathrm{mol}$ \\
\hline 17.2 & & 1998MCK/WRI [99] & G2MP2 & $\mathrm{D}_{0}=14.4 \mathrm{~kJ} / \mathrm{mol}$ \\
\hline 26.8 & & 1996JUN/SEI [132] & CBS-Q/APNO & $\mathrm{D}_{0}=4.8 \mathrm{~kJ} / \mathrm{mol}$ \\
\hline 91.2 & & 1979NAN/BEN [183] & Empirical & \\
\hline
\end{tabular}


of formation of $\mathrm{HO}_{3}$ with an acceptable level of uncertainty. Beames et al. (2011) [158] have since revised the dissociation energy $\mathrm{D}_{0}$ from Le Picard et al. measurements by treating the torsional potential correctly in computing thermochemical functions [156] (see also Sec. 3.2.1). Since then there have been a number of high level quantum chemical calculations that confirmed the experimentally-derived value to within about (2 to 3) $\mathrm{kJ} \mathrm{mol}^{-1}$. The earlier "high" enthalpies of formation from theory were because of the inability of the single reference methods employed to properly treat $\mathrm{HO}_{3}$ due to significant spin contamination and the multi-reference character of the wavefunctions (see discussion in references in Table 8). With the use of multi-reference configuration interaction methods and other treatments this problem was apparently solved. Thus, both the experimental and quantum chemical methods have converged to similar values for the enthalpy of formation of $\mathrm{HO}_{3}$.

We selected an enthalpy of formation using the revised $\mathrm{D}_{0}$ from Beames et al. and using a thermal correction from an enthalpy $H^{\circ}$ calculated treating the molecule as a rigid rotor harmonic oscillator (RRHO), plus using the scaled torsional potential of Beames et al. to compute the contribution of the hindered rotor (see Sec. 3.2.1 for more details). We also increased slightly the uncertainty assigned by Beames et al. (from $0.5 \mathrm{~kJ} \mathrm{~mol}^{-1}$ to $0.6 \mathrm{~kJ} \mathrm{~mol}^{-1}$ ) to reflect the uncertainty (est. $0.3 \mathrm{~kJ} \mathrm{~mol}^{-1}$ ) in the contribution of the torsion to the free energy (considering uncertainties in both enthalpy $H^{\circ}$ and entropy $S^{\circ}$.

We note that the quantum chemical calculations used a wide range of ZPEs (about $500 \mathrm{~cm}^{-1} \equiv$ $6 \mathrm{~kJ} \mathrm{~mol}^{-1}$ ) and this contributes to some of the spread in the theoretical values (see Sec. 3.1 and Table 11). In Table 11, we suggest the use of the ZPE from Grant et al. (2009) [89], which is an average of experimental fundamental and computed harmonic frequencies.

\section{$2.9 \mathrm{H}_{2} \mathrm{O}_{3}$ (hydrogen trioxide)}

There are no experimental determinations for the gas phase enthalpy of formation of $\mathrm{H}_{2} \mathrm{O}_{3}$. Hence, we have selected an enthalpy of formation based on the high level ab initio calculations of Grant et al. (2009) [89]. We have assigned an estimated (liberal) uncertainty of $1.2 \mathrm{~kJ} \mathrm{~mol}^{-1}$ considering the uncertainties in the quantum chemical calculations (see Table 9 for the range of computed values), zero point energies, and the contribution to the enthalpy from the torsions. We have corrected the Grant et al. value slightly using the anharmonic ZPE computed by Hollman and Schaefer (2012) [200] and treating the torsions as hindered rotors (Grant et al. treated them as vibrations). These corrections increased the ZPE (and $\Delta_{\mathrm{f}} H^{\circ}$ at $0 \mathrm{~K}$ ) by about $0.5 \mathrm{~J} / \mathrm{mol}$ and the enthalpy $H^{\circ}(298.15 \mathrm{~K})$ by about $0.3 \mathrm{~kJ} \mathrm{~mol}^{-1}$ for an increase in $\Delta_{\mathrm{f}} H^{\circ}(298.15 \mathrm{~K})$ of about $0.8 \mathrm{~kJ} \mathrm{~mol}^{-1}$ relative to value provided by Grant et al. (There is also a substantial change in entropy $S^{\circ}$ and thus, in free energy $\Delta_{\mathrm{f}} G^{\circ}$ and the equilibrium constant/stability of $\mathrm{H}_{2} \mathrm{O}_{3}$ ). See Sec. 3.2.2 for more details.

\subsection{Summary of Selected Values for Gas Phase Enthalpies of Formation}

Table 10 is a summary of the selected values for the gas phase enthalpies of formation for each hydrogen-oxygen $\mathrm{H}_{\mathrm{x}} \mathrm{O}_{\mathrm{y}}$ species as outlined in previous sections.

The gas phase enthalpies of formation of $\mathrm{H}$ atom, $\mathrm{O}$ atom, $\mathrm{OH}, \mathrm{H}_{2} \mathrm{O}$, and $\mathrm{O}_{3}$ have uncertainties of less than $0.1 \mathrm{~kJ} \mathrm{~mol}^{-1}$. Compared to uncertainties associated with the values in the JANAF [1] and Gurvich et al. [2] thermochemical tables, the updated values in Table 10 are (50-100) times more precise for $\mathrm{H}$ atom, $\mathrm{O}$ atom, and $\mathrm{O}_{3}$ and about 7 times more precise for $\mathrm{OH}$. The precision for $\mathrm{H}_{2} \mathrm{O}$ is only slightly better (about $33 \%$ ). For all of these species (except $\mathrm{O}_{3}$ ), the values from quantum chemical calculations also agree to within $0.1 \mathrm{~kJ} \mathrm{~mol}^{-1}$. In the case of ozone $\left(\mathrm{O}_{3}\right)$, the quantum chemical calculations agree to within the uncertainty of the calculations (estimated at $1.6 \mathrm{~kJ} \mathrm{~mol}^{-1}$ ). This is excellent, and likely fortuitously, agreement given the unpaired electrons in ozone (requiring multiconfigurational calculational approaches).

The gas phase enthalpy of formation of $\mathrm{H}_{2} \mathrm{O}_{2}$ is also known relatively well (to less than $0.2 \mathrm{~kJ} \mathrm{~mol}^{-1}$ ) being derived largely from a spectroscopic measurement of the $\mathrm{D}_{0}(\mathrm{HO}-\mathrm{OH})$ dissociation energy (with a precision of about $3 \mathrm{~cm}^{-1}$ ). The precision is only slightly better (about $25 \%$ ) compared to values in the JANAF and Gurvich thermochemical tables which are largely based on the calorimetric measurements of decades ago for the decomposition of $\mathrm{H}_{2} \mathrm{O}_{2}$ by Matheson and Maas (1929) [142] and Giguere et al. (1955) [140]. 
Table 9. Gas phase enthalpies of formation $\Delta_{\mathrm{f}} \mathrm{H}^{\mathrm{0}}(298.15 \mathrm{~K})$ for $\mathrm{H}_{2} \mathrm{O}_{3}$

\begin{tabular}{|c|c|c|c|c|}
\hline $\begin{array}{c}\begin{array}{c}\Delta_{\mathrm{f}} \mathrm{H}^{\mathrm{0}} \\
\left(\mathrm{kj} \mathrm{mol}^{-1}\right)\end{array} \\
\end{array}$ & $\begin{array}{c}\text { Uncert } \\
\left(\mathbf{k j ~ m o l}^{-1}\right)\end{array}$ & Reference & Method & Notes \\
\hline \multicolumn{5}{|c|}{ Evaluation } \\
\hline-88.1 & 1.2 & This work & Selected & $\begin{array}{l}\text { 2009GRA/DIX [89] } \\
\text { Also this work see text }\end{array}$ \\
\hline-90.5 & 0.9 & 2011RUS [148] & Thermo network & $\Delta_{\mathrm{f}} H^{\circ}(0 \mathrm{~K})=-81.4 \mathrm{~kJ} / \mathrm{mol}$ \\
\hline-90.0 & & 2011SAN/ABB [14] & Review & $\Delta_{\mathrm{f}} H^{\circ}(0 \mathrm{~K})=-81.1 \mathrm{~kJ} / \mathrm{mol}$ \\
\hline \multicolumn{5}{|c|}{ Calculation } \\
\hline-89.4 & & 2014BUR [166] & G3B3 & \\
\hline-92.6 & & 2011MAR/ANG [184] & CC/pVQZ & \\
\hline-88.1 & & 2009GRA/DIX [89] & $\mathrm{CC} / \mathrm{cbs}$ & $\begin{array}{l}\Delta_{\mathrm{f}} H^{\circ}(0 \mathrm{~K})=-79.8 \mathrm{~kJ} / \mathrm{mol} \\
\text { Revised in this work }\end{array}$ \\
\hline-89.1 & & 2009GRA/DIX [89] & CC/cbs & $\Delta_{\mathrm{f}} H^{\circ}(0 \mathrm{~K})=-80.3 \mathrm{~kJ} / \mathrm{mol}$ \\
\hline-90.0 & & 2009DEN/ORN [143] & CC/cbs iso & \\
\hline-95.0 & & 2002KRA/CRE [185] & CC/6-311G & \\
\hline-83.3 & & 2003DEN/KIE $[179,180]$ & G3 & \\
\hline-90.4 & & 2003DEN/KIE $[179,180]$ & CC/cbs & \\
\hline-88.3 & & 2003DEN/KIE $[179,180]$ & CBS-APNO & \\
\hline-98.3 & & 2003DEN/KIE $[179,180]$ & CBS-QB3 & \\
\hline-96.2 & & 1997LAY/BOZ [186] & G2 iso & \\
\hline-83.1 & & 2001LAN/WHE [187] & $\mathrm{CC} / \mathrm{pVTZ}$ & $\begin{array}{c}\mathrm{H}_{2} \mathrm{O}_{3}+\mathrm{H}_{2} \rightarrow \mathrm{H}_{2} \mathrm{O}_{2}+\mathrm{H}_{2} \mathrm{O} \\
\Delta_{\mathrm{r}} H(0 \mathrm{~K})=-294.1 \mathrm{~kJ} / \mathrm{mol}\end{array}$ \\
\hline-99.1 & & 1998MCK/WRI [99] & G2MP2 & $\mathrm{D}_{0}\left(\mathrm{HO}_{2}-\mathrm{OH}\right)=141.9 \mathrm{~kJ} / \mathrm{mol}$ \\
\hline-105.9 & & 1998MCK/WRI [99] & G2MP2 & $\mathrm{D}_{0}\left(\mathrm{HO}_{3}-\mathrm{H}\right)=14.4 \mathrm{~kJ} / \mathrm{mol}$ \\
\hline
\end{tabular}

Table 10. Selected Gas Phase Enthalpies of Formation $\left(\Delta_{\mathrm{f}} H^{\circ}\right)$

\begin{tabular}{|l|c|c|l|l|}
\hline Species & $\begin{array}{c}\mathbf{A}_{\mathbf{f}} \mathbf{H}^{\mathbf{0}} \mathbf{( 2 9 8 . 1 5} \mathbf{~ K )} \\
\left(\mathbf{k j ~ m o l}^{-\mathbf{1}} \mathbf{)}\right.\end{array}$ & $\begin{array}{c}\mathbf{\Delta}_{\mathbf{f}} \mathbf{H}^{\mathbf{0}} \mathbf{( \mathbf { ~ K } )} \\
\mathbf{( k j ~ m o l}^{-\mathbf{1}} \mathbf{)}\end{array}$ & $\begin{array}{c}\text { Uncert } \\
\mathbf{( k j ~ m o l}^{-\mathbf{1}} \mathbf{)}\end{array}$ & Reference \\
\hline $\mathrm{H}$ & 217.9979 & 216.0340 & 0.0001 & 2004ZHA/CHE [22] \\
\hline $\mathrm{O}$ & 249.229 & 246.844 & 0.002 & 2014RUS/FEL [9] \\
\hline $\mathrm{OH}$ & 37.51 & 37.27 & 0.03 & 2013BOY/KOS [76] \\
\hline $\mathrm{H}_{2} \mathrm{O}$ & -241.831 & -238.928 & 0.026 & 2013RUS [100] \\
\hline $\mathrm{HO}_{2}$ & 12.30 & 15.21 & 0.35 & 2006RUS/PIN [73] \\
\hline $\mathrm{H}_{2} \mathrm{O}_{2}$ & -135.51 & -129.50 & 0.16 & 1992LUO/FLE [138] \\
\hline $\mathrm{O}_{3}$ & 141.73 & 144.39 & 0.04 & 2004RUS/PIN [6] \\
\hline $\mathrm{HO}_{3}$ & 22.0 & 25.3 & 0.6 & 2011BEA/LES [158] \\
\hline $\mathrm{H}_{2} \mathrm{O}_{3}$ & -88.1 & -79.8 & 1.2 & $\begin{array}{l}\text { 2009GRA/DIX [89] } \\
\text { revised in this work }\end{array}$ \\
\hline
\end{tabular}

The uncertainty in the gas phase enthalpy of formation for hydroperoxyl radical $\mathrm{HO}_{2}$ is somewhat larger - about $0.4 \mathrm{~kJ} \mathrm{~mol}^{-1}$. The energies of neutral and ion reactions involving $\mathrm{HO}_{2}$ have uncertainties of about (1.5 to 2.5$) \mathrm{kJ} \mathrm{mol}^{-1}$, while high level quantum chemical calculations have (estimated) uncertainties of about (0.2 to 0.4$) \mathrm{kJ} \mathrm{mol}^{-1}$. The selected value for the enthalpy of formation for $\mathrm{HO}_{2}$ is now about 10 times more precise than the values in the JANAF and Gurvich et al. thermochemical tables.

The gas phase enthalpies of formation of the $\mathrm{HO}_{3}$ radical and for $\mathrm{H}_{2} \mathrm{O}_{3}$, which are important species in atmospheric chemistry, are not found in prior evaluation. We provide recommended values here, as well as supplementary data consisting of molecular geometries, vibrational frequencies, and torsional potentials for these species in Sec. 3.2. These data can be used to compute thermochemical functions $\left(C_{\mathrm{p}}, S^{\circ}, H^{\circ}\right.$, and $\Delta_{\mathrm{f}} H^{\circ}$ ) for these species. 
For many years, the enthalpy of formation of the $\mathrm{HO}_{3}$ radical was elusive both from an experimental and theoretical point of view. The experimental values were "too low" by (10 to 20) $\mathrm{kJ} \mathrm{mol}^{-1}$ (compared to the now accepted value), while the theoretical values were "too high" by (10 to 15$) \mathrm{kJ} \mathrm{mol}^{-1}$. In the last 5 years (since 2010), both the experimental and quantum chemical methods converged to similar values - the experimental value (derived from a spectroscopic kinetic/equilibrium measurement) has an uncertainty of about (0.5 to 0.8$) \mathrm{kJ} \mathrm{mol}^{-1}$ and the quantum chemical values are known to about (2 to 3) $\mathrm{kJ} \mathrm{mol}^{-1}$.

There are no experimental measurements for the enthalpy of formation of $\mathrm{H}_{2} \mathrm{O}_{3}$. However, different high level quantum chemical methods predict similar values. We assigned a liberal (and estimated) uncertainty of about $1.2 \mathrm{~kJ} \mathrm{~mol}^{-1}$ to the selected value considering the uncertainties in the contribution of the torsions to the enthalpy $H^{\circ}$, zero point energy (ZPE), and the quantum chemical calculations.

\section{Supplementary Data}

\subsection{Zero Point Energies and Vibrational Frequencies}

Table 11 and Table 12 provide zero point energies (ZPEs) and vibrational frequencies, respectively, for the hydrogen-oxygen species. ZPEs are necessary for correcting electronic total atomization energies $\Sigma \mathrm{D}_{\mathrm{e}}$ to ground state total atomization energies $\Sigma \mathrm{D}_{0}$ (at $\mathrm{T}=0 \mathrm{~K}$ ). The ZPEs are derived from vibrational frequencies including anharmonic terms.

The zero point energies (ZPEs) given in $\mathrm{cm}^{-1}$ (standard spectroscopic units) for the hydrogen-oxygen species are given in Table 11. For the selected values, the ZPEs in $\mathrm{kJ} \mathrm{mol}^{-1}$ are given, along with uncertainties $(2 \sigma)$ (in parenthesis). The ZPEs for the diatomics $\mathrm{H}_{2}, \mathrm{O}_{2}$, and $\mathrm{OH}$ come from the review and analysis by Irikura $[193,194]$ and that for $\mathrm{H}_{2} \mathrm{O}$ from the evaluation by Irikura et al. [195]. These ZPEs for $\mathrm{H}_{2}, \mathrm{O}_{2}, \mathrm{OH}$, and $\mathrm{H}_{2} \mathrm{O}$ are derived from experimental spectroscopic constants.

The ZPEs compiled in Table 11 used by different workers consist of a mix from experimental fundamental frequencies, computed harmonic frequencies, scaled computed harmonic frequencies (equivalent to fundamental frequencies), and averages of the harmonic and anharmonic frequencies (a relatively good approximation). In some cases anharmonic ZPEs were computed (more accurately) using the vibrational configuration interaction (VCI) [188] or second-order vibrational perturbation theory (VPT2) [189] methods. Some discussion regarding uncertainties in computed ZPEs can be found in work by Barone (2004) [190], Irikura et al. (2009) [195], Kesharwanti et al. (2015) [191], and references contained therein.

For each species in Table 11, for reference purposes, we have also provided ZPEs computed directly from the experimental fundamental frequencies $\left(\mathrm{ZPE}_{\mathrm{f}}=1 / 2 \Sigma v_{\mathrm{i}}\right)$ and from the computed harmonic frequencies $\left(Z P E_{h}=1 / 2 \Sigma \omega_{e}\right)$. We have also computed an empirical estimate of anharmonic ZPEs using the relationship $\mathrm{ZPE}$ emp $=(1 / 2)\left(\mathrm{ZPE}_{\mathrm{h}}+\mathrm{ZPE} \mathrm{f}_{\mathrm{f}}\right)+(1 / 8)\left(\mathrm{ZPE}_{\mathrm{h}}-\mathrm{ZPE}_{\mathrm{f}}\right)$ (the average of harmonic and anharmonic frequencies plus a correction) from the work of Csonka et al. (2005) [192] who found that the anharmonic ZPEs for a series of polyatomic molecules obeyed this relationship to about $7 \mathrm{~cm}^{-1}\left(0.08 \mathrm{~kJ} \mathrm{~mol}^{-1}\right)$. We have used these values to screen our selected ZPE values and find a MAD (mean absolute deviation) of about $11 \mathrm{~cm}^{-1}\left(0.13 \mathrm{~kJ} \mathrm{~mol}^{-1}\right)$ for this set of molecules - consistent with that estimated by Csonka et al.

Table 12 provides vibrational frequencies for the species. The first line for each species lists the experimental fundamental frequencies $(v)$ for that species [note: the $v_{2}$ mode of $\mathrm{HO}_{3}$ is the only mode derived from a quantum calculation]. The second line for each species lists the harmonic frequencies $\left(\omega_{\mathrm{e}}\right)$ for that species. For most of these species the harmonic frequencies are derived from experimental spectroscopic rotational-vibrational lines, while for $\mathrm{H}_{2} \mathrm{O}_{2}, \mathrm{HO}_{3}$, and $\mathrm{H}_{2} \mathrm{O}_{3}$ the harmonic frequencies are derived from ab initio calculations. 
Table 11. Zero Point Energies (ZPE)

\begin{tabular}{|c|c|c|c|}
\hline Species & $\mathrm{ZPE}\left(\mathrm{cm}^{-1}\right)$ & $\mathrm{ZPE}\left(\mathrm{kJ} \mathrm{mol}^{-1}\right)$ & Reference \\
\hline $\mathrm{H}_{2}$ & $2179.3(0.1)$ & 26.07 & 2007IRI [193, 194] \\
\hline $\mathrm{O}_{2}$ & $787.380(0.006)$ & 9.42 & 2007IRI [193, 194] \\
\hline \multirow[t]{4}{*}{$\mathrm{OH}$} & $1850.69(0.05)$ & 22.14 & 2007IRI $[193,194]$ \\
\hline & 1856 & & 2015GAN/CSO [71] \\
\hline & 1857 & & 2004TAJ/SZA [129] \\
\hline & 1860 & & 2008HAR/VAZ [91] \\
\hline \multirow[t]{11}{*}{$\mathrm{H}_{2} \mathrm{O}$} & $4636(10)$ & $55.46(0.12)$ & 2009IRI/JOH [195] \\
\hline & 4634 & & 1991GRE/JAN [196] \\
\hline & 4645 & & 2015GAN/CSO [71] \\
\hline & 4639 & & 2013PFE/RAU [197] \\
\hline & 4723 & & 2009KLO/RUS [198] \\
\hline & 4664 & & 2008HAR/VAZ [91] \\
\hline & 4638 & & 2006BAR/SHI [199] \\
\hline & 4659 & & 2004TAJ/SZA [129] \\
\hline & [f] 4504 & & Fundamental $1 / 2 \Sigma v_{\mathrm{i}}$ \\
\hline & [h] 4712 & & Harmonic $1 / 2 \Sigma \omega_{\mathrm{e}}$ \\
\hline & 4634 & & Empirical (see text) \\
\hline \multirow[t]{10}{*}{$\mathrm{HO}_{2}$} & $3068(16)$ & $36.70(0.2)$ & 2014SPR/IRI [125] \\
\hline & 3082 & & 2015GAN/CSO [71] \\
\hline & 3095 & & 2009KAR/PAR [126] \\
\hline & 3086 & & 2008HAR/VAZ [91] \\
\hline & 3097 & & 2004TAJ/SZA [129] \\
\hline & 3095 & & 2004FLO/SZA [128] \\
\hline & [h] 3117 & & 2014SPRI/IRI \\
\hline & [f] 2963 & & Fundamental $1 / 2 \Sigma v_{\mathrm{i}}$ \\
\hline & [h] 3105 & & Harmonic $1 / 2 \Sigma \omega_{e}$ \\
\hline & 3052 & & Empirical (see text) \\
\hline \multirow[t]{16}{*}{$\mathrm{H}_{2} \mathrm{O}_{2}$} & 5714(33) & $68.35(0.4)$ & 2014SPR/IRI [125] \\
\hline & 5685 & & 2012HOL/SCH [200] \\
\hline & 5705 & & 2009KAR/PAR [126] \\
\hline & 5726 & & 2009KLO/RUS [198] \\
\hline & 5750 & & 2009DEN/ORN [143] \\
\hline & 5750 & & 2008FEL/PET [92] \\
\hline & 5751 & & 2008HAR/VAZ [91] \\
\hline & 5748 & & 2004TAJ/SZA [129] \\
\hline & 5726 & & 2002MLA [201] \\
\hline & 5685 & & 1999KUH/RIZ [147] \\
\hline & [h] 5811 & & 1999KUH/RIZ [147] \\
\hline & [h] 5811 & & 2012HOL/SCH [200] \\
\hline & [h] 5814 & & 2014SPR/IRI [125] \\
\hline & [f] 5554 & & Fundamental $1 / 2 \Sigma v_{i}$ \\
\hline & [h] 5837 & & Harmonic $1 / 2 \Sigma \omega_{\mathrm{e}}$ \\
\hline & 5686 & & Empirical (see text) \\
\hline \multirow[t]{9}{*}{$\mathrm{O}_{3}$} & 1451(8) & $17.36(0.1)$ & $\begin{array}{l}\text { 2006KAR/RAB [202] } \\
\text { 2002BAR/CHI [203] }\end{array}$ \\
\hline & 1464 & & 2014SPR/IRI [125] \\
\hline & 1476 & & 2013PFE/RAU [197] \\
\hline & 1452 & & 2010HOL/SZA [154] \\
\hline & 1471 & & 2009KLO/RUS [198] \\
\hline & 1448 & & 2008FEL/PET [92] \\
\hline & [f] 1423 & & Fundamental $1 / 2 \Sigma v_{\mathrm{i}}$ \\
\hline & [h] 1470 & & Harmonic $1 / 2 \Sigma \omega_{\mathrm{e}}$ \\
\hline & 1452 & & Empirical (see text) \\
\hline
\end{tabular}




\begin{tabular}{|c|c|c|c|}
\hline $\mathrm{HO}_{3}$ & $3428(32)$ & $41.0(0.4)$ & 2009GRA/DIX [89] \\
\hline & 3541 & & 2013SUM/SUM [204] \\
\hline & 3342 & & 2012VAR [168] \\
\hline & 3590 & & 2010ANG/OLI [170] \\
\hline & 3614 & & 2009VAR/HAR [171] \\
\hline & 4092 & & 2007MAN/ANG [175] \\
\hline & 3824 & & 2000SET/SAT [182] \\
\hline & 3846 & & 1996JUN/SEI [132] \\
\hline & [a] 3661 & & 2005FAB/KAL [178] \\
\hline & [h] 3682 & & 2014SPR/IRI [125] \\
\hline & [h] 3588 & & 2013ZHO/HU [167] \\
\hline & [h] 3640 & & 2010ANG/OLI [170] \\
\hline & [h] 3834 & & 2005FAB/KAL [178] \\
\hline & [f] 3324 & & Fundamental $1 / 2 \Sigma v_{\mathrm{i}}$ \\
\hline & [h] 3590 & & Harmonic $1 / 2 \Sigma \omega_{\mathrm{e}}$ \\
\hline & 3424 & & Empirical (see text) \\
\hline $\mathrm{H}_{2} \mathrm{O}_{3}$ & $6514(22)$ & $77.92(0.3)$ & 2012HOL/SCH [200] \\
\hline & 6474 & & 2009GRA/DIX [89] \\
\hline & 6554 & & 2009DEN/ORN [143] \\
\hline & [hf] 6474 & & 1993JAC [205] \\
\hline & [f] 6302 & & Fundamental $1 / 2 \Sigma v_{\mathrm{i}}$ \\
\hline & [h] 6664 & & Harmonic $1 / 2 \Sigma \omega_{e}$ \\
\hline & 6528 & & Empirical (see text) \\
\hline \multicolumn{4}{|l|}{ Notes } \\
\hline $\mathrm{h}$ & \multicolumn{3}{|c|}{$\mathrm{ZPE}_{\mathrm{h}}=1 / 2 \Sigma \omega_{\mathrm{e}}$ [harmonic frequencies] } \\
\hline $\mathrm{a}$ & \multicolumn{3}{|c|}{$\mathrm{ZPE}_{\mathrm{a}}=1 / 2 \Sigma v_{\mathrm{a}}$ [computed anharmonic] } \\
\hline $\mathrm{f}$ & \multicolumn{3}{|c|}{$\mathrm{ZPE}_{\mathrm{f}}=1 / 2 \Sigma v_{\mathrm{i}}$ [experimental fundamentals] } \\
\hline hf & \multicolumn{3}{|c|}{$\mathrm{ZPE}_{\mathrm{hf}}=1 / 2\left(\mathrm{ZPE}_{\mathrm{h}}+\mathrm{ZPE} \mathrm{f}_{\mathrm{f}}\right)$ [harmonic and fundamentals] } \\
\hline Empirical & \multicolumn{3}{|c|}{$\mathrm{ZPE}_{\mathrm{emp}}=\mathrm{ZPE} \mathrm{hf}_{\mathrm{f}}+1 / 8\left(\mathrm{ZPE}_{\mathrm{h}}-\mathrm{ZPE}_{\mathrm{f}}\right)$ [see Ref. [192]] } \\
\hline
\end{tabular}

Table 12. Vibrational Frequencies

\begin{tabular}{|c|c|c|}
\hline Species & $\begin{array}{l}v-\text { Fundamental Frequencies }\left(\mathrm{cm}^{-1}\right) \\
\omega_{\mathrm{e}}-\text { Harmonic Frequencies }\left(\mathrm{cm}^{-1}\right)\end{array}$ & Reference \\
\hline $\mathrm{H}_{2}$ & $\begin{array}{l}4161.0 \\
4401.2\end{array}$ & $\begin{array}{l}\text { 1955DIE [209] } \\
\text { 2007IRI [193] }\end{array}$ \\
\hline $\mathrm{O}_{2}$ & $\begin{array}{l}1556.388 \\
1580.161\end{array}$ & $\begin{array}{l}\text { 1992ROU/MIL [210] } \\
\text { 2007IRI [193] }\end{array}$ \\
\hline $\mathrm{OH}$ & $\begin{array}{l}2988.6 \\
3737.8\end{array}$ & $\begin{array}{l}\text { 1956BAR [84] } \\
\text { 2007IRI [193] }\end{array}$ \\
\hline $\mathrm{H}_{2} \mathrm{O}$ & $\begin{array}{l}3657.1,1594.7,3755.9 \\
3832.2,1648.5,3942.5\end{array}$ & $\begin{array}{l}\text { 2001TEN/ZOB [211] } \\
\text { 1967PLI/SPI [212] }\end{array}$ \\
\hline $\mathrm{HO}_{2}$ & $\begin{array}{l}3436,1392,1098 \\
3663,1431,1116 \\
\end{array}$ & $\begin{array}{l}\text { 2013JAC/THO [213] } \\
\text { 2007XU/JIA [214] }\end{array}$ \\
\hline $\mathrm{H}_{2} \mathrm{O}_{2}$ & $\begin{array}{l}3610,1383,866(a), 371(b), 3611,1266 \\
3800,1448,915,380(b), 3800,1331\end{array}$ & $\begin{array}{l}\text { 1988OLS/HUN [215] } \\
\text { 2012HOL/SCH [200] }\end{array}$ \\
\hline $\mathrm{O}_{3}$ & $\begin{array}{l}1103.1,700.9,1042.1 \\
1134.9,716.0,1089.2\end{array}$ & $\begin{array}{l}\text { 1987STE/ADL [216] } \\
\text { 1974BAR/SEC [217] }\end{array}$ \\
\hline $\mathrm{HO}_{3}$ & $\begin{array}{l}\text { 3569, 1225(c), 998, 482, 244, } 129 \\
3726,1372,1129,533,275,144\end{array}$ & $\begin{array}{l}\text { 2008DER/SEC2 [218] } \\
\text { 2010ANG/OLI [170] }\end{array}$ \\
\hline $\mathrm{H}_{2} \mathrm{O}_{3}$ & $\begin{array}{l}3530,1347,821,509,346,3530,1359,776,387 \\
3750,1397,909,531,361,3747,1406,811,415\end{array}$ & $\begin{array}{l}\text { 2002ENG/NEL [219] } \\
\text { 2012HOLSCH [200] }\end{array}$ \\
\hline \multicolumn{3}{|c|}{$\begin{array}{l}\text { (a) 1992CAM/FLA [220] } \\
\text { (b) see text } \\
\text { (c) no experimental fundamental, scaled harmonic frequency by } 0.893 \text {, the average } \\
\text { of other non-hydrogen frequencies in the molecule }\end{array}$} \\
\hline
\end{tabular}


Experimental values for the vibrational frequencies for $\mathrm{HO}_{2}$ and $\mathrm{H}_{2} \mathrm{O}_{2}$ can be found in the review by Jacox [206, 207]. There is a single high resolution measurement of the vibrational frequencies of $\mathrm{H}_{2} \mathrm{O}_{3}$ by Engdahl and Nelander [219]. Much earlier, Arnau and Giguere [208] measured $v_{3}, v_{4}$, and $v_{8}$ for $\mathrm{H}_{2} \mathrm{O}_{3}$ at 857,400 , and $755 \mathrm{~cm}^{-1}$, respectively - about a $21 \mathrm{~cm}^{-1}$ mean deviation from the values of Engdahl and Nelander.

There is some uncertainty in the vibrational modes (and thus in computed ZPEs) for two of the molecules $-\mathrm{H}_{2} \mathrm{O}_{2}$ and $\mathrm{HO}_{3}$.

The torsion potential in $\mathrm{H}_{2} \mathrm{O}_{2}$ is a double well with two torsional frequencies $371 \mathrm{~cm}^{-1}$ (ungerade) and $255 \mathrm{~cm}^{-1}$ (gerade). For the other modes, there is good agreement between the computed anharmonic frequencies and the observed fundamental frequencies (mean absolute deviation of $11 \mathrm{~cm}^{-1}$ ). For the torsional mode, however, there is a discrepancy where the computed anharmonic and harmonic frequencies are $316 \mathrm{~cm}^{-1}$ and $380 \mathrm{~cm}^{-1}$, respectively. That is, the harmonic frequency is comparable to the fundamental frequency $\left(9 \mathrm{~cm}^{-1}\right.$ higher) when one might expect it to be (20 to 35) $\mathrm{cm}^{-1}$ higher. In addition, the computed anharmonic frequency is substantially different than the measured fundamental frequency. See Sec. 3.2.2 for more discussion.

The torsional potential in $\mathrm{HO}_{3}$ is a double well with a cis form about (0.9 to 1.2$) \mathrm{kJ} \mathrm{mol}^{-1}$ less stable than trans form and a trans-to-cis barrier of about (3 to 4) $\mathrm{kJ} \mathrm{mol}^{-1}-$ or $\Delta \mathrm{E}=(75$ to 100$) \mathrm{cm}^{-1}$ and $\mathrm{V}=(250$ to 330) $\mathrm{cm}^{-1}$, respectively. Beames et al. (2011) [158] have computed the torsional potential. The experimental torsional frequency for the trans form is $129 \mathrm{~cm}^{-1}$ and the computed value for the cis form is slightly lower at $122 \mathrm{~cm}^{-1}$. Accurate representation of this torsional potential is necessary to properly compute the thermochemical functions (particularly the entropy) at low temperatures (100 to 300) K which are relevant to atmospheric chemistry. See Sec. 3.2.1 for more discussion.

\subsection{Supplementary Data for $\mathrm{HO}_{3}$ and $\mathrm{H}_{2} \mathrm{O}_{3}$}

In this section, we provide and discuss supplementary data for $\mathrm{HO}_{3}$ and $\mathrm{H}_{2} \mathrm{O}_{3}$ consisting of molecular geometries, vibrational frequencies, and torsional potentials. These data are not provided in prior evaluations and can be used to compute thermochemical functions $\left(C_{\mathrm{p}}, S^{\circ}, H^{\circ}\right.$, and $\left.\Delta_{\mathrm{f}} H^{\circ}\right)$. Both $\mathrm{HO}_{3}$ and $\mathrm{H}_{2} \mathrm{O}_{3}$ are important species in atmospheric chemistry. $\mathrm{HO}_{3}$ is considered to be a key intermediate, but is difficult to detect.

\subsubsection{Data for $\mathrm{HO}_{3}$}

Suma et al. (2005) [177] derived a molecular geometry for $\mathrm{HO}_{3}$ from rotational spectra yielding $\mathrm{r}_{0}(\mathrm{OO} *)=1.225 \AA, \mathrm{r}_{0}(\mathrm{OO})=1.688 \AA, \theta_{0}(\mathrm{OOO})=111.02^{\circ}, \mathrm{r}_{0}(\mathrm{OH})=0.972 \AA$, and $\theta_{0}(\mathrm{OOH})=90.04^{\circ}$ for the trans (most stable) form assuming a planar geometry. More recently, McCarthy et al. (2012) [221] similarly derived a molecular structure and found $\mathrm{r}_{0}\left(\mathrm{OO}^{*}\right)=1.235(4) \AA, \mathrm{r}_{0}(\mathrm{OO})=1.684(3) \AA, \theta_{0}(\mathrm{OOO})=110.7(3)^{\circ}$, $\mathrm{r}_{0}(\mathrm{OH})=0.913(26) \AA$, and $\theta_{0}(\mathrm{OOH})=92.4(14)^{\circ}$. Their measured rotational constants correspond to moments of inertia $\left\{\mathrm{I}_{\mathrm{a}}, \mathrm{I}_{\mathrm{b}}, \mathrm{I}_{\mathrm{c}}\right\}=\{57.76,50.60,7.140\}$ amu $\AA^{2}$ or $\{9.59,8.40,1.186\} \times 10^{-46} \mathrm{~kg} \mathrm{~m}^{2}$ in SI units. We utilize the molecular structure from the work of McCarthy et al. We note that later Suma et al. (2013) [204] derived values for equilibrium structure $\left(\mathrm{r}_{\mathrm{e}}, \theta_{\mathrm{e}}\right)$ using the isotopic rotational constants from their earlier work and that of McCarthy et al. plus theoretically-derived vibration-rotation interaction constants.

Experimental vibrational frequencies for $\mathrm{HO}_{3}$ come from the work of Derro et al. (2008) [218] except they did not observe $v_{2}$. Anglada et al. (2010) [141] computed harmonic vibrational frequencies using the CASSCF $(19,15)$ level of theory. In this work, we used a scaled harmonic $v_{2}$ from Anglada (see vibrational frequencies table in Sec. 3.1). The experimental fundamental and computed harmonic vibrational frequencies are given in Table 12.

The most stable form of $\mathrm{HO}_{3}$ is a trans geometry. A number of workers have computed the difference in energy between the cis and trans forms. Braams and Yu (2008) [146] using the density functional method (DFT) HCTH computed that the cis form was $4.6 \mathrm{~kJ} \mathrm{~mol}^{-1}$ higher with barrier-to-rotation of $8.8 \mathrm{~kJ} \mathrm{~mol}^{-1}$. Beames et al. (2011) [158] using the EOMIP-CCSD/ANO method computed a torsional potential where the cis form was about $49 \mathrm{~cm}^{-1}\left(0.59 \mathrm{~kJ} \mathrm{~mol}^{-1}\right)$ higher and there was a trans-to-cis classical barrier-to-rotation of $255 \mathrm{~cm}^{-1}$ (3.05 kJ mol$\left.{ }^{-1}\right)$. They utilized a scaling factor of 1.35 with the ab initio 
potential to produce a torsional potential of $132 \mathrm{~cm}^{-1}$ that roughly agrees with the experimental torsional frequency of $129 \mathrm{~cm}^{-1}$. Varandas $(2012,2011)$ [143, 222] using CCSD(T) and MRCI-Q methods with cc-pVnZ basis sets extrapolated to the complete basis set limit and including higher order corrections calculated the cis form to be ( 0.5 to 0.6$) \mathrm{kJ} / \mathrm{mol}$ higher with a barrier-to-rotation of about (3.3 to 4.8) $\mathrm{kJ} \mathrm{mol}^{-1}$. Although Varandas computed the torsional potential as a function of torsional angle, unfortunately it is not provided in numerical form for use by others. Hoy et al. (2013) [223] using the 2-RDM density functional method computed that $c i s-\mathrm{HO}_{3}$ was about $7.4 \mathrm{~kJ} \mathrm{~mol}^{-1}$ higher with a barrier-torotation of about $8.5 \mathrm{~kJ} \mathrm{~mol}^{-1}$ (only slightly higher than the cis form).

We recommend using the scaled torsional potential of Beames et al. (2011) [158] to compute thermochemical functions for $\mathrm{HO}_{3}$ (treating the rest of the molecule as a rigid rotor harmonic oscillator). In our work, RRHO calculations were performed using the program ChemRate [224] and hindered rotor thermochemical functions were computed using the program FGH1D (Fourier Grid Hamiltonian 1-D) [225]. We suggest employing a rotational constant of $B=22.93 \mathrm{~cm}^{-1}$ to generate a hindered rotor with a trans form with torsional frequency of $129 \mathrm{~cm}^{-1}$ and a cis form that was $84 \mathrm{~cm}^{-1}$ higher with a torsional frequency of $146 \mathrm{~cm}^{-1}$. We also computed thermochemical functions for the hindered rotor using a simpler analytical torsional potential employing $\mathrm{V}_{\mathrm{n}} \cos (\mathrm{n} \theta)$ terms with $\mathrm{V}_{1}=54 \mathrm{~cm}^{-1}$ and $\mathrm{V}_{2}=257 \mathrm{~cm}^{-1}$. This torsional potential gives a classical barrier of $288 \mathrm{~cm}^{-1}$ with the cis form at $49 \mathrm{~cm}^{-1}\left(0.6 \mathrm{~kJ} \mathrm{~mol}^{-1}\right)$ relative to the trans form and a torsional frequency of $129 \mathrm{~cm}^{-1}$ (we used a rotational constant of $\mathrm{B}=22.93 \mathrm{~cm}^{-1}$ from the molecular geometry). We found small differences in the thermochemical functions relative to that computed using the scaled torsional potential of Beames et al.: entropies $\mathrm{S}^{\circ}$ differing by about 0.1-0.4 J mol ${ }^{-1} \mathrm{~K}^{-1}$ and enthalpies $H^{\circ}$ differing by $0.2-0.4 \mathrm{~kJ} \mathrm{~mol}^{-1}$ at temperatures of $300 \mathrm{~K}$ to $1000 \mathrm{~K}$.

\subsubsection{Data for $\mathrm{H}_{2} \mathrm{O}_{3}$}

Suma et al. (2005) [226] derived a molecular geometry for $\mathrm{H}_{2} \mathrm{O}_{3}$ from rotational transitions yielding $\mathrm{r}_{0}(\mathrm{OO})=1.428 \AA, \theta_{0}(\mathrm{OOO})=107.0^{\circ}, \mathrm{r}_{0}(\mathrm{OH})=0.963 \AA, \theta_{0}(\mathrm{OOH})=101.1^{\circ}$, and $\phi_{0}(\mathrm{OOOH})=81.8^{\circ}$. This structure was derived from rotational constants $B_{a}=1.706 \mathrm{~cm}^{-1}, B_{b}=0.351 \mathrm{~cm}^{-1}$, and $B_{c}=0.312 \mathrm{~cm}^{-1}$. These correspond to moments of inertia $\left\{\mathrm{I}_{\mathrm{a}}, \mathrm{I}_{\mathrm{b}}, \mathrm{I}_{\mathrm{c}}\right\}=\{9.88,47.28,54.02\}$ amu $\AA^{2}$ or $\{1.64,7.85,8.97\} \times 10^{-46} \mathrm{~kg} \mathrm{~m}^{2}$ in SI units. By comparing the measured rotational constants to those derived from structures from their ab initio calculations, they determined that the trans form was more stable than the cis form. We note that the first molecular structures for $\mathrm{H}_{2} \mathrm{O}_{3}$ calculated by Blint and Newton (1973) [227] and Cremer (1978) [228] using quantum chemical methods are in fairly good agreement with those experimentally determined by Suma et al.

Engdahl and Nelander [219] measured all of the vibrational frequencies for $\mathrm{H}_{2} \mathrm{O}_{3}$ (see Table 12). Earlier, Arnau and Giguere (1974) [208] measured three frequencies: $v_{3}, v_{4}$, and $v_{8}$. Hollman and Schaefer (2012) [200] computed anharmonic and harmonic frequencies (the latter are given in Table 12). Jackel (1993) [205] has also computed harmonic frequencies.

The most stable rotational conformer of $\mathrm{H}_{2} \mathrm{O}_{3}$ is a trans form. Su et al. (2002) [229] calculated the cis form to be $10.0 \mathrm{~kJ} \mathrm{~mol}^{-1}$ higher a barrier-to-isomerization of $21.8 \mathrm{~kJ} \mathrm{~mol}^{-1}$. We note that the first quantum chemical calculations (MP2) of the rotational potential of this molecule were done by Cremer (1978) [228] and predicted the cis form to be about $15.9 \mathrm{~kJ} \mathrm{~mol}^{-1}$ less stable and that there was a very high barrier-toisomerization of $46.4 \mathrm{~kJ} \mathrm{~mol}^{-1}$.

To compute thermochemical functions for $\mathrm{H}_{2} \mathrm{O}_{3}$, we recommend treating the molecule as a rigid rotor harmonic oscillator (RRHO) with the two torsions treated as hindered rotors, and employing the molecular structure of Suma et al. and the vibrational frequencies of Engdahl and Nelander.

We note that in order to correctly compute the hindered rotor partition functions one would need to treat them as two coupled rotors and account for the difference between the trans and cis forms. This is a difficult problem that we cannot solve here. We have treated it as the sum of two identical 1-D rotors. We estimated the uncertainty in the free energy $G^{\circ}(298.15 \mathrm{~K})$ to be about $0.3 \mathrm{~kJ} \mathrm{~mol}^{-1}$ to account for this approximate treatment (considering uncertainties in both enthalpy $H^{\circ}$ and entropy $S^{\circ}$ ).

Using the FGH1D program [225], we reproduced the cis-trans energy difference and barrier-to-rotation of $10.0 \mathrm{~kJ} \mathrm{~mol}^{-1}\left(836 \mathrm{~cm}^{-1}\right)$ and $22.1 \mathrm{~kJ} \mathrm{~mol}^{-1}\left(1847 \mathrm{~cm}^{-1}\right)$, respectively, using $\mathrm{V}_{\mathrm{n}} \cos (\mathrm{n} \theta)$ functions with $\mathrm{V}_{1}=860 \mathrm{~cm}^{-1}$ and $\mathrm{V}_{2}=1580 \mathrm{~cm}^{-1}$ employing a rotational constant of $\mathrm{B}=21.09 \mathrm{~cm}^{-1}$ (from the molecular structure). This yielded fundamental frequencies for the trans and cis conformers of $369 \mathrm{~cm}^{-1}$ and 
$313 \mathrm{~cm}^{-1}$. This frequency for the trans conformer is very close to the average of the symmetric torsional $\left(\mathrm{v}_{9}=346 \mathrm{~cm}^{-1}\right)$ and asymmetric torsional modes $\left(\mathrm{v}_{8}=387 \mathrm{~cm}^{-1}\right)$.

The enthalpy of formation that we selected for $\mathrm{H}_{2} \mathrm{O}_{3}$ was derived from the quantum chemical calculations of Grant et al. (2009) [89] (there are no experimental measurements). We have corrected their value slightly using the anharmonic ZPE computed by Hollman and Schaefer (2012) [200] and treated the torsions as hindered rotors (Grant et al. treated them as vibrations). They used a ZPE of $6474 \mathrm{~cm}^{-1}$ (see Table 11) based on an average of the experimental fundamental frequencies ( $v$ ) and computed harmonic frequencies $\left(\omega_{\mathrm{e}}\right)$. We have employed the anharmonic ZPE of $6514 \mathrm{~cm}^{-1}$ computed by Hollman and Schaefer (a difference of $+0.47 \mathrm{~kJ} \mathrm{~mol}^{-1}$ ) and our computed enthalpy $H^{\circ}$ of $13.00 \mathrm{~kJ} \mathrm{~mol}^{-1}$ (a difference of $\left.+0.45 \mathrm{~kJ} \mathrm{~mol}^{-1}\right)$.

$\mathrm{Xu}$ and Goddard (2002) [181] reported on a chemical mechanism for the formation of $\mathrm{H}_{2} \mathrm{O}_{3}$ from $\mathrm{H}_{2}+$ $\mathrm{O}_{3}$ based on quantum chemical calculations [229] and analysis of experimental data from Engdahl and Nelander (2002) [219] and Goddard and coworkers $(2001,2002)$ [229-231]. They found that the reaction $\mathrm{H}_{2} \mathrm{O}_{2}+\mathrm{O}_{3} \rightarrow \mathrm{H}_{2} \mathrm{O}_{3}+\mathrm{O}_{2}$ occurs via a set of complex reactions with ring intermediates. The barrier-toaddition of $\mathrm{O}_{3}$ to $\mathrm{H}_{2} \mathrm{O}_{2}$ to form an $\mathrm{OOOH}-\mathrm{OOH}$ adduct is about $6.3 \mathrm{~kJ} \mathrm{~mol}^{-1}$ and the reaction overall to form $\mathrm{H}_{2} \mathrm{O}_{3}$ is about $135 \mathrm{~kJ} \mathrm{~mol}^{-1}$ exothermic. $\mathrm{H}_{2} \mathrm{O}_{3}$ is formed in a cis configuration (from decomposition of a ring). They calculated that cis form was about $10.0 \mathrm{~kJ} \mathrm{~mol}^{-1}\left(836 \mathrm{~cm}^{-1}\right)$ higher in energy than the trans form and that the barrier-to-isomerization from trans-to-cis was about $22.1 \mathrm{~kJ} \mathrm{~mol}^{-1}\left(1847 \mathrm{~cm}^{-1}\right)$.

Goddard and coworkers calculated vibrational frequencies for $\mathrm{H}_{2} \mathrm{O}_{3}$ both cis and trans using the B3LYP/6-31G** method. They found excellent agreement between the experimental values of Engdahl and Nelander using average scaling factor (expt/theory) of 0.985 . The vibrational frequencies of the cis form in general were very similar to the trans form differing by about ( 0.5 to 1 )\%. However, the symmetric torsion $v_{9}$ for the cis form was $190 \mathrm{~cm}^{-1}$ or much lower than the experimental and calculated values of $346 \mathrm{~cm}^{-1}$ and $347 \mathrm{~cm}^{-1}$, respectively. The ratio of the experimental asymmetric torsion $v_{8}\left(387 \mathrm{~cm}^{-1}\right)$ to the symmetric torsion $v_{9}\left(346 \mathrm{~cm}^{-1}\right)$ of 1.12 is consistent with slightly different $(20 \%)$ rotational constants for the two (opposite) modes on the same potential energy surface. The very low calculated symmetric torsion $v_{9}$ for the cis form implies that the two motions are highly coupled (energetically) and that use of a simple 1 -D torsion potential energy surface is not fully adequate.

\subsection{Ion Energetics}

In Table 13, ion reaction energetics, such as ionization energies, electron affinities, and appearance energies, are provided, along with uncertainties. These quantities are utilized to compute enthalpies of formation for a number of the hydrogen-oxygen species using thermochemical cycles involving ion processes. This compilation is of the most precise values available (not all reported values are included). The values are given both in their original reported units and converted to $\mathrm{kJ} \mathrm{mol}^{-1}$. The conversion factors employed are given in Sec. 1 "Introduction."

Table 13. Ion Reactions

\begin{tabular}{|c|c|c|c|c|}
\hline Species & Quantity & Energy (orig units) & Energy $\left(\mathrm{kJ} \mathrm{mol}^{-1}\right)$ & Reference \\
\hline \multirow[t]{9}{*}{$\mathrm{H}$} & IE & $0.9994665083441(43) \mathrm{Ry}$ & $1312.04948(6)$ & 2015YER/SHA [232] \\
\hline & IE & $109678.77174307(10) \mathrm{cm}^{-1}$ & 1312.04948(6) & $\begin{array}{l}\text { 2015KRA/RAL [233] } \\
\text { 2005JEN/KOT [234] }\end{array}$ \\
\hline & $\mathrm{IE}$ & 109678.7717(na) $\mathrm{cm}^{-1}$ & 1312.04948 & 2005SAN/MAR [235] \\
\hline & IE & 109678.771196(5) $\mathrm{cm}^{-1}$ & $1312.04948(6)$ & 1985JOH/SOF [236] \\
\hline & IE & 109678.764(na) $\mathrm{cm}^{-1}$ & 1312.04939 & 1970MOO [237] \\
\hline & IE & 109678.758(na) $\mathrm{cm}^{-1}$ & 1312.04932 & 1966WIE/SMI [238] \\
\hline & IE & 109678.764(na) $\mathrm{cm}^{-1}$ & 1312.04939 & 1965GAR/MAC [239] \\
\hline & EA & $6082.99(15) \mathrm{cm}^{-1}$ & $72.769(2)$ & 1991LYK/MUR [240] \\
\hline & EA & 6083.0958(na) $\mathrm{cm}^{-1}$ & 72.770 & 1962PEK [241] \\
\hline \multirow[t]{4}{*}{$\mathrm{H}_{2}$} & IE & $124417.49113(37) \mathrm{cm}^{-1}$ & $1488.363722(4)$ & 2009LIU/SAL [20] \\
\hline & IE & $124417.476(12) \mathrm{cm}^{-1}$ & $1488.36354(14)$ & 2002DEL/REI [242] \\
\hline & IE & $124417.491 \mathrm{~cm}^{-1}$ & 1488.36372 & 1995WOL [37] (quantum) \\
\hline & IE & $124417.507(12) \mathrm{cm}^{-1}$ & 1488.36391(14) & 1993SHI/GIL [243] \\
\hline
\end{tabular}


Volume 121 (2016) http://dx.doi.org/10.6028/jres.121.005

Journal of Research of the National Institute of Standards and Technology

\begin{tabular}{|c|c|c|c|c|}
\hline & IE & $124417.501(17) \mathrm{cm}^{-1}$ & 1488.36384(20) & 1992JUN/DAB $[244,245]$ \\
\hline & $\mathrm{IE}$ & $124417.507(18) \mathrm{cm}^{-1}$ & $1488.36391(22)$ & 1992GIL/EYL [246] \\
\hline & IE & $124417.524(15) \mathrm{cm}^{-1}$ & $1488.36412(18)$ & 1989MCC/GIL [247] \\
\hline & $\mathrm{IE}$ & $124417.61(7) \mathrm{cm}^{-1}$ & 1488.3651(8) & 1987GLA/HES [248] \\
\hline & IE & $124417.2(4) \mathrm{cm}^{-1}$ & $1488.360(5)$ & 1972HER/JUN [249] \\
\hline & $\mathrm{AE}\left(\mathrm{H}^{+}\right)$ & $18.078(3) \mathrm{cm}^{-1}$ & $1744.3(3)$ & 1994WEI/MAH [250] \\
\hline & $\mathrm{IPF}(\mathrm{H}+, \mathrm{H}-)$ & $139714.8(1.0) \mathrm{cm}^{-1}$ & 1671.361(10) & 2000SHI/HU [251] \\
\hline & $\mathrm{IPF}\left(\mathrm{H}^{+}, \mathrm{H}^{-}\right)$ & $139714.0(0.2) \mathrm{cm}^{-1}$ & 1671.351(2) & 1992PRA/MCC [252] \\
\hline & $\mathrm{IPF}\left(\mathrm{H}^{+}, \mathrm{H}^{-}\right)$ & 17.3223(2) eV & $1671.35(2)$ & 1975CHU/DEH [253] \\
\hline \multirow[t]{5}{*}{$\mathrm{O}$} & IE & $109837.02(6) \mathrm{cm}^{-1}$ & 1313.9426(7) & 1976MOO [254] \\
\hline & EA & $11784.676(7) \mathrm{cm}^{-1}$ & $140.9760(1)$ & 2005BLO/CHA [255] \\
\hline & EA & $11784.648(6) \mathrm{cm}^{-1}$ & 140.9761(1) & 1995BLO [256] \\
\hline & EA & $11784.645(6) \mathrm{cm}^{-1}$ & $140.9757(1)$ & 1985NEU/LYK [257] \\
\hline & EA & $11784.675(6) \mathrm{cm}^{-1}$ & $140.9760(1)$ & $\begin{array}{l}\text { 1985NEU/LYK [257] } \\
\text { revised by 2005BLO/CHA [255] }\end{array}$ \\
\hline \multirow[t]{4}{*}{$\mathrm{OH}$} & $\mathrm{IE}$ & & $1255.95(4)$ & 2015GAN/CSO [71] \\
\hline & IE & $104989(2) \mathrm{cm}^{-1}$ & $1255.95(2)$ & 1992WIE/TON [81] \\
\hline & EA & $14740.982(7) \mathrm{cm}^{-1}$ & 176.3413(1) & 2005GOL/DRA [258] \\
\hline & EA & $14741.02(3) \mathrm{cm}^{-1}$ & 176.3418(4) & 1997SMI/KIM [259] \\
\hline \multirow[t]{7}{*}{$\mathrm{H}_{2} \mathrm{O}$} & IE & $101766.8(1.2) \mathrm{cm}^{-1}$ & 1217.401(14) & 1998MER/SIG [260] \\
\hline & IE & 101766(2) $\mathrm{cm}^{-1}$ & 1217.392(24) & 1991TON/WIE [261] \\
\hline & IE & $101772(2) \mathrm{cm}^{-1}$ & $1217.463(24)$ & 1990CHI/JUN [262] \\
\hline & $\mathrm{AE}(\mathrm{OH}+)$ & 18.1182(9) eV & 1748.14(9) & 2014BOD/CSO [263] \\
\hline & $\mathrm{AE}(\mathrm{OH}+)$ & $146117(24) \mathrm{cm}^{-1}$ & 1747.95(29) & 2002RUS/WAG [74] \\
\hline & $\mathrm{AE}(\mathrm{OH}+)$ & $18.115(4) \mathrm{eV}$ & $1747.8(4)$ & 2001RUS/FEL [79] \\
\hline & $\mathrm{AE}(\mathrm{OH}+)$ & 18.115(8) eV & $1747.8(8)$ & 1976MCC [82] \\
\hline \multirow[t]{10}{*}{$\mathrm{O}_{2}$} & IE & $97345(4) \mathrm{cm}^{-1}$ & $1164.505(48)$ & 1999SON/EVA [264] \\
\hline & IE & $97352.2(1.2) \mathrm{cm}^{-1}$ & 1164.591(14) & 1998MER/SIG [260] \\
\hline & IE & $97347(1.3) \mathrm{cm}^{-1}$ & 1164.529(16) & 1994KON/HEP [265] \\
\hline & IE & $97348(2) \mathrm{cm}^{-1}$ & $1164.54(2)$ & 1989TON/WIN [266] \\
\hline & IE & $12.071(1) \mathrm{eV}$ & 1164.67(10) & 1975SAM/GAR [267] \\
\hline & EA & $0.448(6) \mathrm{eV}$ & $43.2(6)$ & 2003ERV/ANU [268] \\
\hline & EA & $0.451(7) \mathrm{eV}$ & $43.5(7)$ & 1989TRA/COW [269] \\
\hline & EA & $0.440(8) \mathrm{eV}$ & $42.5(8)$ & 1972CEL/BEN [270] \\
\hline & $\mathrm{IPF}\left(\mathrm{O}^{+}, \mathrm{O}^{-}\right)$ & $139319.1(7) \mathrm{cm}^{-1}$ & $1666.627(8)$ & 1997MAR/HEP [53] \\
\hline & $\mathrm{IPF}\left(\mathrm{O}^{+}, \mathrm{O}^{-}\right)$ & $139312.6(9.7) \mathrm{cm}^{-1}$ & 1666.515(12) & 1975DEH/CHU [59] \\
\hline \multirow{2}{*}{$\mathrm{O}_{2}^{+}$} & $\mathrm{AE}\left(\mathrm{O}^{+}\right)$ & $18.73(1) \mathrm{eV}$ & $1807.2(1.0)$ & 1985RIC/DUT [271] \\
\hline & $\mathrm{AE}(\mathrm{O}+)$ & 18.734(1) eV & $1807.56(0.10)$ & 1981BLY/POW [56] \\
\hline \multirow[t]{7}{*}{$\mathrm{HO}_{2}$} & IE & & $1095.71(0.45)$ & 2015GAN/CSO [71] \\
\hline & IE & $11.352(7) \mathrm{eV}$ & $1095.3(0.7)$ & 1998LIT/RUS [112] \\
\hline & IE & $11.35(1) \mathrm{eV}$ & 1096(1) & 1981DYK/JON [272] \\
\hline & EA & & $103.88(0.44)$ & 2015GAN/CSO [71] \\
\hline & EA & $1.078(6) \mathrm{eV}$ & $104.0(0.6)$ & 2002RAM/BLA [110] \\
\hline & EA & $1.089(6) \mathrm{eV}$ & $105.1(0.6)$ & 1998CLI/WEN [111] \\
\hline & EA & $1.078(17) \mathrm{eV}$ & $104.0(1.6)$ & 1985OAK/HAR [114] \\
\hline \multirow[t]{4}{*}{$\mathrm{H}_{2} \mathrm{O}_{2}$} & IE & 10.631(7) eV & $1025.7(0.7)$ & 1998LIT/RUS [112] \\
\hline & $\mathrm{AE}\left(\mathrm{HO}_{2}+\right)$ & 15.112(35) eV & 1458.1(3.4) & 1998LIT/RUS [112] \\
\hline & $\mathrm{AE}(\mathrm{OH}+)$ & $15.174(4) \mathrm{eV}$ & 1464.1(0.4) & 1998LIT/RUS [112] \\
\hline & $\mathrm{AE}(\mathrm{H}+)$ & & $1575.3(2.1)$ & 2002RAM/BLA [110] \\
\hline \multirow[t]{4}{*}{$\mathrm{O}_{3}$} & IE & & $1208.47(6)$ & 2005WIL/INN [273] \\
\hline & IE & $12.519(4) \mathrm{eV}$ & $1207.9(4)$ & 1977WEI/BER [274] \\
\hline & EA & $2.103(4) \mathrm{eV}$ & $202.9(4)$ & 1994ARN/XU [275] \\
\hline & EA & $2.1028(25) \mathrm{eV}$ & $202.89(24)$ & 1979NOV/ENG [276] \\
\hline
\end{tabular}




\section{Glossary}

Notations, acronyms, and abbreviations referred to in this work are provided in Table 14 along with a short description for each. References are also provided for the quantum chemical methods for more information.

Table 14. Notations and Descriptions

\begin{tabular}{|c|c|c|}
\hline Notation & Description & Reference \\
\hline Absorp limit & Absorption limit & \\
\hline $\mathrm{AE}$ & Appearance Energy & \\
\hline Calorim decomp & Calorimetric decomposition & \\
\hline Dissoc continuum & Dissociation continuum & \\
\hline EA & Electron Affinity & \\
\hline Empirical & Estimated using empirical trends & \\
\hline Equilibrium & Determined from equilibrium & \\
\hline Heat combustion & Determined from heat of combustion. & \\
\hline Heat reaction & Determined from heat of reaction. & \\
\hline $\mathrm{IE}$ & Ionization Energy & \\
\hline Ion cycle & Derived using thermochemical cycles using ion energetics & \\
\hline Ion pair dissoc & Ion pair dissociation & \\
\hline Ioniz threshold & Ionization threshold & \\
\hline Ioniz/Quantum & Ionization threshold combined with quantum (see text for $\mathrm{H}$ atom) & \\
\hline IPF & Ion Pair Formation & \\
\hline Kinetics & Measured using a kinetic method and forward and reverse barriers to reaction & \\
\hline Kinetics/Equil & Measured using kinetics along with equilibrium measurements & \\
\hline Review & Recommend value based on a review/evaluation & \\
\hline PEPICO & Photoelectron photoion coincidence spectroscopy & \\
\hline Photodissoc & Photodissociation & \\
\hline Photofrag spec & Photofragment spectroscopy & \\
\hline Photofragment & Photofragmentation & \\
\hline Spec dissoc limit & Spectroscopic dissociation limit & \\
\hline Thermo network & Thermochemical network & \\
\hline Vib predissoc & Vibrational predissociation & \\
\hline \multicolumn{3}{|c|}{ Quantum Chemical Methods } \\
\hline B3LYP & Becke Three Parameter method with LYP Hybrid Functionals & 1993BEC [277] \\
\hline CASPT2 & Complete active space (second order perturbation) method. & 1998FIN/MAL [278] \\
\hline CASSCF & Complete active space self-consistent field method & 1985KNO/WER [279] \\
\hline CBS-APNO & Complete basis set-quadratic CI model with atomic pair natural orbitals & 1996OCH/PET [280] \\
\hline CBS-Q & Complete basis set-quadratic CI model using QCISD(T) and large basis sets & 1996OCH/PET [281] \\
\hline CBS-QB3 & CBS-Q method with B3LYP DFT geometries and frequencies & 1999MON/FRI [282] \\
\hline CC & $\begin{array}{l}\text { Use of one of a number of coupled cluster methods. Could be CCSD (single and } \\
\text { double excitations), CCSD(T) (approximate triples), CCSDQ (quintuplets), etc. }\end{array}$ & 1978BAR/PUR [283] \\
\hline CC-F12 & Coupled cluster method with F12 corrections/correlations & 2009KNI/ADL [284] \\
\hline CC-R12 & Coupled cluster method with R12 corrections/correlations & 1994NOG/KUT [285] \\
\hline $\operatorname{CCSD}(\mathrm{T})$ & CC with single and double excitation and approximate triples & \\
\hline CISD & Configuration interaction method with single and double excitations & 1977POP/SEE [286] \\
\hline DFT(HCTH) & Density functional method using the HCTH functional & 1998HAM/COH [287] \\
\hline DFT(PBE0) & Density functional method using the PBE0 functional & 1999ADA/BAR [288] \\
\hline EOMIP & Equation of motion ionization problem & 1994STA/GAU [289] \\
\hline$\overline{\text { FCI }}$ & Full configuration interaction method & 1984KNO/HAN [290] \\
\hline FCI(CEEIS) & FCI method with correlation energy extrapolation by intrinsic scaling & 2005BYT/RUE [66] \\
\hline FCI(SCI) & FCI method with selected configuration interaction truncation & 2006BUN [291] \\
\hline G2 & Gaussian-2 quantum chemical method & 1991CUR/RAG [292] \\
\hline G2MP2 & Approximate G2 method using MP2 energies & \\
\hline G3 & Gaussian-3 quantum chemical method & 1999CUR/RAG [98] \\
\hline G3B3 & G3 method using B3LYP DFT geometries and frequencies & \\
\hline G3MP2 & Approximate G3 method using MP2 energies & \\
\hline
\end{tabular}




\begin{tabular}{|l|l|l|}
\hline G3MP2B3 & G3 method using MP2 energies and B3LYP geometries & \\
\hline HEAT & High accuracy extrapolated ab initio thermochemistry method & 2004TAJ/SZA [129] \\
\hline iso & Use of an ab initio method with energies corrected using isodesmic reactions & \\
\hline MR-ACPF & Multireference theory with averaged coupled pair functional & 1988GDA/AHL [293] \\
\hline MRCI & Multireference configuration interaction approach & 1978BUE/PEY [294] \\
\hline MRCI+Q & MRCI method with Davidson correction & 1974LAN [295] \\
\hline MRSDCI & MRCI approach with singlet and doublet excitation & \\
\hline MRMP2 & Use of multireference MP2 energy differences & $1992 H I R$ [296] \\
\hline MR-CISD & Multireference with CISD method & 2010CSA/FUR [87] \\
\hline NEAT & $\begin{array}{l}\text { Network of Computed Reaction Enthalpies to Atom-Based Thermochemistry } \\
\text { method. }\end{array}$ & 1987POP/HEA [297] \\
\hline QCI & Use of a quadratic configuration method & 1999MAR/DEO [298] \\
\hline Quantum & Use of a quantum chemical method (unspecified) & \\
\hline W1 & W1 quantum chemical method & 1999MAR/DEO [298] \\
\hline W1U & Variant of W1 quantum chemical method & 2006KAR/RAB [202] \\
\hline W2 & W2 quantum chemical method & \\
\hline W4 & W4 quantum chemical method & \\
\hline & & $1998 T R U ~[299]$ \\
\hline Quantum Chemical Basis Sets & 1999FEL/PET [300] \\
\hline /AV5Z & Use of an aug-cc-pV5Z type basis set & \\
\hline /cbs & $\begin{array}{l}\text { Use of correlation consistent basis sets (e.g., aug-cc-pVnZ) extrapolated to the } \\
\text { complete basis set limit. }\end{array}$ & \\
\hline /DZ & Use of a double zeta type basis set & \\
\hline /pVTZ & Use of a cc-pVTZ type basis set (may include diffuse functions) & \\
\hline /pVQZ & Use of a cc-pVQZ type basis set (may include diffuse functions) & \\
\hline /pV6Z & Use of a cc-pV6Z type basis set (may include diffuse functions) & \\
\hline
\end{tabular}

\section{References}

[1] M. W. Chase Jr., “NIST-JANAF Thermochemical Tables, Fourth Edition,” J. Phys. Chem. Ref. Data, Monograph 9, 1-1951 (1998).

[2] L. V. Gurvich, I. V. Veyts, and C. B. Alcock, Thermodynamic Properties of Individual Substances. Volume 1, Hemisphere Pub. Co., New York, (1989).

[3] B. N. Taylor and C. E. Kuyatt, Guidelines for Evaluating and Expressing the Uncertainty of NIST Measurement Results, NIST Technical Note 1297, National Institute of Standards and Technology, Gaithersburg, MD (1994).

[4] P. J. Mohr, B. N. Taylor, and D. B. Newell, “CODATA recommended values of the fundamental physical constants: 2010,” J. Phys. Chem. Ref. Data 41, 043109 (2012). http://dx.doi.org/10.1063/1.4724320

[5] B. Ruscic, R. E. Pinzon, M. L. Morton, G. von Laszevski, S. Bittner, S. G. Nijsure, K. A. Amin, M. Minkoff, and A. F. Wagner, "Active Thermochemical Tables Software and Associated Data Libraries,” Argonne National Laboratory, Argonne, IL, 2002-2004.

[6] B. Ruscic, R. E. Pinzon, M. L. Morton, G. von Laszevski, S. J. Bittner, S. G. Nijsure, K. A. Amin, M. Minkoff, and A. F. Wagner, "Introduction to active thermochemical tables: Several "key" enthalpies of formation revisited," J. Phys. Chem. A 108, 9979 (2004). http://dx.doi.org/10.1021/Jp047912y

[7] B. Ruscic, R. E. Pinzon, G. von Laszewski, D. Kodeboyina, A. Burcat, D. Leahy, D. Montoya, and A. F. Wagner, “Active Thermochemical Tables: thermochemistry for the $21^{\text {st }}$ century,” J. Phys. Conf. Ser. 16, 561 (2005). http://dx.doi.org/10.1088/1742-6596/16/1/078

[8] B. Ruscic, J. E. Boggs, A. Burcat, A. G. Csaszar, J. Demaison, R. Janoschek, J. M. L. Martin, M. L. Morton, M. J. Rossi, J. F. Stanton, P. G. Szalay, P. R. Westmoreland, F. Zabel, and T. Berces, "IUPAC critical evaluation of thermochemical properties of selected radicals,” J. Phys. Chem. Ref. Data 34, 573 (2005). http://dx.doi.org/10.1063/1.1724828

[9] B. Ruscic, D. Feller, and K. A. Peterson, "Active Thermochemical Tables: dissociation energies of several homonuclear firstrow diatomics and related thermochemical values,” Theor. Chem. Acct. 133, 1415 (2014). http://dx.doi.org/10.1007/S00214-013-1415-Z

[10] B. Ruscic, "Uncertainty quantification in thermochemistry, benchmarking electronic structure computations, and Active Thermochemical Tables,” Int. J. Quant. Chem. 114, 1097 (2014). http://dx.doi.org/10.1002/qua.24605

[11] B. Ruscic, Active Thermochemical Tables (ATcT), http://atct.anl.gov [Accessed August 31, 2015].

[12] E. Goos, A. Burcat, and B. Ruscic, Extended Third Millenium Ideal Gas Thermochemical Database with Updates from Active Thermochemical Tables, http://burcat.technion.ac.il/dir/BURCAT.THR [Accessed August 31, 2015].

[13] D. Sprecher, C. Jungen, W. Ubachs, and F. Merkt, "Towards measuring the ionisation and dissociation energies of molecular hydrogen with sub-MHz accuracy,” Faraday Discuss. 150, 51 (2011). http://dx.doi.org/10.1039/C0fd00035c 
[14] S. P. Sander, J. Abbatt, J. R. Barker, J. B. Burkholder, R. R. Friedl, D. M. Golden, R. E. Huie, C. E. Kolb, M. J. Kurylo, G. K. Moortgat, V. L. Orkin, and P. H. Wine, Chemical Kinetics and Photochemical Data for Use in Atmospheric Studies, Evaluation No. 17 (JPL Publication 10-6), Jet Propulsion Laboratory, Pasadena (2011). http://jpldataeval.jpl.nasa.gov [Accessed August 12, 2015].

[15] B. P. Stoicheff, “On the dissociation energy of molecular hydrogen,” Can. J. Phys. 79, 165 (2001). http://dx.doi.org/10.1139/cjp-79-2-3-165

[16] J. D. Cox, D. D. Wagman, and V. A. Medvedev, CODATA Key Values for Thermodynamics, Hemisphere Publishing Corp., New York (1989).

[17] W. C. Stwalley, "The dissociation energy of the hydrogen molecule using long-range forces," Chem. Phys. Lett. 6, 241 (1970). http://dx.doi.org/10.1016/0009-2614(70)80t-5

[18] B. deB. Darwent, "Bond dissociation energies in simple molecules,” Nat. Stand. Ref. Data Ser., Nat. Bur. Stand. (U.S.) 31 (1970).

[19] B. Jeziorski and W. Kotos, “On the ionization potential of H2,” Chem. Phys. Lett. 3, 677 (1969). http://dx.doi.org/10.1016/0009-2614(69)87007-7

[20] J. J. Liu, E. J. Salumbides, U. Hollenstein, J. C. J. Koelemeij, K. S. E. Eikema, W. Ubachs, and F. Merkt, "Determination of the ionization and dissociation energies of the hydrogen molecule," J. Chem. Phys. 130, 174306 (2009). http://dx.doi.org/10.1063/1.3120443

[21] J. Liu, D. Sprecher, F. Merkt, E. J. Salumbides, and W. Ubachs, "Determination of the ionization and dissociation energies of H2 and He2,” AIP. Conf. Proc. 1504 (2012). http://dx.doi.org/10.1063/1.4771748

[22] Y. P. Zhang, C. H. Cheng, J. T. Kim, J. Stanojevic, and E. E. Eyler, "Dissociation energies of molecular hydrogen and the hydrogen molecular ion,” Phys. Rev. Lett. 92, 203003 (2004). http://dx.doi.org/10.1103/Physrevlett.92.203003

[23] A. Balakrishnan, V. Smith, and B. P. Stoicheff, "Dissociation energies of the hydrogen and deuterium molecules," Phys. Rev. A 49, 2460 (1994). http://dx.doi.org/10.1103/PhysRevA.49.2460

[24] E. E. Eyler and N. Melikechi, "Near-threshold continuum structure and the dissociation-energies of H2, HD, and D2," Phys. Rev. A 48, R18 (1993). http://dx.doi.org/10.1103/PhysRevA.48.R18

[25] A. Balakrishnan, V. Smith, and B. P. Stoicheff, “Dissociation Energy of the hydrogen molecule,” Phys. Rev. Lett. 68, 2149 (1992). http://dx.doi.org/10.1103/PhysRevLett.68.2149

[26] E. F. McCormack and E. E. Eyler, "Perturbed structure of molecular hydrogen near the 2nd dissociation limit," Phys. Rev. Lett. 66, 1042 (1991). http://dx.doi.org/10.1103/PhysRevLett.66.1042

[27] G. Herzberg, “Dissociation energy of hydrogen molecule,” J. Mol. Spectrosc. 33, 147 (1970). http://dx.doi.org/10.1016/0022-2852(70)90060-3

[28] G. Herzberg and A. Monfils, “The dssociation energies of the H2, HD, and D2 molecules,” J. Mol. Spectrosc. 5, 482 (1960). http://dx.doi.org/10.1016/0022-2852(61)90111-4

[29] H. Beutler and H. O. Junger, "The binding strength in the H2 molecule,” Z. Phys. 101, 304 (1936). http://dx.doi.org/10.1007/BF01342327

[30] O. W. Richardson and P. M. Davidson, "The spectrum of H2 - The bands analogous to the parhelium line spectrum - Part II," Proc. Roy. Soc. Lond. A 123, 466 (1929). http://dx.doi.org/10.1098/rspa.1929.0079

[31] G. H. Dieke and J. J. Hopfield, “The structure of the ultra-violet spectrum of the hydrogen molecule,” Phys. Rev. 30, 400 (1927). http://dx.doi.org/10.1103/PhysRev.30.400

[32] I. Isanrdi, "Concerning the thermal conduction in dissociated gas and concerning dissociation of water material in an atom," $Z$. Elektrochem. 21, 405 (1915). http://dx.doi.org/10.1002/bbpc.19150211701

[33] K. Wohl, "The dissociation of chlorine and hydrogen in the atom 2 Part - The dissociation of hydrogen,” Z. Elektrochem. 30, 49 (1924). http://dx.doi.org/10.1002/bbpc.19240300301

[34] I. Langmuir, "The dissociation of hydrogen into atoms. Part II. Calculation of the degree of dissociation and the heat of formation,” J. Am. Chem. Soc. 37, 417 (1915). http://dx.doi.org/10.1021/ja02168a002

[35] I. Langmuir, "Flames of hydrogen," General Electric Review 29, 153 (1926).

[36] K. Piszczatowski, G. Lach, M. Przybytek, J. Komasa, K. Pachucki, and B. Jeziorski, "Theoretical determination of the dissociation energy of molecular hydrogen,” J. Chem. Theory Comput. 5, 3039 (2009). http://dx.doi.org/10.1021/Ct900391p

[37] L. Wolniewicz, "Nonadiabatic energies of the ground-state of the hydrogen molecule," J. Chem. Phys. 103, 1792 (1995). http://dx.doi.org/10.1063/1.469753

[38] W. Kolos and J. Rychlewski, "Improved theoretical dissociation-energy and ionization-potential for the ground-state of the hydroge molecule,” J. Chem. Phys. 98, 3960 (1993). http://dx.doi.org/10.1063/1.464023

[39] L. Wolniewicz, "Relativistic energies of the ground-state of the hydrogen molecule,” J. Chem. Phys. 99, 1851 (1993). http://dx.doi.org/10.1063/1.465303

[40] C. Schwartz and R. J. Leroy, "Nonadiabatic eigenvalues and adiabatic matrix-elements for all isotopes of diatomic hydrogen," J. Mol. Spectrosc. 121, 420 (1987). http://dx.doi.org/10.1016/0022-2852(87)90059-2

[41] W. Kolos, K. Szalewicz, and H. J. Monkhorst, "New Born-Oppenheimer potential-energy curve and vibrational energies for the electronic ground-state of the hydrogen molecule," J. Chem. Phys. 84, 3278 (1986). http://dx.doi.org/10.1063/1.450258

[42] L. Wolniewicz, "The X1 $\Sigma \mathrm{g}+$ state vibration-rotational energies of the H2, HD, and D2 molecules," J. Chem. Phys. 78, 6173 (1983). http://dx.doi.org/10.1063/1.444580

[43] D. M. Bishop and L. M. Cheung, "Rigorous theoretical investigation of ground-state of H2,” Phys. Rev. A 18, 1846 (1978). http://dx.doi.org/10.1103/PhysRevA.18.1846

[44] W. Kolos and L. Wolniewicz, "Improved potential-energy curve and vibrational energies for electronic ground-state of hydrogen molecule,” J. Mol. Spectrosc. 54, 303 (1975). http://dx.doi.org/10.1016/0022-2852(75)90083-1

[45] P. R. Bunker, "Breakdown of Born-Oppenheimer approximation for a diatomic molecule,” J. Mol. Spectrosc. 42, 478 (1972) http://dx.doi.org/10.1016/0022-2852(72)90224-X 
[46] W. Kolos and L. Wolniewicz, “Improved theoretical ground-state enegy of hydrogen molecule,” J. Chem. Phys. 49, 404 (1968). http://dx.doi.org/10.1063/1.1669836

[47] G. Hunter, “Adiabatic dissociation energies for the ground states of the H2, HD, and D2 molecules, J. Chem. Phys. 45, 3022 (1966). http://dx.doi.org/10.1063/1.1728057

[48] W. Kolos and L. Wolniewicz, "Accurate computation of vibronic energies and of some expectation values for H2, D2, and T2,” J. Chem. Phys. 41, 3674 (1964). http://dx.doi.org/10.1063/1.1725797

[49] W. Kolos and C. C. J. Roothaan, “Accurate electronic wave functions for the H2 molecule,” Rev. Mod. Phys. 32, 219 (1960). http://dx.doi.org/10.1103/RevModPhys.32.219

[50] H. M. James and A. S. Coolidge, "The ground state of the hydrogen molecule,” J. Chem. Phys. 1, 825 (1933). http://dx.doi.org/10.1063/1.1749252

[51] C. E. Moore, Tables of Spectra of Hydrogen, Carbon, Nitrogen, and Oxygen Atoms and Ions, CRC Press, Boca Raton, FL (1993).

[52] P. C. Cosby and D. L. Huestis, "On the dissociation-energy of O2 and the energy of the O2(+)B4Eg State," J. Chem. Phys. 97, 6108 (1992). http://dx.doi.org/10.1063/1.463720

[53] J. D. D. Martin and J. W. Hepburn, "Electric field induced dissociation of molecules in Rydberg-like highly vibrationally excited ion-pair states,” Phys. Rev. Lett. 79, 3154 (1997). http://dx.doi.org/10.1103/PhysRevLett.79.3154

[54] S. T. Gibson, B. R. Lewis, K. G. H. Baldwin, and J. H. Carver, "Rotational features in the fluorescence excitation spectrum of O(1D2) from vacuum ultraviolet-laser photodissociation of O2,” J. Chem. Phys. 94, 1060 (1991). http://dx.doi.org/10.1063/1.460062

[55] B. R. Lewis, L. Berzins, J. H. Carver, and S. T. Gibson, "Decomposition of the photoabsorption continuum underlying the Schumann-Runge bands of 1602 .1. Role of the B3 $\Sigma \mu$ - state - a new dissociation limit,” J. Quant. Spectrosc. Radiative Transfer 33, 627 (1985). http://dx.doi.org/10.1016/0022-4073(85)90031-7

[56] R. G. C. Blyth, I. Powis, and C. J. Danby, “Competing pre-dissociations of O2+,” Chem. Phys. Lett. 84, 272 (1981) http://dx.doi.org/10.1016/0009-2614(81)80343-0

[57] C. Pernot, J. Durup, J. B. Ozenne, J. A. Beswick, P. C. Cosby, and J. T. Moseley, “Angular-distributions and separation energies of predissociation photofragments of O2+,” J. Chem. Phys. 71, 2387 (1979). http://dx.doi.org/10.1063/1.438644

[58] D. L. Albritton, J. T. Moseley, P. C. Cosby, and M. Tadjeddine, “Dissociation-energy of O2,” J. Mol. Spectrosc. 70, 326 (1978). http://dx.doi.org/10.1016/0022-2852(78)90169-8

[59] P. M. Dehmer and W. A. Chupka, “High resolution study of photoionization processes in O2,” J. Chem. Phys. 62 , 4525 (1975). http://dx.doi.org/10.1063/1.430359

[60] C. J. Danby and J. H. D. Eland, "Photoelectron-photoion coincidence spectroscopy: II. Design and performance of a practical instrument,” Int. J. Mass Spectrom. Ion Phys. 8, 153 (1972). http://dx.doi.org/10.1016/0020-7381(72)80005-6

[61] P. Brix and G. Herzberg, "Fine structure of the Schumann-Runge bands near the convergence limit and the dissociation energy of the oxygen molecule,” Can. J. Phys. 32, 110 (1954). http://dx.doi.org/10.1139/p54-013

[62] D. Feller, K. A. Peterson, and B. Ruscic, "Improved accuracy benchmarks of small molecules using correlation consistent basis sets,” Theor. Chem. Acc. 133, 1407 (2014). http://dx.doi.org/10.1007/s00214-013-1407-z

[63] H. Liu, D. H. Shi, J. F. Sun, Z. L. Zhu, and Z. Shulin, "Accurate calculations on the 22 electronic states and 54 spin-orbit states of the O2 molecule: Potential energy curves, spectroscopic parameters and spin-orbit coupling,” Spectrochim Acta A 124, 216 (2014). http://dx.doi.org/10.1016/j.saa.2014.01.003

[64] L. Bytautas, N. Matsunaga, and K. Ruedenberg, "Accurate ab initio potential energy curve of O2. II. Core-valence correlations, relativistic contributions, and vibration-rotation spectrum,” J. Chem. Phys. 132, 074307 (2010). http://dx.doi.org/10.1063/1.3298376

[65] A. J. C. Varandas, "Accurate global ab initio potentials at low-cost by correlation scaling and extrapolation to the one-electron basis set limit,” Chem. Phys. Lett. 443, 398 (2007). http://dx.doi.org/10.1016/j.cplett.2007.06.061

[66] L. Bytautas and K. Ruedenberg, "Correlation energy extrapolation by intrinsic scaling. IV. Accurate binding energies of the homonuclear diatomic molecules carbon, nitrogen, oxygen and fluorine,” J. Chem. Phys. 122, 154110 (2005). http://dx.doi.org/10.1063/1869493

[67] K. A. Peterson, A. K. Wilson, D. E. Woon, and T. H Dunning Jr., "Benchmark calculations with correlated molecular wave functions XII. Core correlation effects on the homonuclear diatomic molecules B2-F2,” Theor. Chem. Acc. 97, 251 (1997). http://dx.doi.org/10.1007/s002140050259

[68] A. G. Csaszar and W. D. Allen, "The effect of $1 \mathrm{~s}$ correlation on De, re, and we of first-row diatomics," J. Chem. Phys. 104, 2746 (1996). http://dx.doi.org/10.1063/1.471008

[69] S. J. Cole, M. Hasan, and B. Kirtman,” Single-Reference Coupled-Cluster Calculations of the Triplet Ground-State O2 Dissociation Potential,” Isr. J. Chem. 31, 303 (1991). http://dx.doi.org/10.1002/ijch.199100035

[70] S. L. Guberman, “Accurate ab initio potential curve for ground state O2,” J. Chem. Phys. 67, 1125 (1977). http://dx.doi.org/10.1063/1.434963

[71] A. Ganyecz, J. Csontos, B. Nagy, and M. Kallay, "Theoretical and thermochemical network approaches to determine the heats of formation for HO2 and its ionic counterparts,” J. Phys. Chem. A 119, 1164 (2015). http://dx.doi.org/10.1021/jp5104643

[72] B. Ruscic, Active Thermochemical Tables. ATcT B. Version 1.110 Core Argonne 30.5.2010. Available at http://atct.anl.gov/Thermochemical Data/version 1.110 and http://burcat.technion.ac.il/dir/Archives/BURCAT2010.THR [Accessed July 30, 2015].

[73] B. Ruscic, R. E. Pinzon, M. L. Morton, N. K. Srinivasan, M. C. Su, J. W. Sutherland, and J. V. Michael, “Active thermochemical tables: Accurate enthalpy of formation of hydroperoxyl radical, HO2,” J. Phys. Chem. A 110, 6592 (2006). http://dx.doi.org/10.1021/jp056311j

[74] B. Ruscic, A. F. Wagner, L. B. Harding, R. L. Asher, D. Feller, D. A. Dixon, K. A. Peterson, Y. Song, X. M. Qian, C. Y. Ng, J. B. Liu, W. W. Chen, and D. W. Schwenke, "On the enthalpy of formation of hydroxyl radical and gas-phase bond dissociation energies of water and hydroxyl,” J. Phys. Chem. A. 106, 2727 (2002). http://dx.doi.org/10.1021/jp013909s 
[75] J. A. Joens, "The dissociation energy of $\mathrm{OH}$ and the enthalpy of formation of $\mathrm{OH}, \mathrm{ClOH}$, and $\mathrm{BrOH}$ from thermochemical cycles,” J. Phys. Chem. A 105, 11041(2001). http://dx.doi.org/10.1021/jp011833u

[76] O. V. Boyarkin, M. A. Koshelev, O. Aseev, P. Maksyutenko, T. R. Rizzo, N. F. Zobov, L. Lodi, J. Tennyson, and O. L. Polyansky, "Accurate bond dissociation energy of water determined by triple-resonance vibrational spectroscopy and ab initio calculations,” Chem. Phys. Lett. 568, 14 (2013). http://dx.doi.org/10.1016/j.cplett.2013.03.007

[77] P. Maksyutenko, T. R. Rizzo, and O. V. Boyarkin, "A direct measurement of the dissociation energy of water. J. Chem. Phys. 125, 181101 (2006). http://dx.doi.org/10.1063/1.2387163

[78] J. T. Herbon, R. K. Hanson, D. M. Golden, and C. T. Bowman, "A shock tube study of the enthalpy of formation of OH," Proc. Combust. Inst. 29, 1201 (2002). http://dx.doi.org/10.1016/S1540-7489(02)80149-3

[79] B. Ruscic, D. Feller, D. A. Dixon, K. A. Peterson, L. B. Harding, R. L. Asher, and A. F. Wagner, "Evidence for a lower enthalpy of formation of hydroxyl radical and a lower gas-phase bond dissociation energy of water," J. Phys. Chem. A 105, 1 (2001). http://dx.doi.org/10.1021/jp003711s

[80] S. A. Harich, D. W. H. Hwang, X. Yang, J. J. Lin, X. Yang, and R. N. Dixon, "Photodissociation of H2O at 121.6 nm: A stateto-state dynamical picture,” J. Chem. Phys. 113, 10073 (2000). http://dx.doi.org/10.1063/1.1322059

[81] R. T. Wiedmann, R. G. Tonkyn, M. G. White, K. H. Wang, and V. McKoy, "Rotationally resolved threshold photoelectron spectra of OH and OD,” J. Chem. Phys. 97, 768 (1992). http://dx.doi.org/10.1063/1.463179

[82] K. E. McCulloh, "Energetics and mechanisms of fragment ion formation in the photoionization of normal and deuterated water and ammonia,” Int. J. Mass Spectrom. Ion Phys. 21, 333 (1976). http://dx.doi.org/10.1016/0020-7381(76)80131-3

[83] C. Carlone and F. W. Dalby, "Spectrum of hydroxyl radical," Can. J. Phys. 47, 1945 (1969). http://dx.doi.org/10.1139/p69-245

[84] R. F. Barrow, “The $\mathrm{B}^{2} \Sigma^{+}-\mathrm{A}^{2} \Sigma^{+}$band systems of OH and OD," Ark. Fys. 11, 281 (1956).

[85] R. J. Dwyer and O. Oldenberg, “The dissociation of H2O into H + OH,” J. Chem. Phys. 12, 351 (1944). http://dx.doi.org/10.1063/1.1723957

[86] O. Riechemeier, H. Senftleben, and H. Pastorff, “Über die Energieverhältnisse bei der Dissoziation des Wasserdampfmoleküls in seine Atome,” Ann. d. Phys. 411, 202 (1934). http://dx.doi.org/10.1002/andp.19344110206

[87] A. G. Csaszar and T. Furtenbacher, "From a Network of Computed Reaction Enthalpies to Atom-Based Thermochemistry (NEAT)," Chem. Eur. J. 16, 4826 (2010). http://dx.doi.org/10.1002/chem.200903252

[88] A. G. Csaszar, E. Matyus, T. Szidarovszky, L. Lodi, N. F. Zobov, S. V. Shirin, O. L. Polyansky, and J. Tennyson, "Firstprinciples prediction and partial characterization of the vibrational states of water up to dissociation,” J. Quant. Spect. Radiat. Transfer 111, 1043 (2010). http://dx.doi.org/10.1016/j.jqsrt.2010.02.009

[89] D. J. Grant, D. A. Dixon, J. S. Francisco, D. Feller and K. A. Peterson, "Heats of formation of the H1,2OmSn (m, n=0-3) molecules from electronic structure calculations,” J. Phys. Chem. A 113, 11343 (2009). http://dx.doi.org/10.1021/Jp905847e

[90] M. Grechko, O. V. Boyarkin, T. R. Rizzo, P. Maksyutenko, N. F. Zobov, S. V. Shirin, L Lodi, J. Tennyson, A. G. Csaszar, and O. L. Polyansky, "State-selective spectroscopy of water up to its first dissociation limit," J. Chem. Phys. 131, 221105 (2009). http://dx.doi.org/10.1063/1.3273207

[91] M. E. Harding, J. Vazquez, B. Ruscic, A. K. Wilson, J. Gauss, and J. F. Stanton, "High-accuracy extrapolated ab initio thermochemistry. III. Additional improvements and overview,” J. Chem. Phys. 128, 114111 (2008). http://dx.doi.org/10.1063/1.2835612

[92] D. Feller, K. A. Peterson, and D. A. Dixon, "A survey of factors contributing to accurate theoretical predictions of atomization energies and molecular structures,” J. Chem. Phys. 129, 204105 (2008). http://dx.doi.org/10.1063/1.3008061

[93] H. T. Ma, W. S. Bian, S. J. Zheng, and L. P. Meng, "Highly accurate quantum chemical study of the OH radical," Acta Chim. Sin. 63, 263 (2005).

[94] L. R. Peebles and P. Marshall, "High-accuracy coupled-cluster computations of bond dissociation energies in SH, H2S, and H2O,” J. Chem. Phys. 117, 3132 (2002). http://dx.doi.org/10.1063/1.1493175

[95] R. Janoschek and M. J. Rossi, “Thermochemical properties of free radicals from G3MP2B3 calculations,” Int. J. Chem. Kinet. 34, 550 (2002). http://dx.doi.org/10.1002/kin.10082

[96] J. M. L. Martin, "A fully ab initio potential curve of near-spectroscopic quality for $\mathrm{OH}$ - ion: importance of connected quadruple excitations and scalar relativistic effects," Spectrochim. Acta A 57, 875 (2001). http://dx.doi.org/10.1016/S1386-1425(00)00450-9

[97] L. A. Curtiss, K. Raghavachari, P. C. Redfern, and B. B. Stefanov, "Assessment of complete basis set methods for calculation of enthalpies of formation,” J. Chem. Phys. 108, 692 (1998). http://dx.doi.org/10.1063/1.475442

[98] L. A. Curtiss, K. Raghavachari, P. C. Redfern, V. Rassolov, and J. A. Pople, "Gaussian-3 (G3) theory for molecules containing first and second-row atoms,” J. Chem. Phys. 109, 7764 (1998). http://dx.doi.org/10.1063/1.477422

[99] D. J. Mckay and J. S. Wright, “How long can you make an oxygen chain?,” J. Am. Chem. Soc. 120, 1003 (1998). http://dx.doi.org/10.1021/ja971534b

[100] B. Ruscic, “Active Thermochemical Tables: water and water dimer,” J. Phys. Chem. A 117, 11940 (2013). http://dx.doi.org/10.1021/jp403197t

[101] R. C. King and G. T. Armstrong, "Constant pressure flame calorimetry with fluorine. 2. Heat of formation of oxygen difluoride,” J. Res. Nat. Bur. Stand. Sect. A 72, 113 (1968). http://dx.doi.org/10.6028/jres.072A.012

[102] F. D. Rossini, "Heat and free energy of formation of water and of carbon monoxide,” J. Res. Nat. Bur. Stand. 22, 407 (1939). http://dx.doi.org/10.6028/Jres.022.029

[103] F. D. Rossini, “The heat of formation of water,” J. Res. Nat. Bur. Stand. 6, 1 (1931). http://dx.doi.org/10.6028/jres.006.001

[104] F. D. Rossini, "The heat of formation of water and the heats of combustion of methane and carbon monoxide. A correction," $J$. Res. Nat. Bur. Stand. 7, 329 (1931). http://dx.doi.org/10.6028/jres.007.017

[105] C. X. Almora-Diaz, "Highly correlated configuration interaction calculations on water with large orbital bases," J. Chem. Phys. 140, 184302 (2014). http://dx.doi.org/10.1063/1.4874319

[106] D. Feller and K. A. Peterson, "High level coupled cluster determination of the structure, frequencies, and heat of formation of water,” J. Chem. Phys. 131, 154306 (2009). http://dx.doi.org/10.1063/1.3246353 
[107] L. Bytautas and K. Ruedenberg, "Correlation energy extrapolation by intrinsic scaling. V. Electronic energy, atomization energy, and enthalpy of formation of water,” J. Chem. Phys. 124, 174304 (2006). http://dx.doi.org/10.1063/1.2194542

[108] T. Helgaker, W. Klopper, H. Koch, and J. Noga, "Basis set convergence of the molecular electric dipole moment," J. Chem. Phys. 106, 9639 (1997). http://dx.doi.org/10.1063/1.473863

[109] L. G. S. Shum and S. W. Benson, "Review of the heat of formation of the hydroperoxyl radical," J. Phys. Chem. 87, 3479 (1983). http://dx.doi.org/10.1021/j100241a025

[110] T. M. Ramond, S. J. Blanksby, S. Kato, V. M. Bierbaum, G. E. Davico, R. L. Schwartz, W. C. Lineberger, and G. B. Ellison, "Heat of formation of the hydroperoxyl radical via negative ion studies," J. Phys. Chem. A 106, 9641 (2002). http://dx.doi.org/10.1021/jp014614h

[111] E. P. Clifford, P. G. Wenthold, R. Gareyev, W. C. Lineberger, C. H. DePuy, V. M. Bierbaum, and G. B. Ellison, "Photoelectron spectroscopy, gas phase acidity, and thermochemistry of tert-butyl hydroperoxide: Mechanisms for the rearrangement of peroxyl radicals,” J. Chem. Phys. 109, 10293 (1998). http://dx.doi.org/10.1063/1.477725

[112] M. Litorja and B. Ruscic, “A photoionization study of the hydroperoxyl radical, $\mathrm{HO}_{2}$, and hydrogen peroxide," $\mathrm{H}_{2} \mathrm{O}_{2}$. J. Electr. Spectr. Rel. Phenom. 97, 131 (1998). http://dx.doi.org/10.1016/S0368-2048(98)00264-3

[113] E. R. Fisher and P. B. Armentrout, "Heat of formation of the hydroperoxyl radical HO2. A direct determination from guided ion beam studies of oxygen-methane [O2+ + CH4] reaction,” J. Phys. Chem. 94, 4396 (1990). http://dx.doi.org/10.1021/j100374a007

[114] J. M. Oakes, L. B. Harding, and G. B. Ellison, “The photoelectron spectroscopy of HO2,” J. Chem. Phys. 83, 5400 (1985). http://dx.doi.org/10.1063/1.449709

[115] A. J. Hills and C. J. Howard, "Rate coefficient temperature dependence and branching ratio for the $\mathrm{OH}+\mathrm{ClO}$ reaction,” $J$. Chem. Phys. 81, 4458 (1984). http://dx.doi.org/10.1063/1.447414

[116] L. G. S. Shum and S. W. Benson, "Mechanism and thermochemistry of oxidation of $\mathrm{HCl}$ and $\mathrm{HBr}$ at high temperatures. The heat of formation of HO2,” Int. J. Chem. Kinet. 15, 341 (1983). http://dx.doi.org/10.1002/kin.550150404

[117] Y. P. Lee and C. J. Howard, "Temperature dependence of the rate constant and the branching ratio for the reaction $\mathrm{Cl}+\mathrm{HO}$," J. Chem. Phys. 77, 756 (1982). http://dx.doi.org/10.1063/1.443892

[118] L. A. Khachatryan, O. M. Niazyan, A. A. Mantashyan, V. I. Vedeneev, and M. A. Teitel'Boim, "Experimental determination of the equilibrium constant of the reaction $\mathrm{CH} 3+\mathrm{O} 2=\mathrm{CH} 3 \mathrm{O} 2$ during the gas-phase oxidation of methane,” Int. J. Chem. Kinet. 14, 1231 (1982). http://dx.doi.org/10.1002/kin.550141107

[119] C. J. Howard, "Kinetic study of the equilibrium $\mathrm{HO} 2+\mathrm{NO}=\mathrm{OH}+\mathrm{NO} 2$ and the thermochemistry of HO2," J. Am. Chem. Soc. 102, 6937 (1980). http://dx.doi.org/10.1021/ja00543a006

[120] K. Glanzer and J. Troe, "HO2 formation in shock heated HNO3-NO2 mixtures,” Ber. Bunsenges, Phys. Chem. 79, 465 (1975). http://dx.doi.org/10.1002/bbpc.19750790514

[121] V. F. Kochubei and J. B. Moin, "Determination of HO2 radical formation heat by kinetic method,” Dokl. Akad. Nauk SSRR 219, 141 (1974)

[122] S. N. Foner and R. L. Hudson, “Mass spectrometry of HO2 free radical,” J. Chem. Phys. 36, 2681 (1962). http://dx.doi.org/10.1063/1.1732352

[123] W. A. Rosser Jr. and H. Wise, “The kinetics of oxidation of HBr,” J. Phys. Chem. 63, 1753 (1959). http://dx.doi.org/10.1021/j150580a044

[124] S. N. Foner and R. L. Hudson, "Ionization potential of the free HO2 radical and the H-O2 bond dissociation energy,” J. Chem. Phys. 23, 1364 (1955). http://dx.doi.org/10.1063/1.1742299

[125] M. K. Sprague and K. K. Irikura, "Quantitative estimation of uncertainties from wavefunction diagnostics,” Theor. Chem. Acc. 133, 1544 (2014). http://dx.doi.org/10.1007/s00214-014-1544-z

[126] A. Karton, S. Parthiban, and J. M. Martin, "Post-CCSD(T) ab Initio thermochemistry of halogen oxides and related hydrides XOX, XOOX, HOX, XOn, and HXOn, (X = F, Cl), and evaluation of DFT methods for these systems," J. Phys. Chem. A 113, 4802 (2009). http://dx.doi.org/10.1021/jp8087435

[127] Y. J. Bomble, J. Vazquez, M. Kallay, C. MIchauk, P. G.Szalay, A. G. Csaszar, J. Gauss, and J. F. Stanton, "High-accuracy extrapolated ab initio thermochemistry. II. Minor improvements to the protocol and a vital simplification,” J. Chem. Phys. 125, 064108 (2006), http://dx.doi.org/10.1063/1.2206789

[128] B. A. Flowers, P. G. Szalay, J. F. Stanton, M. Kallay, J. Gauss, and A. G. Csaszar, "Benchmark thermochemistry of the hydroperoxyl radical,” J. Phys. Chem. A 108, 3195 (2004). http://dx.doi.org/10.1021/jp037347j

[129] A. Tajti, P. G. Szalay, A. G. Csaszar, M. Kallay, J. Gauss, E. F. Valeev, B. A. Flowers, J. Vazquez, and J. F. Stanton, "HEAT: High accuracy extrapolated ab initio thermochemistry,” J. Chem. Phys. 121, 11599 (2004). http://dx.doi.org/10.1063/1.1811608

[130] D. A. Dixon, D. Feller, C. G. Zhan, and J. S. Francisco, "Decomposition pathways of peroxynitrous acid: gas-phase and solution energetics,” J. Phys. Chem. A 106, 3191 (2002). http://dx.doi.org/10.1021/jp013783z

[131] S. P. Karkach and V. I. Osherov, "Ab initio analysis of the transition states on the lowest triplet $\mathrm{H} 2 \mathrm{O} 2$ potential surface," $J$. Chem. Phys. 110, 11918 (1999). http://dx.doi.org/10.1063/1.479131

[132] T. P. W. Jungkamp and J. H. Seinfeld, "The enthalpy of formation of trioxy radicals ROOO (R=H, CH3, C2H5). An ab initio study,” Chem. Phys. Lett. 257, 15 (1996). http://dx.doi.org/10.1016/0009-2614(96)00520-9

[133] C. W. Bauschlicher Jr. and H. Partridge, “An accurate determination of the HO2 heat of formation,” Chem. Phys. Lett. 208, 241 (1993). http://dx.doi.org/10.1016/0009-2614(93)89069-T

[134] B. Ruscic, “Active Thermochemical Tables (ATcT). ATcT D - version 1.110 Core ARGONNE 30.12.2013,” http://atct.anl.gov [Accessed August 12, 2015].

[135] O. V. Dorofeeva, V. S. Iorish, V. P. Novikov, and D. B. Neumann, "NIST-JANAF thermochemical tables. II. Three molecules related to atmospheric chemistry. HNO3, H2SO4, and H2O2,” J. Phys. Chem. Ref. Data 323, 879 (2003). http://dx.doi.org/10.1063/1.1547435

[136] P. A. Giguere and I. D. Liu, "Recommended values for the thermodynamic properties of hydrogen and deuterium peroxides," $J$. Am. Chem. Soc. 77, 6477 (1955). http://dx.doi.org/10.1021/ja01629a012 
[137] F. R. Bichowsky and F. D. Rossini, The Thermochemistry of Individual Substances, Reinhold Pub. Corp, New York (1936).

[138] X. Luo, P. R. Fleming, and T. R. Rizzo, "Vibrational overtone spectroscopy of the $4 v \mathrm{OH}+v \mathrm{OH}$ ' combination level of $\mathrm{HOOH}$ via sequential local mode-local mode excitation,” J. Chem. Phys. 96, 5659 (1992). http://dx.doi.org/10.1063/1.462665

[139] W. Forst, "Second-order unimolecular kinetics in the thermal decomposition of hydrogen peroxide vapor," Can. J. Chem. 36, 1308 (1958).

[140] P. A. Giguere, B. G. Morissette, A. W. Olmos, and O. Knop, "Hydrogen peroxide and its analogues. 7. Calorimetric properties of the systems H2O-H2O2 and D2O-D2O2,” Can. J. Chem. 33, 804 (1955). http://dx.doi.org/10.1139/v55-098

[141] O. Maass and W. H. Hatcher, “The properties of pure hydrogen peroxide. I,” J. Am. Chem. Soc. 42, 2548 (1920). http://dx.doi.org/10.1021/ja01457a013

[142] G. L. Matheson and O. Maass, “The properties of pure hydrogen peroxide. VI,” J. Am. Chem. Soc. 51, 674 (1929). http://dx.doi.org/10.1021/ja01378a004

[143] P. A. Denis and F. R. Ornellas, "Theoretical characterization of hydrogen polyoxides: $\mathrm{HOOH}, \mathrm{HOOOH}, \mathrm{HOOOOH}$, and HOOO,” J. Phys. Chem. A 113, 499 (2009). http://dx.doi.org/10.1021/jp808795e

[144] S. R. Sellevag, Y. Georgievskii, and J. A. Miller, "Kinetics of the gas-phase recombination reaction of hydroxyl radicals to form hydrogen peroxide,” J. Phys. Chem. A 113, 4457 (2009). http://dx.doi.org/10.1021/jp8110524

[145] S. Parthiban and J. M. L. Martin, "Assessment of W1 and W2 theories for the computation of electron affinities, ionization potentials, heats of formation, and proton affinities,” J. Chem. Phys. 114, 6014 (2001). http://dx.doi.org/10.1063/1.1356014

[146] S. J. Blanksby, T. M. Ramond, G. E. Davico, M. R. Nimlos, S. Kato, V. M. Bierbaum, W. C. Lineberger, G. B. Ellison, and M. Okumura, "Negative-ion photoelectron spectroscopy, gas-phase acidity, and thermochemistry of the peroxyl radicals CH3OO and CH3CH2OO,” J. Am. Chem. Soc. 123, 9585 (2001). http://dx.doi.org/10.1021/ja010942j

[147] B. Kuhn, T. R. Rizzo, D. Luckhaus, M. Quack, and M. A. Suhm, "A new six-dimensional analytical potential up to chemically significant energies for the electronic ground state of hydrogen peroxide,” J. Chem. Phys. 111, 2565 (1999). http://dx.doi.org/10.1063/1.479534

[148] B. Ruscic, Active Thermochemical Tables. ATcT C. Version 1.112 Core Argonne 4.2.2011. Bromine Species. Data available in http://burcat.technion.ac.il/dir/Archives/BURCAT2014.THR [Accessed July 30, 2015].

[149] N. Taniguchi, K. Takahashi, Y. Matsumi, S. M. Dylewski, J. D. Geiser, and P. L. Houston, "Determination of the heat of formation of O3 using vacuum ultraviolet laser-induced fluorescence spectroscopy and two-dimensional product imaging techniques,” J. Chem. Phys. 111, 6350 (1999). http://dx.doi.org/10.1063/1.479939

[150] K. Takahashi, M. Kishigami, N. Taniguchi, Y. Matsumi, and M. Kawasaki, "Photofragment excitation spectrum for O(D1) from the photodissociation of jet-cooled ozone in the wavelength range 305-329 nm,” J. Chem. Phys. 106, 6390 (1997). http://dx.doi.org/10.1063/1.473629

[151] M. A. A. Clyne, D. J. McKenney, and B. A. Thrush, "Rate of Combination of Oxygen Atoms with Oxygen Molecules," Trans Faraday Soc 61, 2701 (1965). http://dx.doi.org/10.1039/Tf9656102701

[152] P. Gunther, E. Wassmuth, and L. A. Schryver, "The formation warmth of ozones," Z. Phys. Chem. A 158, 297 (1932).

[153] A. Kailan and S. Jahn, "Articles on the knowledge of the ozone V. The heat hues of the decomposition," Z. Anorg. Chem. 68 , 243 (1910). http://dx.doi.org/10.1002/zaac.19100680122

[154] F. Holka, P. G. Szalay, T. Muller, and V. G. Tyuterev, “Toward an improved ground state potential energy surface of ozone,” J. Phys. Chem. A 114, 9927 (2010). http://dx.doi.org/10.1021/jp104182q

[155] P. Fleurat-Lessard, S. Y. Grebenshchikov, R. Siebert, and R. Schinke, "Theoretical investigation of the temperature dependence of the O + O2 exchange reaction,” J. Chem. Phys. 118, 610 (2003). http://dx.doi.org/10.1063/1.1525255

[156] Le Picard et al. (2010) in supplementary material for the paper indicate that they used an enthalpy of formation $\Delta_{\mathrm{f}} H^{\circ}(298.15 \mathrm{~K})$ for $\mathrm{OH}$ of $37.2 \mathrm{~kJ} / \mathrm{mol}$ instead of the currently accepted value of $37.5 \mathrm{~kJ} / \mathrm{mol}$ (see Table 3). They also indicated that they calculated the vibrational partition function $Q_{\text {vib }}\left(\mathrm{HO}_{3}\right)$ using the four lowest frequency vibrations taken from Derro et al. (2008). Using this partition function, we compute that $\mathrm{H}^{\circ}$ at $298 \mathrm{~K}$ is about $0.3 \mathrm{~kJ} / \mathrm{mol}$ lower than our computed value and that $\Delta \mathrm{S}^{\circ}$ is about $1.5 \mathrm{~kJ} / \mathrm{mol}$. Employing their computed thermofunctions, we derive a thermal correction $\Delta \Delta_{\mathrm{f}} H(298.15 \mathrm{~K})$ of about -5.4 $\mathrm{kJ} / \mathrm{mol}$ (their reported $\Delta_{\mathrm{f}} H(298.15 \mathrm{~K})$ and $\mathrm{D}_{0}$ correspond to about $\left.\Delta \Delta_{\mathrm{f}} H(298.15 \mathrm{~K})=-5.6 \mathrm{~kJ} / \mathrm{mol}\right)$. This compares to our computed value (treating the torsion as a torsion) of $\Delta \Delta_{\mathrm{f}} H(298.15 \mathrm{~K})=-3.27 \mathrm{~kJ} \mathrm{~mol}^{-1}$ (see Sec. 3.2.2) - a difference of about (2.1 to 2.3$) \mathrm{kJ} \mathrm{mol}^{-1}$.

[157] I. W. M. Smith, S. D. Le Picard, M. Tizniti, A. Canosa, and I. R. Sims, “The Quest for the Hydroxyl-Peroxy Radical,” Z. Phys. Chem. 224, 949 (2010). http://dx.doi.org/10.1524/zpch.2010.6135

[158] J. M. Beames, M. I. Lester, C. Murray, M. E. Varner, and J. F. Stanton, “Analysis of the HOOO torsional potential,” J. Chem. Phys. 134, 044304 (2011). http://dx.doi.org/10.1063/1.3518415

[159] See text in this section, reference 156 (an endnote), Sec. 3.2.1 for details.

[160] S. D. Le Picard, M. Tizniti, A. Canosa, I. R. Rims, and I. W. M. Smith, "The thermodynamics of the elusive HO3 radical," Science 328, 1258 (2010). http://dx.doi.org/10.1126/Science.1184459

[161] C. Murray, E. L. Derro, T. D. Sechler, and M. I. Lester, "Weakly bound molecules in the atmosphere: a case study of HOOO," Acct. Chem. Res. 42, 419 (2009). http://dx.doi.org/10.1021/ar8001987

[162] E. Derro, T. D. Sechler, C. Murray, and M. I. Lester, "Infrared action spectroscopy of the OD stretch fundamental and overtone transitions of the DOOO radical,” J. Phys. Chem. A 112, 9269 (2008). http://dx.doi.org/10.1021/jp801232a

[163] C. Murray, E. L. Derro, T. D. Sechler, and M. I. Lester, "Stability of the hydrogen trioxy radical via infrared action spectroscopy,” J. Phys. Chem. A 111, 4727 (2007). http://dx.doi.org/10.1021/jp071473w

[164] E. L. Derro, C. Murray, T. D. Sechler, and M. I. Lester, "Infrared action Spectroscopy and dissociation dynamics of the HOOO radical,” J. Phys. Chem. A 111, 11592 (2007). http://dx.doi.org/10.1021/jp0760915

[165] M. Speranza, "Structure, stability, and reactivity of cationic hydrogen trioxides and thermochemistry of their neutral analogs. A fourier-transform ion cyclotron resonance study,” Inorg. Chem. 35, 6140 (1996). http://dx.doi.org/10.1021/ic960549s 
[166] A. Burcat, unpublished results. Available at http://burcat.technion.ac.il/dir/Archives/BURCAT2014.THR [Accessed July 30, 2015].

[167] Y. Zhou, H. Hu, L. Li, H. Hou, and B. Wang, “Ab initio study of the elusive HO3 radical and the HO + O2 = HO3 reaction," Comput. Theor. Chem. 1026, 24 (2013). http://dx.doi.org/10.1016/j.comptc.2013.10.010

[168] A. J. C. Varandas, “Ab initio treatment of bond-breaking reactions: accurate course of HO3 dissociation and revisit to isomerization,” J. Chem. Theory Comput. 8, 428 (2012). http://dx.doi.org/10.1021/ct200773b

[169] A. J. C. Varandas, “On the stability of the elusive HO3 radical,” Phys. Chem. Chem. Phys. 13, 15619 (2011). http://dx.doi.org/10.1039/c1cp20791a

[170] J. M. Anglada, S. Olivella, and A. Sole, “On the Dissociation of Ground State trans-HOOO Radical: A Theoretical Study,” J. Chem. Theory Comput. 6, 2743 (2010). http://dx.doi.org/10.1021/ct100358e

[171] M. E. Varner, M. E. Harding, J. Vazquez, J. Gauss, and J. F. Stanton, “Dissociation Energy of the HOOO Radical,” J. Phys. Chem. A 113, 11238 (2009). http://dx.doi.org/10.1021/jp907262s

[172] B. J. Braams and H. G. Yu, "Potential energy surface and quantum dynamics study of rovibrational states for HO3," Phys. Chem. Chem. Phys. 10, 3150 (2008). http://dx.doi.org/10.1039/b801928b

[173] D. G. Semes'ko and S. L. Khursan, "Quantum-chemical calculations of the structure of trioxyl radicals," Russ. J. Phys. Chem. A 82, 1277 (2008). http://dx.doi.org/10.1134/S0036024408080074

[174] P. A. Denis and F. R. Ornellas, "Spin contamination in XOO radicals X=F,Cl,Br,HO: how is the investigation of the HOOO radical affected,” Chem. Phys. Lett. 464, 150 (2008). http://dx.doi.org/10.1016/j.cplett.2008.09.025

[175] A. Mansergas, J. M. Anglada, S. Olivella, M. F. Ruiz-Lopez, and M. Martins-Costa, "On the nature of the unusually long OO bond in HO3 and HO4 radicals,” Phys. Chem. Chem. Phys. 9, 5865 (2007). http://dx.doi.org/10.1039/b711464h

[176] R. Janoschek and W. M. F. Fabian, "Enthalpies of formation of small free radicals and stable intermediates: Interplay of experimental and theoretical values,” J. Mol. Struct. 780-81, 80 (2006). http://dx.doi.org/10.1016/j.molstruc.2005.04.050

[177] K. Suma, Y. Sumiyoshi, and Y. Endo, "The rotational spectrum and structure of the HOOO radical,” Science 308, 1885 (2005). http://dx.doi.org/10.1126/Science.1112233

[178] W. M. F. Fabian, J. Kalcher, and R. Janoschek, "Stationary points on the energy hypersurface of the reaction $\mathrm{O} 3+\mathrm{H}=\mathrm{O} 3 \mathrm{H}=$ $\mathrm{O} 2+\mathrm{OH}$ and thermodynamic functions of O3H at G3MP2B3, CCSD(T)-CBS(W1U) and MR-ACPF-CBS levels of theory," Theor. Chem. Acct. 114, 182 (2005). http://dx.doi.org/10.1007/s00214-005-0659-7

[179] P. A. Denis, M. Kieninger, O. N. Ventura, R. E. Cachau, and G. H. F. Diercksen, "Erratum to: 'Complete basis set and density functional determination of the enthalpy of formation of the controversial HO3 radical. A discrepancy between theory and experiment' [Chem. Phys. Lett. 365 (2002) 440-449],” Chem. Phys. Lett. 377, 483 (2003). http://dx.doi.org/10.1016/S0009-2614(03)01078-9

[180] P. A. Denis, M. Kieninger, O. N. Ventura, R. E. Cachau, and G. H. F. Diercksen, "Complete basis set and density functional determination of the enthalpy of formation of the controversial HO3 radical: a discrepancy between theory and experiment," Chem. Phys. Lett. 365, 440 (2002). http://dx.doi.org/10.1016/S0009-2614(02)01432-X

[181] X. Xu and W. A. Goddard, "Peroxone chemistry: Formation of H2O3 and ring-(HO2)(HO3) from O-3/H2O2," Proc. Natl. Acad. Sci. U.S.A. 99, 15308 (2002). http://dx.doi.org/10.1073/pnas.202596799

[182] O. Setokuchi, M. Sato, and S. Matuzawa, "A theoretical study of the potential energy surface and rate constant for an O(3P) + HO2 reaction,” J. Phys. Chem. A 104, 3204 (2000). http://dx.doi.org/10.1021/jp993573a

[183] P. S. Nangia, P.S, and S. W. Benson, "Thermochemistry of organic polyoxides and their free radicals," J. Phys. Chem. 83, 1138 (1979). http://dx.doi.org/10.1021/j100472a006

[184] M. Martins-Costa, J. M. Anglada, and M. F. Ruiz-López, “Structure, stability, and dynamics of hydrogen polyoxides,” Int. J. Quant. Chem. 111, 1543 (2011). http://dx.doi.org/10.1002/qua.22695

[185] E. Kraka, D. Cremer, J. Koller, and B. Plesnicar, “Peculiar structure of the HOOO- anion.” J. Am. Chem. Soc. 124, 8462 (2002). http://dx.doi.org/10.1021/ja012553v

[186] T. H. Lay and J. W. Bozzelli, "Enthalpies of formation and group Additivity of alkyl peroxides and trioxides," J. Phys. Chem. A 101, 9505 (1997). http://dx.doi.org/10.1021/jp972103i

[187] Y. Lan, S. E. Wheeler, and K. N. Houk, "Extraordinary Difference in Reactivity of Ozone (OOO) and Sulfur Dioxide (OSO): A Theoretical Study,” J. Chem. Theory Comput. 7, 2104 (2011). http://dx.doi.org/10.1021/ct200293w

[188] M. Neff and G. Rauhut, “Toward large scale vibrational configuration interaction calculations,” J. Chem. Phys. 131, 124129 (2009). http://dx.doi.org/10.1063/1.3243862

[189] V. Barone, “Anharmonic vibrational properties by a fully automated second-order perturbative approach,” J. Chem. Phys. 122, 014108 (2005). http://dx.doi.org/10.1063/1.1824881

[190] V. Barone, "Vibrational zero-point energies and thermodynamic functions beyond the harmonic approximation," J. Chem. Phys. 120, 3059 (2004). http://dx.doi.org/10.1063/1.1637580

[191] M. K. Kesharwani, B. Brauer, and J. M. L. Martin, "Frequency and Zero-Point Vibrational Energy Scale Factors for DoubleHybrid Density Functionals (and Other Selected Methods): Can Anharmonic Force Fields Be Avoided?,” J. Phys. Chem. A 119, 1701 (2015). http://dx.doi.org/10.1021/jp508422u

[192] G. I. Csonka, A. Ruzsinszky, and J. P. Perdew, "Estimation, computation, and experimental correction of molecular zero-point vibrational energies,” J. Phys. Chem. A 109, 6779 (2005). http://dx.doi.org/10.1021/jp0519464

[193] K. K. Irikura, “Experimental vibrational zero-point energies: Diatomic molecules,” J. Phys. Chem. Ref. Data 36, 389 (2007). http://dx.doi.org/10.1063/1.2436891

[194] K. K. Irikura, "Erratum: Experimental Vibrational Zero-Point Energies: Diatomic Molecules [ J. Phys. Chem. Ref. Data 36, 389-397 (2007)],” J. Phys. Chem. Ref. Data 38, 749 (2009). http://dx.doi.org/10.1063/1.3167794

[195] K. K. Irikura, R. D. Johnson III, R. N. Kacker, and R. Kessel, "Uncertainties in scaling factors for ab initio vibrational zeropoint energies,” J. Chem. Phys. 130, 114102 (2009). http://dx.doi.org/10.1063/1.3086931

[196] R. S. Grev, C. L. Janssen, and H. F. Schaefer III, “Concerning zero-point vibrational energy corrections to electronic energies," J. Chem. Phys. 95, 5128 (1991). http://dx.doi.org/10.1063/1.461680 
[197] F. Pfeiffer, G. Rauhut, D. Feller, and K. A. Peterson, "Anharmonic zero point vibrational energies: Tipping the scales in accurate thermochemistry calculations?,” J. Chem. Phys. 138, 044311 (2013). http://dx.doi.org/10.1063/1.4777568

[198] W. Klopper, B. Ruscic, D. P. Tew, F. A. Bischoff, and S. Wolfsegger, "Atomization energies from coupled-cluster calculations augmented with explicitly-correlated perturbation theory,” Chem. Phys. 356, 14 (2009). http://dx.doi.org/10.1016/j.chemphys.2008.11.013

[199] P. Barletta, S. V. Shirin, N. F. Zobov, O. L. Polyansky, J. Tennyson, E. F. Valeev, and A. G. Csaszar, "CVRQD ab initio ground-state adiabatic potential energy surfaces for the water molecule,” J. Chem. Phys. 125, 204307 (2006). http://dx.doi.org/10.1063/1.2378766

[200] D. S. Hollman and H. F. Schaefer III, "In search of the next Holy Grail of polyoxide chemistry: Explicitly correlated ab initio full quartic force fields for $\mathrm{HOOH}, \mathrm{HOOOH}, \mathrm{HOOOOH}$, and their isotopologues,” J. Chem. Phys. 136, 084302 (2012). http://dx.doi.org/10.1063/1.3684231

[201] M. Mladenovic, "Discrete variable approaches to tetratomic molecules: part II: application to H2O2 and H2CO,” Spectrochim. Acta A 58, 809 (2002). http://dx.doi.org/10.1016/S1386-1425(01)00670-9

[202] A. Kanton, E. Rabinovich, J. M. L. Martin, and B. Ruscic, "W4 theory for computational thermochemistry: In pursuit of confident sub-kJ/mol predictions,” J. Chem. Phys. 125, 144108 (2006). http://dx.doi.org/10.1063/1.2348881

[203] A. Barbe, A. Chichery, T. Cours, V. G. Tyuterev, and J. J. Plateaux, "Update of the anharmonic force field parameters of the ozone molecule,” J. Mol. Struct. 616, 55 (2002). http://dx.doi.org/10.1016/S0022-2860(02)00183-7

[204] K. Suma, Y. Sumiyoshi, and Y. Endo, "Force-field calculation and geometry of the HOOO radical,” J. Chem. Phys. 139, 094301 (2013). http://dx.doi.org/10.1063/1.4819323

[205] C. F. Jackels, “The vibrational spectrum of H2O3 - an ab initio investigation,” J. Chem. Phys. 99, 5768 (1993). http://dx.doi.org/10.1063/1.465928

[206] M. E. Jacox, “Vibrational and electronic energy levels of polyatomic transient molecules. Supplement B,” J. Phys. Chem. Ref. Data 32, 1 (2003). http://dx.doi.org/10.1063/1.1497629

[207] M. E. Jacox, "Vibrational and Electronic Energy Levels of Polyatomic Transient Molecules" in NIST Chemistry WebBook, NIST Standard Reference Database Number 69, Eds. P. J. Linstrom and W. G. Mallard, National Institute of Standards and Technology, Gaithersburg MD, 20899, http://webbook.nist.gov, (retrieved August 13, 2015). [Accessed August 13, 2015].

[208] J. L. Arnau and P. A. Giguere, "Vibrational analysis and molecular structure of the hydrogen polyoxides, H2O3, H2O4, D2O3, and D2O4,” J. Chem. Phys. 60, 270 (1974). http://dx.doi.org/10.1063/1.1680779

[209] G. H. Dieke, "The molecular spectrum of hydrogen and its isotopes,” J. Mol. Spec. 2, 494 (1958) http://dx.doi.org/10.1016/0022-2852(58)90095-X

[210] G. Rouille, G. Millot, R. Saint-Loup, and H. Berger, “High-resolution stimulated Raman spectroscopy of O2,” J. Mol. Spectr. 154, 372 (1992). http://dx.doi.org/10.1016/0022-2852(92)90215-A

[211] J. Tennyson, N. F. Zobov, R. Williamson, O.L. Polyanski, and P. F. Bernath, "Experimental energy levels of the water molecule,” J. Phys. Chem. Ref. Data 30, 735 (2001). http://dx.doi.org/10.1063/1.1364517

[212] J. Pliva, V. Spirko, and D. Papousek, "Anharmonic potential functions of polyatomic molecules *: Part VII. Iterational calculation of anharmonic corrections to fundamental frequencies,” J. Mol. Spectr. 23, 331 (1967). http://dx.doi.org/10.1016/S0022-2852(67)80022-5

[213] M. E. Jacox and W. E. Thompson, "Infrared spectra of products of the reaction of $\mathrm{H}$ atoms with $\mathrm{O} 2$ trapped in solid neon: HO2, HO2(+), HOHOH(-), and H2O(HO),” J. Phys. Chem. A 117, 9380 (2013). http://dx.doi.org/10.1021/jp310849s

[214] C. X. Xu, B. Jiang, D. Q. Xie, S. C. Farantos, S. Y. Lin, and H. Guo,” Analysis of the HO2 vibrational spectrum on an accurate ab initio potential energy surface,” J. Phys. Chem. A 111, 10353 (2007). http://dx.doi.org/10.1021/jp072319c

[215] W. B. Olson, R. H. Hunt, B. W. Young, A. G. Maki, and J. W. Brault, "Rotational constants of the lowest torsional component (0G) of the ground state and lowest torsional component (1G) of the first excited torsional state of hydrogen peroxide," Mol. Spectrosc. 127, 12 (1988). http://dx.doi.org/10.1016/0022-2852(88)90004-5

[216] J. I. Steinfeld, S. M. Adler-Golden, and J. W. Gallagher, "Critical survey of data on the spectroscopy and kinetics of ozone in the mesosphere and thermosphere,” J. Phys. Chem. Ref. Data 16, 911 (1987). http://dx.doi.org/10.1063/1.555796

[217] A. Barbe, C. Secroun, and P. Jouve, "Infrared spectra of $16 \mathrm{O}$ and 18O3: Darling and Dennison resonance and anharmonic potential function of ozone,” J. Mol. Spectr. 49, 171 (1974). http://dx.doi.org/10.1016/0022-2852(74)90267-7

[218] E. L. Derro, T. D. Sechler, C. Murray, and M. I. Lester, "Observation of $v_{1}+v_{\mathrm{n}}$ combination bands of the HOOO and DOOO radicals using infrared action spectroscopy,” J. Chem. Phys. 128, 244313 (2008). http://dx.doi.org/10.1063/1.2945872

[219] A. Engdahl and B. Nelander, "The vibrational spectrum of H2O3,” Science 295, 482 (2002). http://dx.doi.org/10.1126/Science.1067235

[220] C. Camy-Peyret, J. M. Flaud, J. W. C. Johns, and M. Noel, “Torsion-vibration interaction in H2O2: First high-resolution observation of v v," J. Mol. Spectrosc. 155, 84 (1992). http://dx.doi.org/10.1016/0022-2852(92)90550-8

[221] M. C. McCarthy, V. Lattanzi, D. Kokkin, O. Martinez Jr., and J. F. Stanton, “On the molecular structure of HOOO,” J. Chem. Phys. 136, 034303 (2012). http://dx.doi.org/10.1063/1.3673875

[222] A. J. C. Varandas, "Is HO3 minimum cis or trans? An analytic full-dimensional ab initio isomerization path," Phys. Chem. Chem. Phys. 13, 9796 (2011). http://dx.doi.org/10.1039/c1cp20221a

[223] E. P. Hoy, C. A. Schwerdtfeger, and D. A. Mazziotti, "Relative energies and geometries of the cis- and trans-HO3 radicals from the parametric 2-electron density matrix method,” J. Phys. Chem. A 117, 1817 (2013). http://dx.doi.org/10.1021/jp3105562

[224] V. Mokrushin, V. Bedanov, W. Tsang, M. Zachariah, and V. Knyazev, ChemRate, Version 1.5, National Institute of Standards and Technology, Gaithersburg, Maryland (2008).

[225] R. D. Johnson III, FGH1D Program for one-dimensional solution of the Schrodinger equation. Version 1.01, National Institute of Standards and Technology, Gaithersburg, Maryland (1999).

[226] K. Suma, Y. Sumiyoshi, and Y. Endo, “The rotational spectrum and structure of HOOH,” J. Am. Chem. Soc. 127, 14998 (2005). http://dx.doi.org/10.1021/ja0556530 
[227] R. J. Blint and M. D. Newton, “Ab initio studies of interoxygen bonding in O2, HO2, H2O2, O3, HO3, and H2O3,” J. Chem. Phys. 59, 6220 (1973). http://dx.doi.org/10.1063/1.1680001

[228] D. Cremer, "Theoretical determination of molecular structure and conformation. II. Hydrogen trioxide—a model compound for studying the conformational modes of geminal double rotors and five membered rings,” J. Chem. Phys. 69, 4456 (1978). http://dx.doi.org/10.1063/1.436435

[229] X. Xu, R. P. Muller, and W. A. Goddard III, "The gas phase reaction of singlet dioxygen with water: A water-catalyzed mechanism,” Proc. Natl. Acad. Sci. U.S.A. 99, 3376 (2002). http://dx.doi.org/10.1073/pnas.052710099

[230] P. Wentworth Jr., L. H. Jones, A. D. Wentworth, X. Y. Zhu, N. A. Larsen, I. A. Wilson, X. Xu, W. A. Goddard III, K. D. Janda, A. Eschenmoser, and R. A. Lerner, “Antibody catalysis of the oxidation of water," Science 293, 1806 (2001). http://dx.doi.org/10.1126/Science.1062722

[231] D. Datta, N. Vaidehi, X. Xu, and W. A. Goddard III, "Mechanism for antibody catalysis of the oxidation of water by singlet dioxygen,” Proc. Natl. Acad. Sci. U.S.A. 99, 2636 (2002). http://dx.doi.org/10.1073/pnas.052709399

[232] V. A. Yerokhin and V. M. Shabaev, "Lamb shift of $\mathrm{n}=1$ and $\mathrm{n}=2$ states of hydrogen-like atoms, $1<=\mathrm{Z}<=110$," J. Phys. Chem. Ref. Data 44, 033103 (2015). http://dx.doi.org/10.1063/1.4927487

[233] A. Kramida, Yu. Ralchenko, and J. Reader, NIST Atomic Spectra Database (ver. 5.2), [Online]. Available: http://physics.nist.gov/asd [2015, August 5]. National Institute of Standards and Technology, Gaithersburg, MD. [Accessed August 12, 2015].

[234] U. D. Jentschura, S. Kotochigova, E. O. Le Bigot, P. J. Mohr, and B. N. Taylor, "Precise calculation of transition frequencies of hydrogen and deuterium based on a least-squares analysis,” Phys. Rev. Lett. 95, 163003 (2005). http://dx.doi.org/10.1103/PhysRevLett.95.163003

[235] J. E. Sansonetti and W. C. Martin, “Handbook of basic atomic spectroscopic data,” J. Phys. Chem. Ref. Data 34, 1559 (2005). http://dx.doi.org/10.1063/1.1800011

[236] W. R. Johnson and G. Soff, “The Lamb shift in hydrogen-like atoms, $1<=Z<=110$,” At. Data Nucl. Tab. 33, 405 (1985) http://dx.doi.org/10.1016/0092-640X(85)90010-5

[237] C. E. Moore, "Ionization potentials and ionization limits derived from the analyses of optical spectra," Nat. Stand. Ref. Data Ser., NSRDS-NBS 34, 22p (Nat. Bur. Stand, U.S., 1970).

[238] W. L. Wiese, M. W. Smith, and B. M. Glennon, "Atomic Transition Probabilities. Volume 1. Hydrogen through Neon." NSRDS-NBS 4 (National Bureau of Standards, U. S. Government Printing Office, 1966).

[239] J. D. Garcia and J. E. Mack, "Energy level and line tables for 1-electron atomic spectra,” J. Opt. Soc. Am. 55, 654 (1965). http://dx.doi.org/10.1364/JOSA.55.000654

[240] K. R. Lykke, K. K. Murray, and W. C. Lineberger, “Threshold Photodetachment of H-,” Phys. Rev. A 43, 6104 (1991). http://dx.doi.org/10.1103/PhysRevA.43.6104

[241] C. L. Pekeris, :”1 2S, 2 1S, and 2 3S states of H- and of He,” Phys. Rev. 126, 1470 (1962). http://dx.doi.org/10.1103/PhysRev.126.1470

[242] A. de Lange, E. Reinhold, and W. Ubachs, "Spectroscopy on some g symmetry states in H2 and determination of the ionization potential,” Phys. Rev. A 65, 064501 (2002). http://dx.doi.org/10.1103/PhysRevA.65.064501

[243] D. Shiner, J. M. Gilligan, B. M. Cook, and W. Lichten, "H2, D2, and HD ionization potentials by accurate calibration of several iodine lines,” Phys. Rev. A 47, 4042 (1993). http://dx.doi.org/10.1103/PhysRevA.47.4042

[244] Ch. Jungen, I. Dabrowski, G. Herzberg, and M. Vervloet, “The ionization potential of D2,” J. Mol. Spectrosc. 153, 11 (1992). http://dx.doi.org/10.1016/0022-2852(92)90452-T

[245] Ch. Jungen, I. Dabrowski, G. Herzberg, and W. Kendall,” High orbital angular momentum states in H2 and D2. II. The 6h-5g and 6g-5f transitions ," J. Chem. Phys. 91, 3926 (1989). http://dx.doi.org/10.1063/1.456824

[246] J. M. Gilligan and E. E. Eyler, "Precise determinations of ionization potentials and EF-state energy levels of H2, HD, and D2," Phys. Rev. A. 46, 3676 (1992). http://dx.doi.org/10.1103/PhysRevA.46.3676

[247] E. McCormack, J. M. Gilligan, C. Cornaggia, and E. E. Eyler, "Measurement of high Rydberg states and the ionization potential of H2,” Phys. Rev. A 39, 2260 (1989). http://dx.doi.org/10.1103/PhysRevA.39.2260

[248] W. L. Glab and J. P. Hessler, "Multiphoton excitation of high singlet np Rydberg states of molecular hydrogen: Spectroscopy and dynamics,” Phys. Rev. A 35, 2102 (1987). http://dx.doi.org/10.1103/PhysRevA.35.2102

[249] G. Herzberg and Ch. Jungen, "Rydberg series and ionization potential of the H2 molecule," J. Mol. Spectrosc. 41, 425 (1972). http://dx.doi.org/10.1016/0022-2852(72)90064-1

[250] K. M. Weitzel, J. Mahnert, and M. Penno, “ZEKE-PEPICO investigations of dissociation energies in ionic reactions,” Chem. Phys. Lett. 224, 371 (1994). http://dx.doi.org/10.1016/0009-2614(94)00567-2

[251] R. C. Shiell, X. K. Hu, Q. C. J. Hu, and J. W. Hepburn, "Threshold ion-pair production spectroscopy (TIPPS) of H2 and D2," Farad. Disc. 115, 331 (2000). http://dx.doi.org/10.1039/a909428h

[252] S. T. Pratt, E. F. McCormack, J. L. Dehmer, and P. M. Dehmer, "Field-induced ion-pair formation in molecular hydrogen," Phys. Rev. Lett. 68, 584 (1992). http://dx.doi.org/10.1103/PhysRevLett.68.584

[253] W. A. Chupka, P. M. Dehmer, and W. T. Jivery, "High resolution photoionization study of ion-pair formation in H2, HD, and D2,” J. Chem. Phys. 63, 3929 (1975). http://dx.doi.org/10.1063/1.431833

[254] C. E. Moore, "Selected Tables of Atomic Spectra, Atomic Energy Levels and Multiplet Tables - O I,” Nat. Stand. Ref. Data Ser., NSRDS-NBS 3 (Sect. 7), 33 pp. (Nat. Bur. Stand., U.S.., 1976).

[255] C. Blondel, W. Chaibi, C. Delsart, C. Drag, F. Goldfarb, and S. Kroger, "The electron affinities of O, Si, and S revisted with the photodetachment microscope,” Eur. Phys. J. D 33, 335 (2005). http://dx.doi.org/10.1140/epjd/e2005-00069-9

[256] C. Blondel, "Recent experimental achievements with negative ions," Physica Scripta T58, 31 (1995). http://dx.doi.org/10.1088/0031-8949/1995/T58/004

[257] D. M. Neumark, K. R. Lykke, T. Andersen, and W. C. Lineberger, "Laser photodetachment measurement of the electron affinity of atomic oxygen,” Phys. Rev. A 32, 1890(1985). http://dx.doi.org/10.1103/PhysRevA.32.1890 
[258] F. Goldfarb, C. Drag, W. Chaibi, S. Kroger, C. Blondel, and C. Delsart, "Photodetachment microscopy of the P, Q, and R branches of the $\mathrm{OH}-(\mathrm{v}=0)$ to $\mathrm{OH}(\mathrm{v}=0)$ detachment threshold," J. Chem. Phys. 122, 014308 (2005). http://dx/doi.org/10.1063/1.1824904

[259] J. R. Smith, J. B. Kim, and W. C. Lineberger, “High-resolution threshold photodetachment spectroscopy of OH-,” Phys. Rev. A 55, 2036 (1997). http://dx.doi.org/10.1103/PhysRevA.55.2036

[260] F. Merkt, R. Signorell, H. Palm, A. Osterwalder, and M. Sommavilla, "Towards resolving the hyperfine structure in ions by photoelectron spectroscopy,” Mol. Phys. 95, 1045 (1998). http://dx.doi.org/10.1080/002689798166657

[261] R. G. Tonkyn, R. Wiedmann, E. R. Grant, and M. G. White, "Rotationally resolved photoionization of H2O,” J. Chem. Phys. 95, 7033 (1991). http://dx.doi.org/10.1063/1.461431

[262] M. S. Child and Ch. Jungen, “Quantum defect theory for asymmetric tops: Application to the Rydberg spectrum of H2O,” $J$. Chem. Phys. 93, 7756 (1990). http://dx.doi.org/10.1063/1.459355

[263] A. Bodi, J. Csontos, M. Kallay, S. Borkar, and B. Sztaray, “On the protonation of water,” Chem. Sci. 5, 3057 (2014). http://dx.doi.org/10.1039/c4sc00791c

[264] Y. Song, M. Evans, C. Y. Ng, C. W. Hsu, and G. K. Jarvis, "Rotationally resolved pulsed field ionization photoelectron bands of O2+ in the energy range of 12.05-18.15 eV,” J. Chem. Phys. 111, 1905 (1999). http://dx.doi.org/10.1063/1.479459

[265] W. Kong and J. W. Hepburn, "Rotationally resolved threshold photoelectron spectroscopy of O2 using coherent XUV: formation of vibrationally excited ions in the Franck-Condon gap,” Can. J. Phys. 72, 1284 (1994). http://dx.doi.org/10.1139/p94-164

[266] R. G. Tonkyn, J. W. Winniczek, and M. G. White, "Rotationally resolved photoionization of O2 near threshold,” Chem. Phys. Lett. 164, 137 (1989). http://dx.doi.org/10.1016/0009-2614(89)85005-5

[267] J. A. R. Samson and J. L. Gardner, “On the ionization potential of molecular oxygen,” Can. J. Phys. 53, 1948 (1975). http://dx.doi.org/10.1139/p75-244

[268] K. M. Ervin, W. Anusiewicz, P. Skurski, J. Simons, and W. C. Lineberger, "The only stable state of O2-"is the X2 state and it (still!) has an adiabatic electron detachment energy of $0.45 \mathrm{eV}$,” J. Phys. Chem. A 107, 8521 (2003). http://dx.doi.org/10.1021/jp0357323

[269] M. J. Travers, D. C. Cowles, and G. B. Ellison, "Reinvestigation of the Electron Affinities of O2 and NO,” Chem. Phys. Lett. 164, 449 (1989). http://dx.doi.org/10.1016/0009-2614(89)85237-6

[270] R. J. Celotta, R. A. Bennett, J. L. Hall, M. W. Siegel, and J. Levine, "Molecular photodetachment spectrometry. II. The electron affinity of O2 and the structure of O2-,” Phys. Rev. A 6, 631 (1972). http://dx.doi.org/10.1103/PhysRevA.6.631

[271] M. Richard-Viard, O. Dutuit, M. Lavollee, T. Govers, P. M. Guyon, and J. Durup, "O2+ ions dissociation studied by threshold photoelectron-photoion coincidence method,” J. Chem. Phys. 82, 4054 (1985). http://dx.doi.org/10.1063/1.448846

[272] J. M. Dyke, N. B. H. Jonathan, A. Morris, and M. J. Winter, "Vacuum ultraviolet photoelectron spectroscopy of transient species. Part 13. Observation of the X3A state of HO2,” Mol. Phys. 44, 1059 (1981). http://dx.doi.org/10.1080/00268978100103011

[273] S. Willitsch, F. Innocenti, J. M. Dyke, and F. Merkt, "High-resolution pulsed-field-ionization zero-kinetic-energy photoelectron spectroscopic study of the two lowest electronic states of the ozone cation O3+,” J. Chem. Phys. 122, 024311 (2005). http://dx.doi.org/10.1063/1.1829974

[274] M. J. Weiss, J. Berkowitz, and E. H. Appelman, “Photoionization of ozone: Formation of O4+ and O5+," J. Chem. Phys. 66, 2049 (1977). http://dx.doi.org/10.1063/1.434164

[275] D. W. Arnold, C. S. Xu, E. H. Kim, and D. M. Neumark, "Study of low-lying electronic states of ozone by anion photoelectron spectroscopy of O3-,” J. Chem. Phys. 101, 912 (1994). http://dx.doi.org/10.1063/1.467745

[276] S. E. Novick, P. C. Engelking, P. L. Jones, J. H. Futrell, and W. C. Lineberger, "Laser photoelectron, photodetachment, and photodestruction spectra of O3-," J. Chem. Phys. 70, 2652 (1979). http://dx.doi.org/10.1063/1.437842

[277] A. D. Becke, “Density-functional thermochemistry. III. The role of exact exchange,” J. Chem. Phys. 98, 5648 (1993). http://dx.doi.org/10.1063/1.464913

[278] J. Finley, P. A. Malmqvist, B. O. Roos, and L. Serrano-Andres, “The multi-state CASPT2 method,” Chem. Phys. Lett. 288, 299 (1998). http://dx.doi.org/10.1016/S0009-2614(98)00252-8

[279] P. J. Knowles and H. J. Werner, “An efficient second-order MC SCF method for long configuration expansions,” Chem. Phys. Lett. 115, 259 (1985). http://dx.doi.org/10.1016/0009-2614(85)80025-7

[280] J. A. Montgomery Jr., J. W. Ochterski, and G. A. Petersson, “A complete basis set model chemistry. IV. An improved atomic pair natural orbital method,” J. Chem. Phys. 101, 5900 (1994). http://dx.doi.org/10.1063/1.467306

[281] J. W. Ochterski, G. A. Petersson, and J. A. Montgomery Jr., "A complete basis set model chemistry .5. Extensions to six or more heavy atoms,” J. Chem. Phys. 104, 2598 (1996). http://dx.doi.org/10.1063/1.470985

[282] J. A. Montgomery, M. J. Frisch, J. W. Ochterski, and G. A. Petersson, "A complete basis set model chemistry. VI. Use of density functional geometries and frequencies,” J. Chem. Phys. 110, 2822 (1999). http://dx.doi.org/10.1063/1.477924

[283] R. J. Bartlett and G. D. Purvis III, "Many-body perturbation-theory, coupled-pair many-electron theory, and importance of quadruple excitations for correlation problem,” Int. J. Quant. Chem. 14, 561 (1978). http://dx.doi.org/10.1002/qua.560140504

[284] G. Knizia, T. B. Adler, and H. J. Werner, "Simplified CCSD(T)-F12 methods: theory and benchmarks," J. Chem. Phys. 130, 054104 (2009). http://dx.doi.org/10.1063/1.3054300

[285] J. Noga and W. Kutzelnigg, "Coupled cluster theory that takes care of the correlation cusp by inclusion of linear terms in the interelectronic coordinates,” J. Chem. Phys. 101, 7738 (1994). http://dx.doi.org/10.1063/1.468266

[286] J. A. Pople, R. Seeger, and R. Krishnan, "Variational configuration interaction methods and comparison with perturbation theory,” Int. J. Quant. Chem. Suppl. Y-11, 149 (1977). http://dx.doi.org/10.1002/qua.560120820

[287] F. A. Hamprecht, A. J. Cohen, D. J. Tozer, and N. C. Handy, "Development and assessment of new exchange-correlation functionals,” J. Chem. Phys. 109, 6264 (1998). http://dx.doi.org/10.1063/1.477267

[288] C. Adamo and V. Barone, "Toward reliable density functional methods without adjustable parameters: The PBE0 model," $J$. Chem. Phys. 110, 6158 (1999). http://dx.doi.org/10.1063/1.478522 
[289] J. F. Stanton and J. Gauss, "Analytic energy derivatives for ionized states described by the equation of motion coupled cluster method,” J. Chem. Phys. 101, 8938 (1994). http://dx.doi.org/10.1063/1.468022

[290] P. J. Knowles and N. C. Handy, “A new determinant-based full configuration interaction method,” Chem. Phys. Lett. 111, 315 (1984). http://dx.doi.org/10.1016/0009-2614(84)85513-X

[291] C. F. Bunge, "Selected configuration interaction with truncation energy error and application to the Ne atom," J. Chem. Phys. 125, 014107 (2006). http://dx.doi.org/10.1063/1.2207620

[292] L. A. Curtiss, K. Raghavachari, G. W. Trucks, and J. A. Pople, “Gaussian-2 theory for molecular energies of 1st row and 2nd row compounds,” J. Chem. Phys. 94, 7221 (1991). http://dx.doi.org/10.1063/1.460205

[293] R. J. Gdanitz and R. Ahlrichs, "The averaged coupled-pair functional (ACPF): A size-extensive modification of MRCI(SD)," Chem. Phys. Lett. 143, 413 (1988). http://dx.doi.org/10.1016/0009-2614(88)87388-3

[294] R. J. Buenker, S. D. Peyerimhoff, and W. Butscher, "Applicability of the multi-reference double-excitation CI (MRD-CI) method to the calculation of electronic wavefunctions and comparison with related techniques,” Mol. Phys. 35, 771 (1978). http://dx.doi.org/10.1080/00268977800100581

[295] S. R. Langhoff and E. R. Davidson, “Configuration interaction calculations on the nitrogen molecule,” Int. J. Quantum Chem. 8, 61 (1974). http://dx.doi.org/10.1002/qua.560080106

[296] K. Hirao, “Multireference Moller-Plesset method,” Chem. Phys. Lett. 190, 374 (1992). http://dx.doi.org/10.1016/0009-2614(92)85354-D

[297] J. A. Pople, M. Head-Gordon, and K. Raghavachari, "Quadratic configuration interaction - a general technique for determining electron correlation energies,” J. Chem. Phys. 87, 5968 (1987). http://dx.doi.org/10.1063/1.453520

[298] J. M. L. Martin and G. de Oliveira, "Towards standard methods for benchmark quality ab initio thermochemistry - W1 and W2 theory,” J. Chem. Phys. 111, 1843 (1999). http://dx.doi.org/10.1063/1.479454

[299] D. G. Truhlar, "Basis set extrapolation,” Chem. Phys. Lett. 294, 45 (1998). http://dx.doi.org/10.1016/S0009-2614(98)00866-5

[300] D. Feller and K. A. Peterson, "Re-examination of atomization energies for the Gaussian-2 set of molecules," J. Chem. Phys. 110, 8384 (1999). http://dx.doi.org/10.1063/1.478747

About the author: Donald R. Burgess, Jr. is a research chemist in the Chemical Sciences Division of the Material Measurement Laboratory at NIST. His work focuses on compilation, evaluation, computation, and modeling of thermochemical and chemical kinetic data primarily related to the fields of hydrocarbon combustion chemistry and atmospheric chemistry. He is also involved with several NIST databases in these and other fields, several external data-related committees, and Open Data efforts both at NIST and external to NIST. He is co-editor (since 2007) of the Journal of Physical and Chemical Reference Data copublished by the American Institute of Physics and NIST. The National Institute of Standards and Technology is an agency of the U.S. Department of Commerce. 